\title{
Modification of the MML Turbulence Model for Adverse Pressure Gradient Flows
}

Julianne M. Conley

Lewis Research Center

Cleveland, Ohio

April 1994

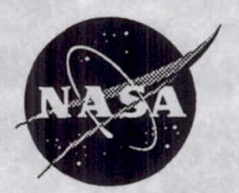

National Aeronautics and Space Administration 
MODIFICATION OF THE MML TURBULENCE MODEL FOR ADVERSE PRESSURE GRADIENT FLOWS

\author{
A Thesis \\ Presented to \\ The Graduate Faculty of The University of Akron
}

\author{
In Partial Fulfillment \\ of the Requirements for the Degree \\ Master of Science
}

Julianne M. Conley

December, 1993 


\begin{abstract}
Computational fluid dynamics is being used increasingly to predict flows for aerospace propulsion applications, yet there is still a need for an easy to use, computationally inexpensive turbulence model capable of accurately predicting a wide range of turbulent flows. The Baldwin-Lomax model is the most widely used algebraic model, even though it has known difficulties calculating flows with strong adverse pressure gradients and large regions of separation. The modified mixing length model (MML) was developed specifically to handle the separation which occurs on airfoils and has given significantly better results than the Baldwin-Lomax model. The success of these calculations warrants further evaluation and development of MML.

The objective of this work was to evaluate the performance of MML for zero and adverse pressure gradient flows, and modify it as needed. The Proteus NavierStokes code was used for this study and all results were compared with experimental data and with calculations made using the Baldwin-Lomax algebraic model, which is currently available in Proteus.

The MML model was first evaluated for zero pressure gradient flow over a fiat plate, then modified to produce the proper boundary layer growth. Additional modifications, based on experimental data for three adverse pressure gradient flows, were also implemented. The adapted model, called MMLPG (modified mixing length model for pressure gradient flows), was then evaluated for a typical propulsion flow problem, flow through a transonic diffuser. Three cases were examined: flow with no shock, a weak shock and a strong shock.
\end{abstract}


The results of these calculations indicate that the objectives of this study have been met. Overall, MMLPG is capable of accurately predicting the adverse pressure gradient flows examined in this study, giving generally better agreement with experimental data than the Baldwin-Lomax model. 
TABLE OF CONTENTS

Page

LIST OF TABLES $\ldots \ldots \ldots \ldots \ldots \ldots \ldots \ldots \ldots \ldots \ldots \ldots \ldots \ldots \ldots$ vi

LIST OF FIGURES $\ldots \ldots \ldots \ldots \ldots \ldots \ldots \ldots \ldots \ldots \ldots \ldots \ldots \ldots \ldots$ vii

LIST OF SYMBOLS $\ldots \ldots \ldots \ldots \ldots \ldots \ldots \ldots \ldots \ldots \ldots \ldots \ldots \ldots \ldots \ldots \ldots$

CHAPTER

I. INTRODUCTION $\ldots \ldots \ldots \ldots \ldots \ldots \ldots \ldots \ldots \ldots \ldots \ldots \ldots$

1.1 Motivation and Objectives $\ldots \ldots \ldots \ldots \ldots \ldots \ldots \ldots \ldots \ldots$

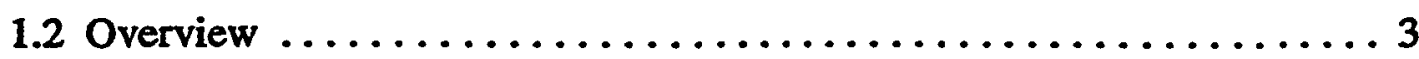

II. BACKGROUND $\ldots \ldots \ldots \ldots \ldots \ldots \ldots \ldots \ldots \ldots \ldots \ldots \ldots$

2.1 The Proteus Navier-Stokes Code. ................... 4

2.2 Algebraic Turbulence Modeling and the Baldwin-Lomax Model ......5

2.3 The Modified Mixing Length Turbulence Model............. 9

III. EVALUATION AND MODIFICATION OF MML. . $\ldots \ldots \ldots \ldots \ldots 14$

3.1 Optimization of Sं hear Stress Estimate $\ldots \ldots \ldots \ldots \ldots \ldots \ldots \ldots \ldots$

3.2 Evaluation and Modification for Zero Pressure Gradient Flows . . . . . 20

3.3 Modifications for Adverse Pressure Gradient Flows . . . . . . . 25

3.4 Final Model. ..................................... 33

3.5 Averaging for Multiple Boundaries ................. 38

IV. ADVERSE PRESSURE GRADIENT TEST CASES $\ldots \ldots \ldots \ldots \ldots \ldots$

4.1 Weak Shock Case $\ldots \ldots \ldots \ldots \ldots \ldots \ldots \ldots \ldots \ldots \ldots \ldots$

4.2 No Shock Case $\ldots \ldots \ldots \ldots \ldots \ldots \ldots \ldots \ldots \ldots \ldots \ldots \ldots$

4.3 Strong Shock Case $\ldots \ldots \ldots \ldots \ldots \ldots \ldots \ldots \ldots \ldots \ldots \ldots$ 
V. SUMMARY AND CONCLUSIONS $\ldots \ldots \ldots \ldots \ldots \ldots \ldots \ldots \ldots$

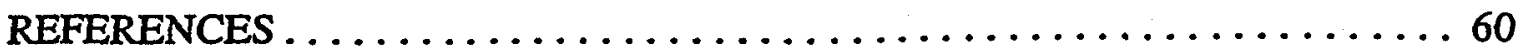

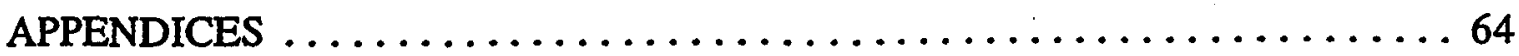

APPENDIX 1: GOVERNING EQUATIONS OF PROTEUS . . . . . . 65

APPENDIX 2: ARTIFICIAL VISCOSITY AND GRID CONVERGENCE. . . . 70

APPENDIX 3: THE BALDWIN-LOMAX TURBULENCE MODEL . . . . . 78 


\section{LIST OF TABLES}

Table Page

1. Parameters used in pressure gradient modifications $\ldots \ldots \ldots \ldots \ldots \ldots 30$

2. Computational times for flat plate flows................. 37

3. Shock location and Mach number, weak shock case $\ldots \ldots \ldots \ldots \ldots . \ldots 45$

4. Maximum Mach number, no shock case................. 48

5. Shock location and Mach number, strong shock case........... 52

6. Time differencing schemes in Proteus $\ldots \ldots \ldots \ldots \ldots \ldots \ldots \ldots \ldots, \ldots \ldots \ldots$ 


\section{LIST OF FIGURES}

Figure

Page

1. $F(y)$ profiles for attached and separated flow conditions $\ldots \ldots \ldots \ldots \ldots$

(a) Attached flow

(b) Separated flow

2. Dimensionless mixing length distribution across a turbulent boundary layer, taken from reference $20 \ldots \ldots \ldots \ldots \ldots \ldots \ldots \ldots \ldots \ldots$

3. Mixing length profile for the $\mathrm{MML} \operatorname{model}^{5} \ldots \ldots \ldots \ldots \ldots$

4. Estimation of $\tau_{w}$ using equation (3.3) $\ldots \ldots \ldots \ldots \ldots \ldots \ldots \ldots \ldots$

5. Illustration of flow over a flat plate. $\ldots \ldots \ldots \ldots \ldots \ldots \ldots \ldots$

6. Computational grid for zero pressure gradient flat plate case... . . . . . . 18

7. Velocity-defect profiles for zero pressure gradient flat plate flow, $\operatorname{Re}=7 \times 10^{6}$.

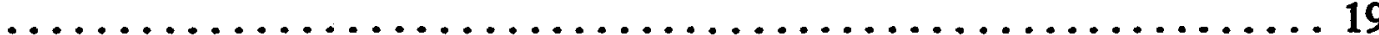

(a) MML

(b) BLM

8. Shear stress profile near the wall for zero pressure gradient flat plate flow, $\operatorname{Re}_{\mathrm{x}}=7 \times 10^{6}$

(a) $\mathrm{MML}$

9. Velocity-defect profiles for zero pressure gradient flat plate flow at three Reynolds numbers .

(a) $\mathrm{MML}$ -

(b) BLM

10. Turbulent viscosity for zero pressure gradient flat plate flow at three Reynolds

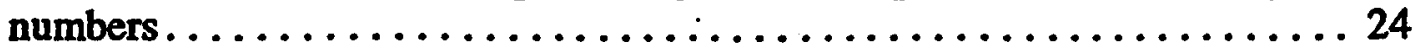

(a) $\mathrm{MML}$

(b) BLM

11. Velocity-defect for zero pressure gradient flat plate flow calculated using the

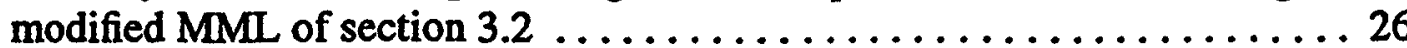


12. Local skin friction coefficient for zero pressure gradient flat plate flow; MML of

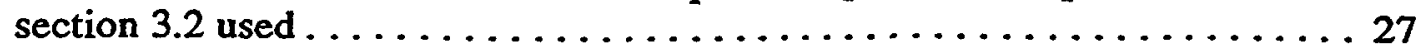

13. Mixing length profiles at three pressure gradients. ${ }^{25} \ldots \ldots \ldots \ldots \ldots 28$

14. Velocity-defect for zero pressure gradient flow calculated using the modified

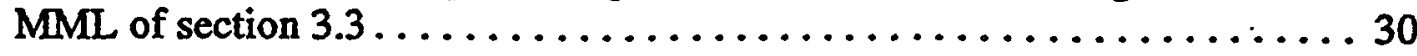

15. Velocity-defect for mild pressure gradient flow............... 31
(a) Modified MML of section 3.3
(b) BLM

16. Velocity-defect for strong pressure gradient flow

(a) Modified MML of section 3.3

(b) BLM

17. Velocity-defect profiles computed using MMLPG

(a) Zero pressure gradient flow. . . . . . . . . . . . . . . . . . . 35

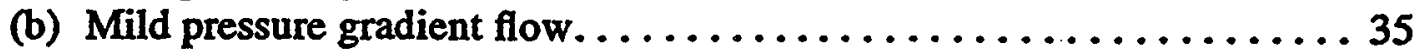

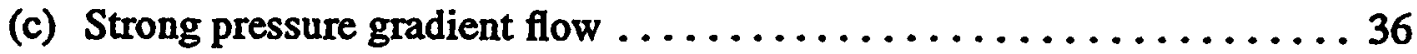

18. Illustration of the Sajben diffuser geometry $\ldots \ldots \ldots \ldots \ldots \ldots \ldots \ldots 40$

19. Computational grid for the Sajben diffuser $\ldots \ldots \ldots \ldots \ldots \ldots \ldots \ldots 40$

20. Static pressure history at two locations on the top wall: just upstream and just downstream of the normal shock $\ldots \ldots \ldots \ldots \ldots \ldots \ldots \ldots \ldots \ldots . \ldots \ldots$
(a) MMLPG
(b) BLM2

21. Static pressure distribution on the top and bottom walls of the Sajben diffuser, weak shock case. ............................. 44
(a) Top wall
(b) Bottom wall

22. Static pressure distribution on the top and bottom walls of the Sajben diffuser, no shock case
(a) Top wall
(b) Bottom wall

23. Shock static pressure on top wall for the Sajben diffuser, strong shock case.. 50

24. Static pressure distribution on the top and bottom walls of the Sajben diffuser, strong shock case . ............................ 51
(a) Top wall
(b) Bottom wall 
25. Velocity profiles for the strong shock case.
(a) $\mathrm{x} / \mathrm{H}=2.88$
(b) $\mathrm{x} / \mathrm{H}=4.61$
(c) $x / \mathrm{H}=6.34$
(d) $\mathrm{x} / \mathrm{H}=7.49$

26. Turbulent viscosity ratio, $\mu_{t} / \mu$, for the Sajben diffuser, strong shock case . . 55
(a) MMLPG
(b) BLM1
(c) BLM2

27. Comparison of weak shock static pressure distributions, computed using MMLPG and three different amounts of artificial viscosity ......... 75
(a) Top Wall
(b) Bottom Wall

28. Comparison of no shock static pressure distributions, computed using MMLPG and two different grids.

(a) Top Wall

(b) Bottom Wall 


\section{LIST OF SYMBOLS}

$a, b, c$ parameters used to compute shear stress

$\mathrm{A}^{+} \quad \operatorname{van}$ Driest damping constant $=26$

$c_{f}$

local skin friction coefficient

$c_{p}$

$\mathrm{C}_{1}$

specific heat at constant pressure

$\mathrm{C}_{2}$

MML parameter; controls mixing length saturation level

$\mathrm{C}_{\mathrm{cp}}$

MML parameter; controls curvature of blending region

$\mathrm{C}_{\mathrm{Kleb}}$

Baldwin-Lomax turbulence model constant $=1.6$

$\mathrm{C}_{\mathrm{wk}}$

Baldwin-Lomax turbulence model constant $=0.3$

$D_{1}, D_{2}$

Baldwin-Lomax turbulence model constant $=0.25$

$\mathbf{E}, \mathbf{F}$

parameters used in turbulence model averaging for multiple walls

$\mathrm{E}_{T}$

inviscid flux vectors

$\mathbf{E}_{V}, \mathbf{F}_{V}$

total energy per unit volume

$f_{1}, f_{2}$

viscous flux vectors

$F(y)$ parameters used in turbulence model averaging for multiple walls

$\mathrm{F}_{\mathbf{K l e b}}$ function in Baldwin-Lomax turbulence model (equation (C.7))

$\mathbf{F}_{\max }$

Klebanoff intermittency factor

$F_{\text {wake }}$

parameter in Baldwin-Lomax turbulence model

$\mathrm{G}_{1}$

parameter in Baldwin-Lomax turbulence model (equation (C.6))

$\mathrm{G}_{2}$

MMLPG parameter; controls mixing length saturation level

$\mathrm{G}_{3}$

MMLPG parameter; controls curvature of blending region

MMLPG parameter; controls slope of inner layer mixing length 


\begin{tabular}{|c|c|}
\hline $\mathbf{G}_{\mathbf{4}}$ & MMLPG parameter; nondimensional boundary layer thickness \\
\hline $\mathrm{G}_{5}, \mathrm{G}_{6}$ & MMLPG parameters; used to compute $G_{4}$ \\
\hline $\mathrm{G}_{7}, \mathrm{G}_{8}$ & MMLPG parameters; used to compute displacement thickness \\
\hline $\mathbf{H}$ & throat height of Sajben diffuser \\
\hline $\mathbf{k}$ & coefficient of thermal conductivity \\
\hline$l$ & turbulent mixing length \\
\hline $\mathbf{p}$ & static pressure \\
\hline $\mathbf{p}_{\mathbf{t}}$ & total pressure \\
\hline $\operatorname{Pr}$ & Prandtl number \\
\hline$q_{x}, q_{y}$ & heat fluxes in the $\mathrm{x}$ and $\mathrm{y}$ directions \\
\hline $\mathbf{Q}$ & vector of dependent variables (equation (A.2)) \\
\hline $\mathbf{R}$ & ratio of exit static pressure to inlet total pressure for Sajben diffuser \\
\hline $\mathbf{R e}_{\mathbf{x}}$ & Reynolds number based on $\mathrm{x}$-coordinate \\
\hline $\mathbf{t}$ & time \\
\hline $\mathbf{T}$ & static temperature \\
\hline $\mathbf{u}, \mathbf{v}$ & velocities \\
\hline$u_{\infty}$ & freestream $\mathrm{x}$-velocity \\
\hline$u_{\tau}$ & shear velocity \\
\hline V & total velocity \\
\hline$V_{\text {diff }}$ & difference between maximum and minimum total velocities \\
\hline$x, y$ & Cartesian coordinates \\
\hline $\mathbf{y}^{+}$ & y coordinate nondimensionalized by shear length scale \\
\hline $\mathrm{y}^{*}$ & shear length scale (equation (2.7)) \\
\hline$y_{\max }$ & parameter in Baldwin-Lomax turbulence model \\
\hline$\beta$ & $\begin{array}{l}\text { Clauser's equilibrium parameter } \\
\text { boundary layer thickness }\end{array}$ \\
\hline
\end{tabular}




\begin{tabular}{|c|c|}
\hline$\delta_{1}$ & displacement thickness \\
\hline$\varepsilon_{E}^{(2)}, \varepsilon_{E}^{(4)}$ & $\begin{array}{l}\text { second- and fourth-order artificial viscosity coefficients in constant } \\
\text { coefficient model }\end{array}$ \\
\hline$\varepsilon_{I}$ & implicit artificial viscosity coefficient \\
\hline$\theta_{1}, \theta_{2}$ & parameters determining type of time differencing used \\
\hline $\boldsymbol{\kappa}$ & von Karman constant $=0.4$ \\
\hline$\kappa_{2}, \kappa_{4}$ & constants in nonlinear coefficient artificial viscosity model \\
\hline$\lambda$ & second coefficient of viscosity \\
\hline $\boldsymbol{\mu}$ & molecular viscosity \\
\hline$\xi, \eta$ & computational coordinate directions \\
\hline $\mathbf{p}$. & density \\
\hline$\sigma$ & $\begin{array}{l}\text { pressure gradient scaling parameter in nonlinear coefficient artificial } \\
\text { viscosity model (equation (B.9)) }\end{array}$ \\
\hline$\Psi$ & $\begin{array}{l}\text { spectral radius in nonlinear coefficient artificial viscosity model } \\
\text { (equation (B.6)) }\end{array}$ \\
\hline$\tau$ & shear stress \\
\hline$\tau_{1}, \tau_{2}$ & shear stress at interior grid points \\
\hline$\tau_{x x}, \tau_{y y}, \tau_{x y}$ & elements of shear stress tensor (equation (A.3)) \\
\hline$\omega$ & vorticity \\
\hline
\end{tabular}

Subscripts

cap capping or saturation value

e edge of boundary layer

eff effective

$\mathrm{i}, \mathrm{j} \quad$ indexes in the $\mathrm{x}$ and $\mathrm{y}$ directions 


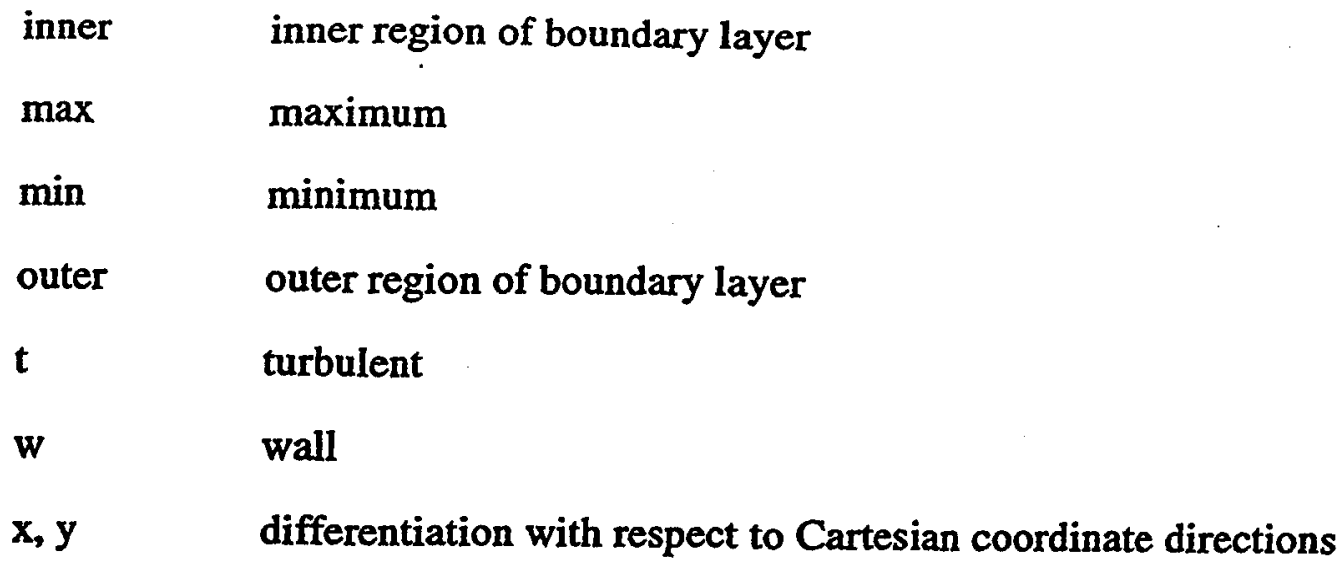





\section{CHAPTER I}

\section{INTRODUCTION}

\subsection{Motivation and Objectives}

Computational Fluid Dynamics (CFD) is a valuable tool for calculating the turbulent flow fields that occur in engineering fluid flow problems. Some of the characteristics of turbulent flow include random fluctuations in fluid properties, the enhancement of mixing, diffusion and dissipation, and the presence of eddies of various sizes. Turbulent flow is, therefore, very difficult to predict theoretically. Experiments provide much useful information about turbulent flow fields but are costly and time consuming, so CFD is being used increasingly to reduce or optimize the amount of experimental testing which must be done.

Most CFD codes solve the equations of conservation of mass, momentum (Navier-Stokes) and energy and, in principle, completely describe the details of turbulent flow. However, except for very simple problems, these equations cannot be solved exactly due to the limited capabilities of computational resources. Most engineering problems are primarily concerned with mean fluid properties and not with the details of the turbulent fluctuations; the mean properties can therefore be computed using the Reynolds-averaged form of the Navier-Stokes equations. ${ }^{1}$ In Reynolds averaging, the conservation equations are averaged over a time scale that is large compared to the largest time scale of the fluctuating motion. ${ }^{1,2,3}$ The averaging procedure introduces new terms which represent the turbulent transport of mean momentum, heat and mass. The resulting averaged equations are not closed and 
empirical information, in the form of a turbulence model, must be used to close the system.

A turbulence model is a mathematical model consisting of an equation or set of equations which determines the turbulent transport terms in the mean flow equations and hence closes the system of equations. ${ }^{1}$ Turbulence models give an approximate description of the flow by describing the overall effect of turbulence on the mean flow, rather than describing the details of the turbulent motion. Since turbulent transport processes depend on factors such as geometry, swirl effects and buoyancy, turbulence models, which are usually developed based on hypotheses about a certain flow or range of flows, usually have a limited range of applicability. Typically, a model which is complex and consists of a large number of equations is difficult to use and is computationally expensive. Often this increase in "cost" is not proportional to the improvements in the computation.

For most engineering applications, a turbulence model should be easy to implement, computationally inexpensive and applicable to a wide range of flows. Algebraic turbulence models, also called zero-equation models, are simple and inexpensive, however they generally have only a narrow range of applicability. The most widely used algebraic model, the Baldwin-Lomax model (BLM), ${ }^{4}$ fits this description, but it is known to have difficulties calculating adverse pressure gradient and separated flows, ${ }^{5-12}$ the regime it was designed to handle.

In 1989, the modified mixing length model (MML) was developed and used to calculate separated flows over airfoils, flowfields that BLM was unable to accurately predict. $^{5}$ It is based on Prandtl's mixing length hypothesis ${ }^{3}$ and uses a mixing length that is dependent on the local wall shear stress. The objective of this work is to 
continue the development of MML to expand its range of applicability to include boundary layer flows with adverse pressure gradients.

\subsection{Overview}

Chapter II gives some background information on the Proteus Navier-Stokes code; which was used to make all of the calculations in this work. It also describes the implementation of turbulence into the governing equations and describes problems encountered with BLM, the current algebraic turbulence model in Proteus. Chapter II also describes the original formulation of MML. Chapter III reports calculations made with MML for zero pressure gradient flow over a flat plate, and then describes the modifications made to improve these results for both zero and adverse pressure gradient flows. The resulting modified version of MML is called MMLPG. Chapter IV compares MMLPG and BLM for three transonic diffuser flow test cases: flow with a weak shock, strong shock, and no shock. Chapter V contains a summary of this work and a discussion of the conclusions drawn. 


\section{CHAPTER II}

\section{BACKGROUND}

\subsection{The Proteus Navier-Stokes Code}

The Proteus Navier-Stokes code, ${ }^{13}, 14$ developed at the NASA Lewis Research Center, is a user-oriented, full Navier-Stokes code for aerospace propulsion applications. Proteus solves the Reynolds-averaged, unsteady, compressible NavierStokes equations in strong conservation law form. Two separate versions of the code exist: one for two-dimensional plane or axisymmetric flow, and one for three-dimensional flow. A primary objective of the Proteus effort was to make the code easy to use and modify. Therefore, code readability, modularity and documentation were emphasized, rendering the code ideal for the insertion and development of a new turbulence model.

The governing equations in Proteus are written in Cartesian coordinates and then transformed to a nonorthogonal, body-fitted system (see Appendix 1). ${ }^{13}$ They are solved by marching in time using a fully-coupled alternating direction implicit solution procedure with generalized first or second order time differencing. ${ }^{15,} 16$ The boundary conditions are also treated implicitly and can be steady or unsteady. All terms, including diffusion terms, are linearized to second order using Taylor series expansions. The two turbulence models originally available in Proteus are the Baldwin-Lomax algebraic model ${ }^{4}$ and the Chien k- $\varepsilon$ two-equation model. ${ }^{17}$

In addition to solving the full, time-averaged Navier-Stokes equations, Proteus includes options to solve the thin-layer and Euler equations, and to eliminate 
the energy equation by assuming constant stagnation enthalpy. Artificial viscosity is used to minimize the odd-even decoupling resulting from the use of central spatial differencing for the convective terms, and to control pre- and post-shock oscillations in supersonic flow. ${ }^{13}$ Two artificial viscosity models are available: a combination implicit/explicit constant coefficient model, ${ }^{18}$ and an explicit nonlinear coefficient model designed specifically for flows with shock waves. ${ }^{19}$ The artificial viscosity is discussed in more detail in Appendix 2. At the NASA Lewis Research Center the code is typically run either on the CRAY X-MP or CRAY Y-MP computer, and is highly vectorized. For all calculations made herein, the two-dimensional/axisymmetric version of the code was run on the CRAY Y-MP computer.

\subsection{Algebraic Turbulence Modeling and the Baldwin-Lomax Model}

Accurate modeling of turbulence is essential to the computation of complex propulsion flow fields. Several types of turbulence models are available, ranging from zero-equation algebraic models to multi-equation Reynolds-stress models. Algebraic models are the most algorithmically simple and computationally inexpensive models and were therefore chosen as the focus of this effort.

Proteus, along with the majority of Navier-Stokes codes, uses the Boussinesq assumption, ${ }^{3}$ which states that the turbulent stresses behave like the molecular viscous stresses and therefore are proportional to the mean velocity gradient. The resulting total shear stress for a two-dimensional flow is given by ${ }^{13}$

$$
\tau=\mu_{\text {eff }}\left(\frac{\partial u}{\partial y}+\frac{\partial v}{\partial x}\right)
$$

The effective viscosity is defined as $\mu_{\text {eff }}=\mu+\mu_{t}$, where $\mu$ is the molecular viscosity and $\mu_{t}$ is the turbulent, or "eddy" viscosity. The same analogy applies to the heat flux and the normal stresses, which are both defined in Appendix 1, such that an effective 
second coefficient of viscosity is defined as $\lambda_{\text {eff }}=\lambda+\lambda_{t}$ and an effective thermal conductivity coefficient is defined as $k_{\text {eff }}=k+k_{t}$.

Most algebraic turbulence models are based on Prandtl's mixing length hypothesis which builds on the Boussinesq assumption. ${ }^{1}$ Prandtl made an analogy between molecular motion and turbulent flow. In molecular motion, the molecular viscosity is proportional to the average velocity and the mean free path of the molecules. In turbulent flow, Prandtl assumed that the turbulent viscosity is proportional to the characteristic velocity of the fluctuating motion and to a typical length, called the "mixing length", of this motion. In other words,

$$
\mu_{\mathrm{t}}=\rho \mathrm{v}_{\mathrm{t}} l
$$

where $v_{t}$ is the turbulent velocity scale and the mixing length, $l$, is the transverse distance over which fluid particles maintain their original momentum. Prandtl further assumed that the turbulent velocity scale is equal to the mixing length times the velocity gradient so that

$$
\mu_{\mathrm{s}}=\rho l^{2}\left|\frac{\partial \mathrm{u}}{\partial \mathrm{y}}\right|
$$

The quantity $l\left|\frac{\partial \mathrm{u}}{\partial \mathrm{y}}\right|$ is the velocity scale, where $\mathrm{u}$ is the component of velocity in the primary flow direction and $y$ is the coordinate perpendicular to the primary flow direction.

The current algebraic turbulence model in Proteus, the Baldwin-Lomax model (BLM), is given in Appendix 3. It is the most well-known and widely used algebraic turbulence model. An extension of the Cebeci-Smith model, ${ }^{20}$ which requires knowledge of the outer edge of the boundary layer, the Baldwin-Lomax model was developed to handle separated flows while avoiding the necessity of finding this outer edge. 
Several references report problems with BLM in regions of strong pressure gradient and in flows with large regions of separation. $\mathrm{Yu}^{6}$ reports problems calculating surface pressures on the outboard wing region of a wing-body configuration when the angle of attack is high and separation occurs. Visbal and $\mathrm{Knight}^{7}$ report that the BLM outer formulation is unsuitable for separated supersonic flow and also is unable to predict the recovery of the boundary layer downstream of reattachment. Degani \& Schiff $^{8}$ report that BLM is unsuitable in regions of cross flow separation due to ambiguities in computing the outer length scale. Menter ${ }^{9}$ reports that BLM underestimates the displacement thickness for the increasingly adverse pressure gradient flow of Samuel \& Joubert ${ }^{21}$ and that it also gives an incorrect prediction of the adverse pressure gradient flow of Driver. ${ }^{22}$ Potapczuk $^{5}$ reports problems with BLM in predicting the separation and unsteady behavior on airfoils with and without leading edge ice accretion. Stock and Haase ${ }^{10}$ report that BLM does not predict the correct trends for $\mu_{t}$ or the Reynolds stresses in adverse pressure gradient and separated flows.

There are several reasons why BLM has problems computing flows with large pressure gradients and large regions of separation. The primary difficulty occurs in finding the maximum of the $F(y)$ function (defined Appendix 3), which has two or more peaks in regions of separated flow. This behavior is shown in figure 1 taken from reference 5. As the relative magnitudes of the local maxima change, $y_{\max }$ .(defined in Appendix 3), may suddenly jump, producing unrealistic discontinuities in the turbulent viscosity. Selection of the global maxima often results in a gross overprediction of the turbulent viscosity. Some authors ${ }^{7,23}$ have found that choosing the outermost peak produces better results, while others have elected to use the innermost peak. ${ }^{8}$ To account for upstream turbulence history effects, Visbal and Knight ${ }^{7}$ used 


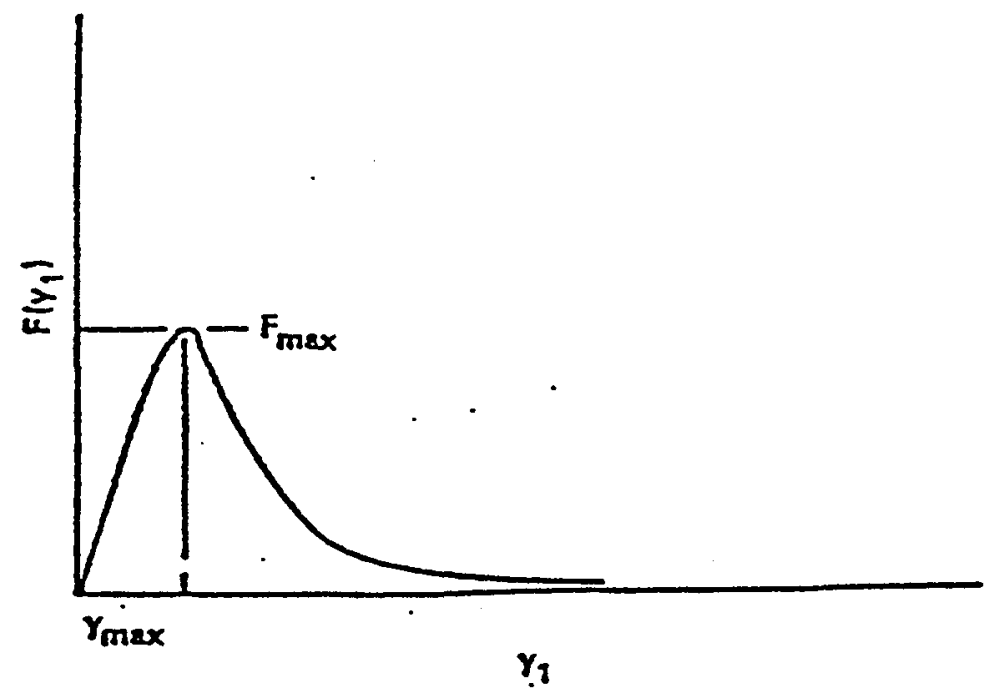

(a) Attached flow

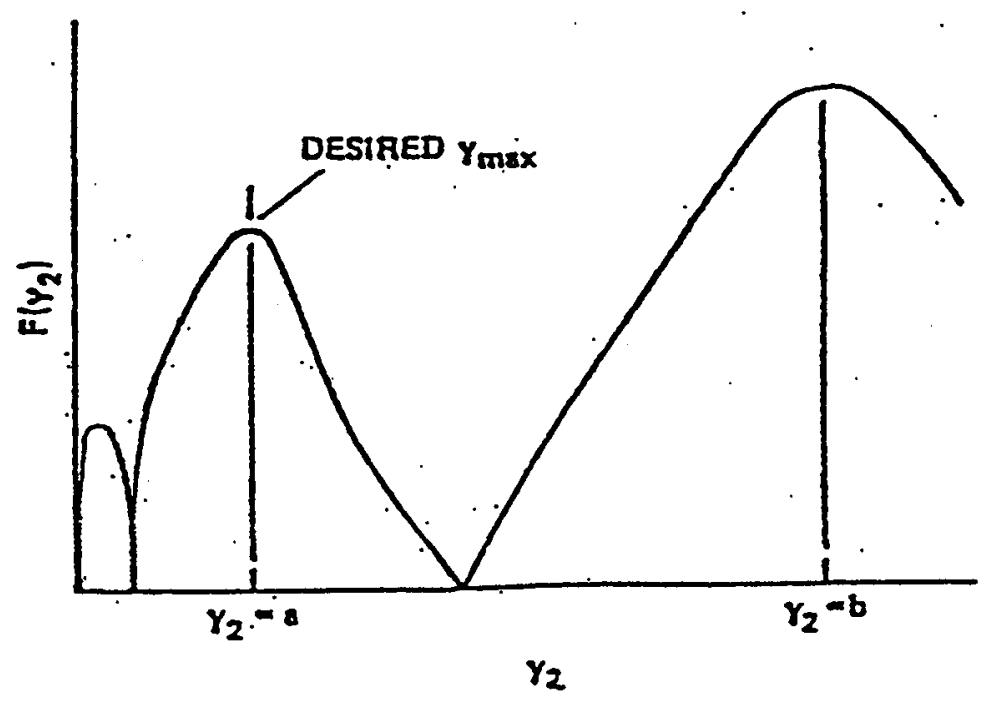

(b) Separated flow

Figure 1. $F(y)$ profiles for attached and separated flow conditions. 
BLM with relaxation. They also found that the BLM constants $C_{c p}$ and $C_{k l e b}$ (see Appendix 3) should vary with Mach number. Sakowski et al ${ }^{11}$ expounded upon this by finding a relation for $\mathrm{C}_{\mathrm{cp}}$ as a function of Mach number and pressure gradient, but encountered problems caused by the vanishing of the Van Driest factor when $\tau_{w}$, the local shear stress at the wall, approaches zero. To remedy this, they used the local shear in place of $\tau_{w}$. Launder and Pridden ${ }^{24}$ report several modifications to the Van Driest factor ${ }^{2}$ for pressure gradient flows, many of which incorporate the local shear stress instead of $\tau_{w}$.

A simpler, yet effective, approach was used by Potapczuk, ${ }^{5}$ who developed a modified mixing length (MML) model that does not require a boundary layer thickness, but also avoids all problems associated with the determination of a maximum $\mathrm{F}(\mathrm{y})$. This model is described in detail in the following section.

\subsection{The Modified Mixing Length Turbulence Model}

The modified mixing length (MML) model was developed by Potapczuk ${ }^{5}$ to fill the need for an algebraic model to handle turbulent flow with large separated regions. The particular problem of interest was an airfoil at angle of attack with and without leading edge ice accretions. Previous calculations made with BLM gave poor results and the source of the problem was the function $F(y)$, which had multiple peaks for this flow case.

The MML model avoids the need to seek a maximum of some ad hoc function. In accordance with Prandtl's mixing length theory, the MML model determines the mixing length using the wall shear stress and the normal distance from the wall, with the maximum mixing length capped off at a given value. Thus, it is a two layer model, such that the length scale depends on conditions near the surface and remains 
constant in the separated region. This assumption is valid since there is no substantial enhancement of turbulence in separated regions. The turbulent viscosity is given by

$$
\mu_{t}=\rho l^{2}|\omega|
$$

where the velocity gradient in equation (2.3) has been replaced by the vorticity magnitude, $|\omega|$. Figure 2, taken from reference 20 , shows the behavior of the mixing length in a turbulent boundary layer. Several empirical formulas are available to evaluate the inner region, 20,24 which consists of the viscous sublayer and the overlap layer. The MML model uses the van Driest formulation, ${ }^{20}$ which is given by

$$
l_{\text {inner }}=\operatorname{ky}\left(1-\mathrm{e}^{\frac{y^{+}}{\Lambda^{+}}}\right)
$$

where $A^{+}=26$ and the value of $k$, the von Karman constant, is 0.4 . The quantity $y^{*}$ is defined as

$$
y^{*}=\frac{y}{y^{*}}
$$

where $y^{*}$ is the shear length scale,

$$
y^{*}=\frac{\mu}{\sqrt{\rho\left|\tau_{w}\right|}}
$$

For $\mathrm{y}^{+} \geq 5 \mathrm{~A}^{+}$(but still in the "inner" region), the mixing length is approximated by Ky; this is the original Prandtl theory, and is consistent with the well-known logarithmic profile. In the outer region of the boundary layer, the outer mixing length behaves according to

$$
l_{\text {outer }}=\text { constant } \times y^{*}
$$




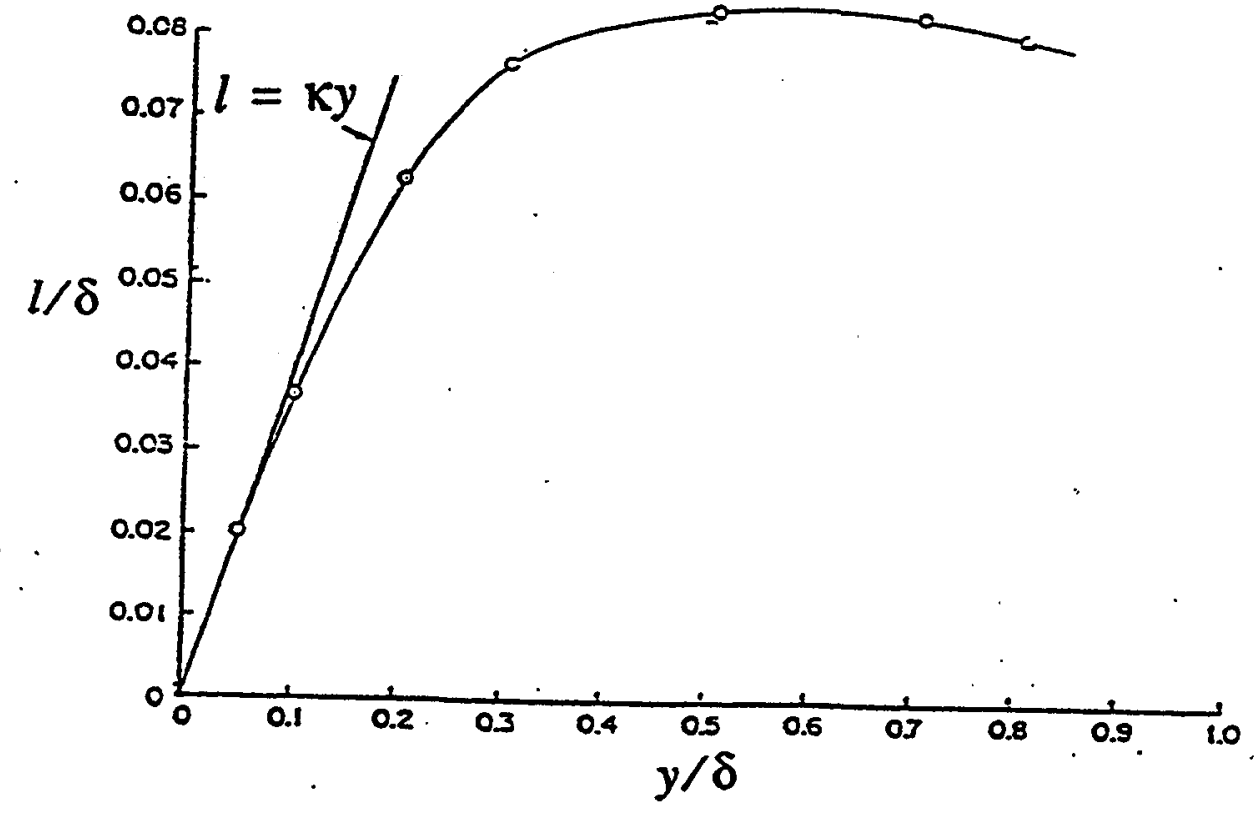

Figure 2. Dimensionless mixing length distribution across a turbulent boundary layer, taken from reference 20 . 
The MML model uses a blending function to give a smooth transition between the inner and outer layers and is given by

$$
\begin{gathered}
l(\mathrm{y})=\kappa \frac{\mathrm{C}_{1}}{\mathrm{C}_{2}} \mathrm{y}^{*}\left(1-\left(1-\frac{\mathrm{y}^{+}}{\mathrm{C}_{1}}\right)\right)\left(1-\mathrm{C}^{\left(\frac{\mathrm{y}^{+}}{\mathrm{A}^{+}}\right)}\right), \quad \mathrm{y}^{+}<\mathrm{C}_{1} \\
l(\mathrm{y})=\kappa \frac{\mathrm{C}_{1}}{\mathrm{C}_{2}} \mathrm{y}^{*}, \quad \mathrm{y}^{*} \geq \mathrm{C}_{1}
\end{gathered}
$$

In this formulation, $\mathrm{C}_{1} \mathrm{y}^{*}$ is the distance above the surface at which $l$ saturates, and $\mathrm{C}_{2}$ controls the curvature of the blending region. See figure 3 for a typical MML model mixing length profile.

Calculations made by Potapczuk with the MML model showed improvements over the BLM calculations for the prediction of the separated region, the maximum lift coefficient and vortex shedding frequencies. Since the MML model was developed to solve the specific problem of flow over airfoils, a comprehensive evaluation of the model for more general flowfields was not a part of that study. The objective of the present study is to evaluate the MML model for general zero pressure gradient and adverse pressure gradient turbulent boundary layer flows and examine possible modifications to improve the performance of the model. 


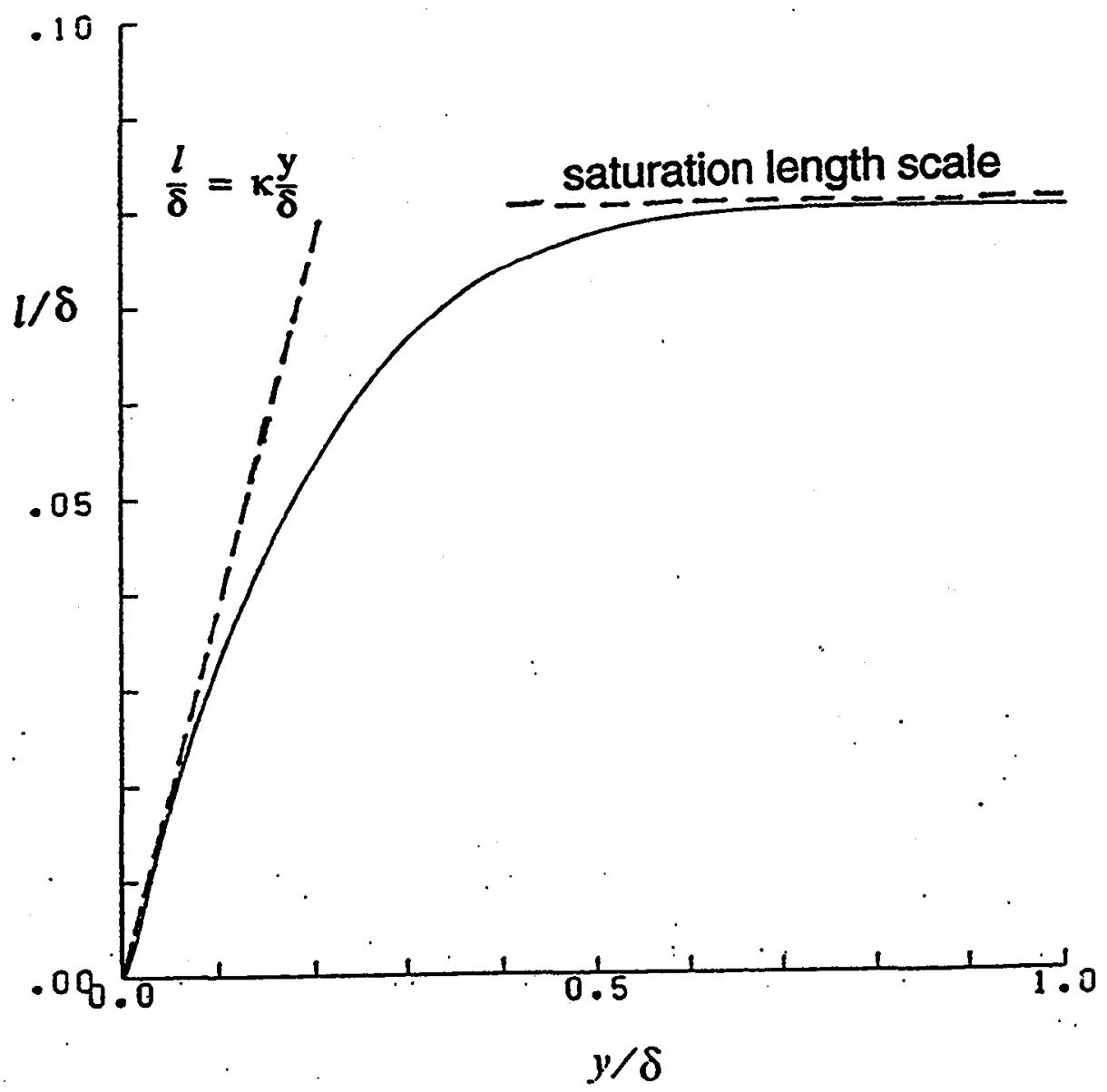

Figure 3. Mixing length profile for the MML model. ${ }^{5}$ 


\section{CHAPTER III EVALUATION AND MODIFICATION OF MML}

The MML model, described in Chapter II, was modified so that it could better calculate turbulent boundary layer flows with zero and adverse pressure gradients. The first step in this process was to optimize the computation of the wall shear stress used in MML. Next, MML was used to calculate a turbulent boundary layer with zero pressure gradient. These results exhibited poor agreement with experimental data, so modifications were made to MML to remedy this problem. Then modifications corresponding to two adverse pressure gradient flows of Bradshaw ${ }^{25}$ were successfully incorporated into MML. Finally, all of the modifications were combined into one general model, called MMLPG.

\subsection{Optimization of Shear Stress Estimate}

Since the MML turbulence model is a function of the wall shear stress, it is important to accurately calculate this quantity. The wall shear stress is given by

$$
\tau_{w}=\mu\left(\frac{\partial u}{\partial \dot{y}_{w}}\right.
$$

The molecular viscosity, $\mu$, is a very small quantity compared to the velocity gradient, $\left(\frac{\partial u}{\partial y}\right)_{w}$, which is strongly dependent on several factors such as the finite difference scheme used, the grid spacing and the numerical features of the code. It is important to minimize the sensitivity of these factors because small changes in the estimate of $\left(\frac{\partial u}{\partial y}\right)_{w}$ may actually produce large changes in $\tau_{w}$. A more global approach is to use a 
parabolic extrapolation of $\tau_{w}$, using the shear stress at two interior grid points, and the momentum equation in the streamwise direction, which reduces to

$$
\left(\frac{\partial \tau}{\partial y}\right)_{w}=\left(\frac{\partial p}{\partial x}\right)_{w}
$$

at the wall. Using a parabola to define $\tau$,

$$
\tau=a y^{2}+b y+c
$$

where,

$$
\begin{gathered}
a=\frac{\tau_{1}-\tau_{2}-b\left(y_{1}-y_{2}\right)}{y_{1}^{2}-y_{2}^{2}} \\
b=\left(\frac{\partial p}{\partial x_{w}}\right)_{w} \\
c=\frac{1}{2}\left[\tau_{1}+\tau_{2}-a\left(y_{1}^{2}+y_{2}^{2}\right)-b\left(y_{1}+y_{2}\right)\right]
\end{gathered}
$$

Here, the subscripts 1 and 2 denote interior points as depicted in figure 4 . Note that $\tau_{w}=c$, since $y=0$ at the wall. Also note that the shear stress at interior points is defined by

$$
\tau=\mu_{\text {eff }}\left(\frac{\partial u}{\partial y}+\frac{\partial v}{\partial x}\right)
$$

The parabolic extrapolation in equations (3.3) through (3.6) gives a reliable value for $\tau_{w}$ and avoids problems that could arise from sensitivity of the $\left(\frac{\partial u}{\partial y}\right)$ estimate. In fact, $\left(\frac{\partial u}{\partial y}\right)_{w}$ can be found from $\left(\frac{\partial u}{\partial y}\right)_{w}=\tau_{w} / \mu$. 


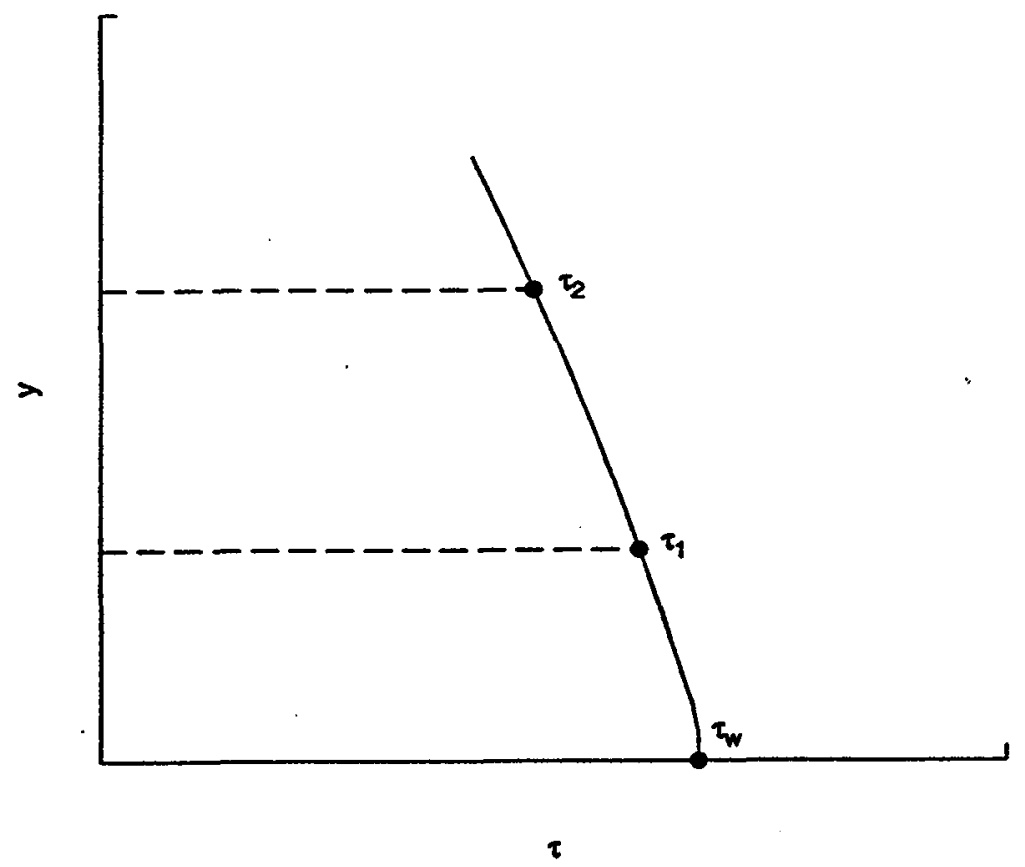

Figure 4. Estimation of $\tau_{w}$ using equation (3.3). 
Modifications were made to the Proteus code to calculate the shear stress profile in the boundary layer. These modifications made use of the generalized grid transformations in Proteus such that

$$
\tau=\mu_{\text {eff }}\left(\xi_{\mathrm{y}} \frac{\partial \mathrm{u}}{\partial \xi}+\eta_{\mathrm{y}} \frac{\partial \mathrm{u}}{\partial \eta}+\xi_{\mathrm{x}} \frac{\partial \mathrm{v}}{\partial \xi}+\eta_{\mathrm{x}} \frac{\partial \mathrm{v}}{\partial \eta}\right)
$$

where $\xi_{y}=\eta_{x}=0$ for an orthogonal grid. ${ }^{13}$ The derivatives in the above equation are calculated in Proteus using 3-point, second-order central differencing. To see if higher order differencing would improve the calculation, 5-point, fourth-order central differencing ${ }^{26}$ was also used to calculate the velocity gradients.

The test case of incompressible, zero pressure gradient, turbulent flow over a flat plate, as shown in figure 5, was used to evaluate the shear stress calculations. The grid, shown in figure 6, had 51 points in both the streamwise and normal directions and had grid points clustered at the wall to resolve the boundary layer and at the upstream boundary to resolve the imposed boundary condition. In addition, it was evaluated to insure grid indepence for zero pressure gradient flow. The reference velocity, temperature, pressure and length used in Proteus were $33.53 \mathrm{~m} / \mathrm{s}, 288.3 \mathrm{~K}$, $101.3 \mathrm{kPa}$ and $1.98 \mathrm{~m}$, respectively. At the upstream boundary, the velocity profile, which was computed using the correlation of Musker, ${ }^{27}$ was held fixed. The flow was computed using both MML and BLM, using both higher and lower order differencing of the velocity gradients in the shear stress computation. The MML constants were chosen as $C_{1}=3000$ and $C_{2}=5$, which were found to give good results at $\operatorname{Re}_{x}=7 \times 10^{6}$. Both turbulence models produced good agreement with experimental velocity-defect profiles, ${ }^{28}$ as shown in figure 7 , which shows calculations at $R_{x}=7 \times 10^{6}$ made with the lower order differencing of the velocity gradients. The quantity $u_{\tau}$ in figure 7 is the shear velocity, given by $u_{\tau}=\sqrt{\left(\left|\tau_{w}\right| / \rho\right)}$. The accuracy of the finite differencing 


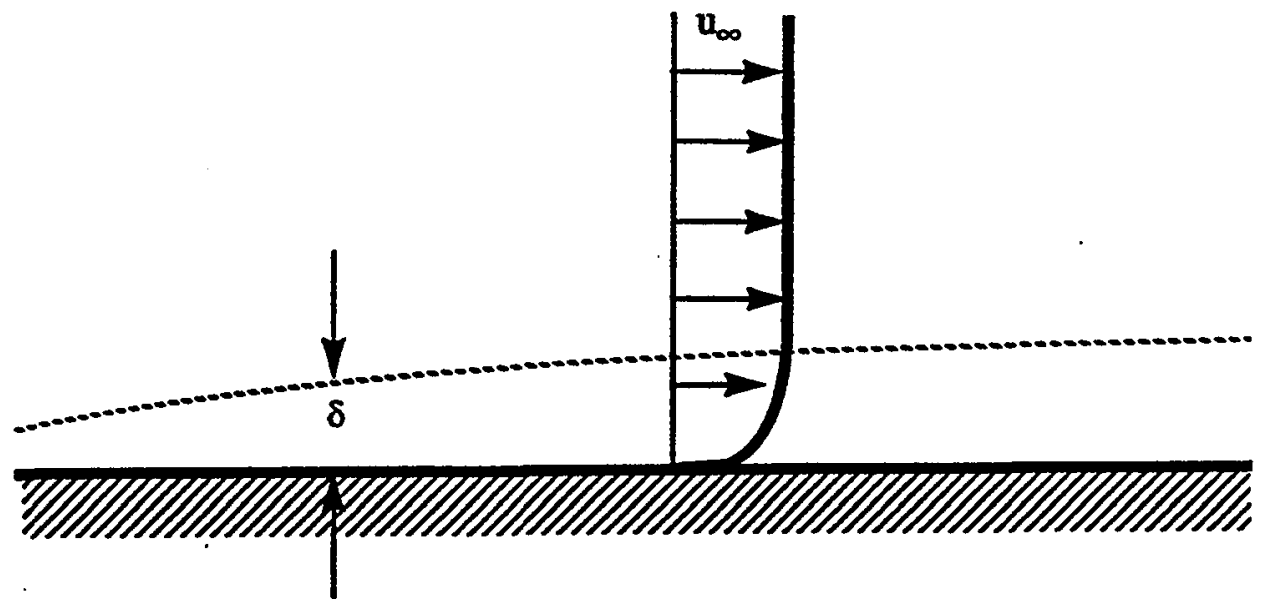

Figure 5. Illustration of flow over a flat plate.

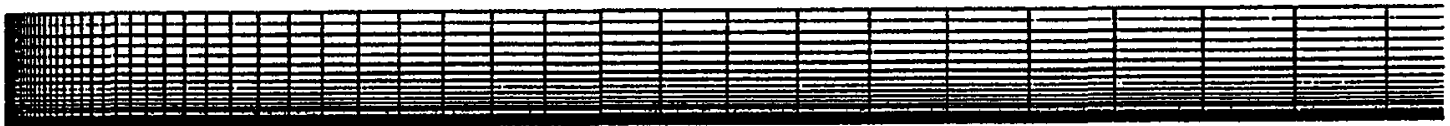

Figure 6. Computational grid for zero pressure gradient flat plate case. 


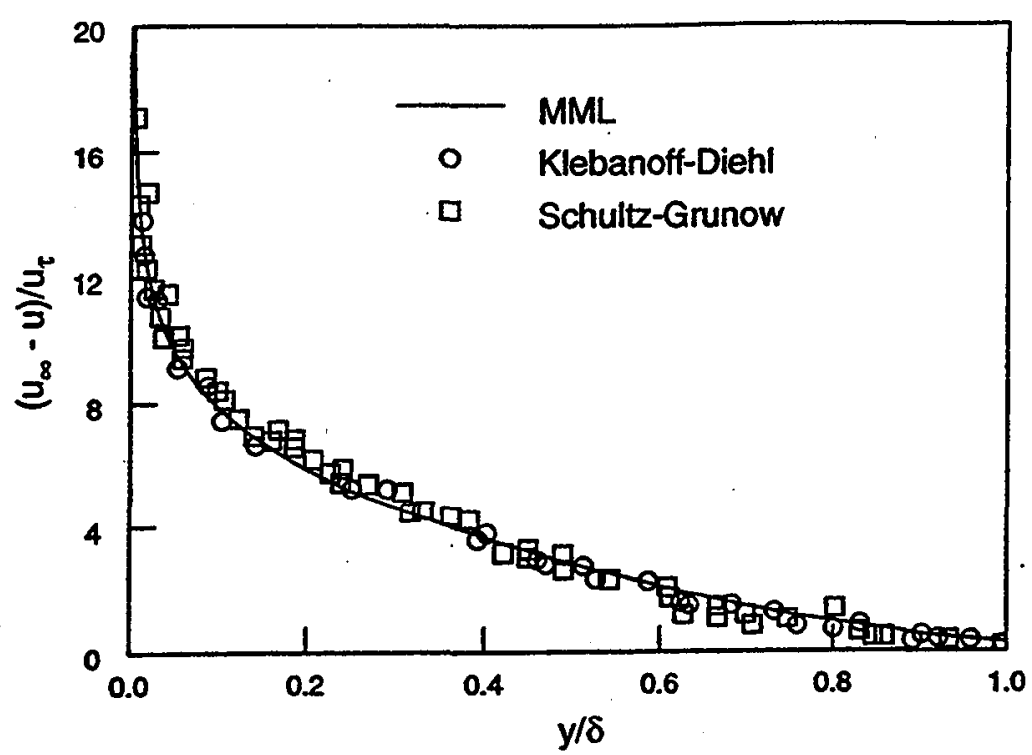

(a) MML

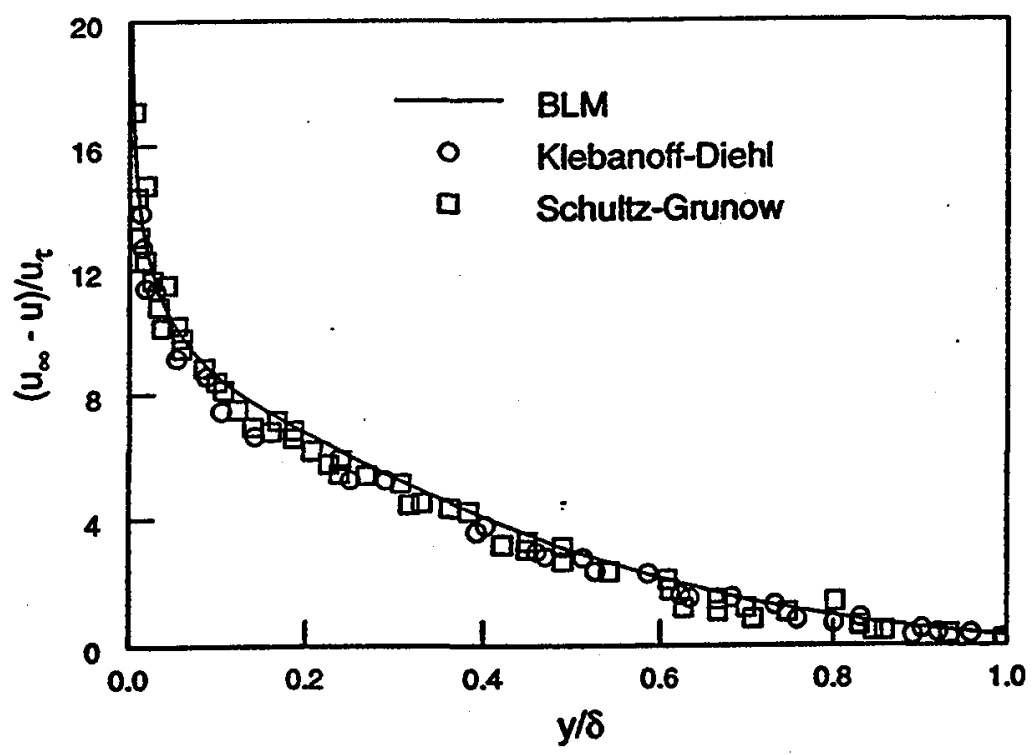

(b) BLM

Figure 7. Velocity-defect profiles for zero pressure gradient flat plate flow, $\operatorname{Re}_{\mathrm{x}}=7 \times 10^{6}$ 
produced no noticeable improvement in the velocity profiles, but there were slight differences in the shear stress profile very close to the wall, which can be observed in the plots of figure 8 . The higher-order differencing produced a smoother shear stress profile near the wall, and thus subsequent calculations will make use of the higherorder calculation of the velocity gradients.

Near separated regions of flow, $\tau_{\mathrm{w}}$ approaches zero which will cause $\mathrm{y}^{*}$ and thus the mixing length to become infinitely large. To avoid this problem, the following local average used by Potapczuk ${ }^{5}$ was incorporated:

$$
\left|\tau_{i}\right|=0.1\left|\tau_{i-2}\right|+0.2\left|\tau_{i-1}\right|+0.4\left|\tau_{i}\right|+0.2\left|\tau_{i+1}\right|+0.1\left|\tau_{i+2}\right|
$$

The subscripts in equation (3.9) refer to grid points in the streamwise direction along the wall.

\subsection{Evaluation and Modification for Zero Pressure Gradient Flows}

In reference 5, a series of cases were run for flow over a NACA0012 airfoil at conditions near stall using both BLM and MML. The MML constants $C_{1}=2000$ and $\mathrm{C}_{2}=5$ were chosen based on correlations with experimental data. The Baldwin-Lomax model tended to suppress the trailing-edge separation, which occurs on the top surface of the airfoil, by over-predicting $\mu_{t}$ throughout the separated region. On the other hand, MML predicted high values of $\mu_{t}$ only near the separation point, thus allowing the reverse flow to develop downstream. In the current study, MML was evaluated for turbulent flow over a flat plate at zero pressure gradient, as described below.

In the preliminary analysis presented in section 3.1 , the constants $C_{1}=3000$ and $C_{2}=5$ were found to give good agreement for $R e_{x}=7 \times 10^{6}$. At other locations on the plate, i.e., at other Reynolds numbers, the BLM velocity-defect profiles correctly exhibit similarity but the MML profiles do not, as shown in figure 9. In a turbulent 


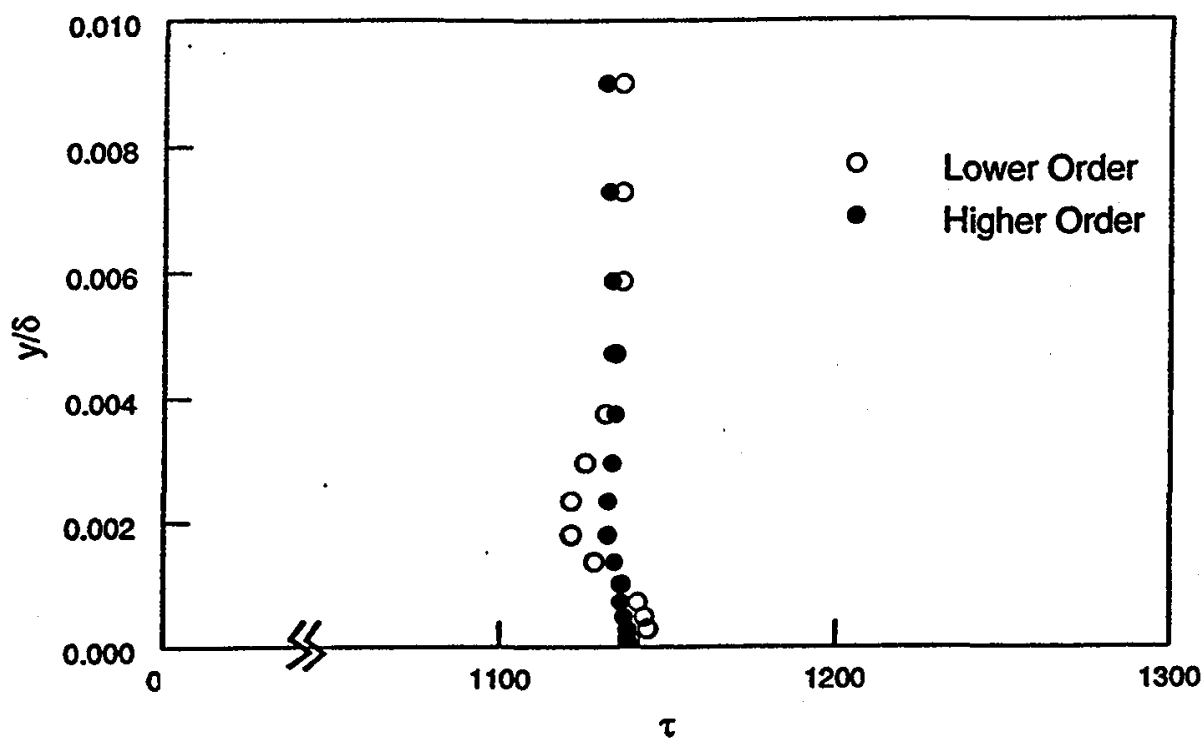

(a) $\mathrm{MML}$

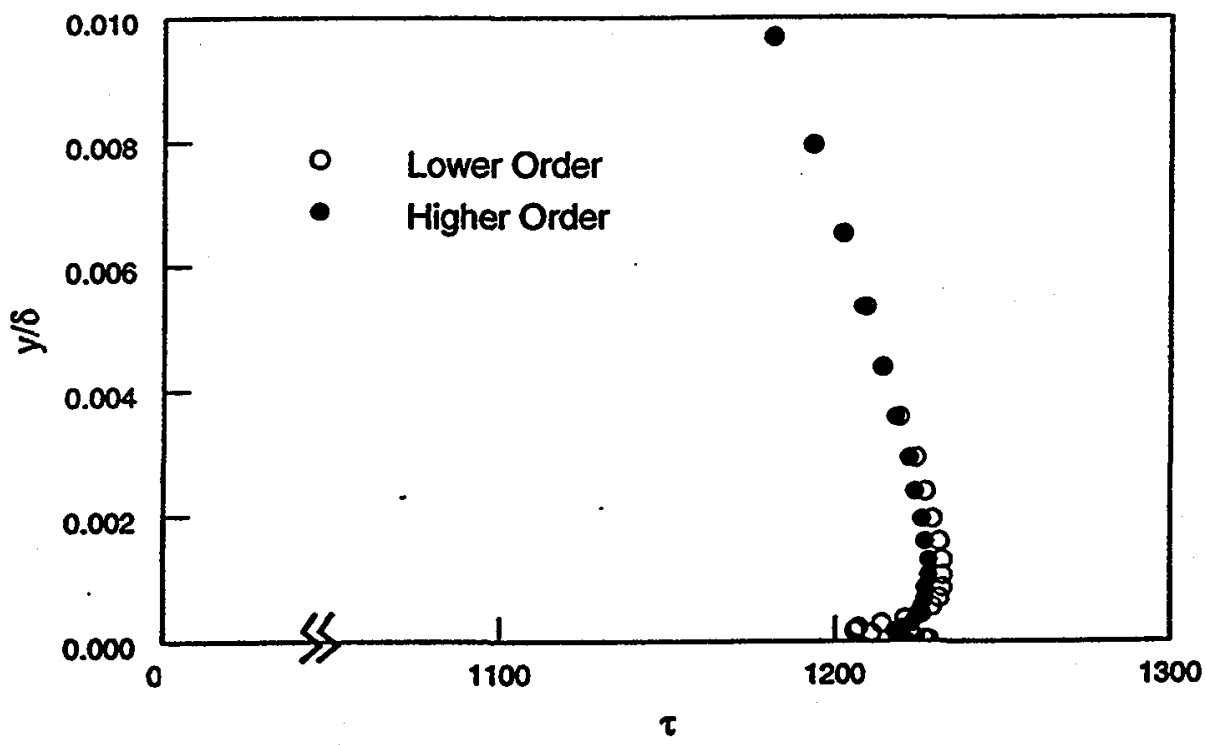

(b) BLM

Figure 8. Shear stress profile near the wall for zero pressure gradient flat plate flow, $\operatorname{Re}_{\mathrm{x}}=7 \times 10^{6}$ 


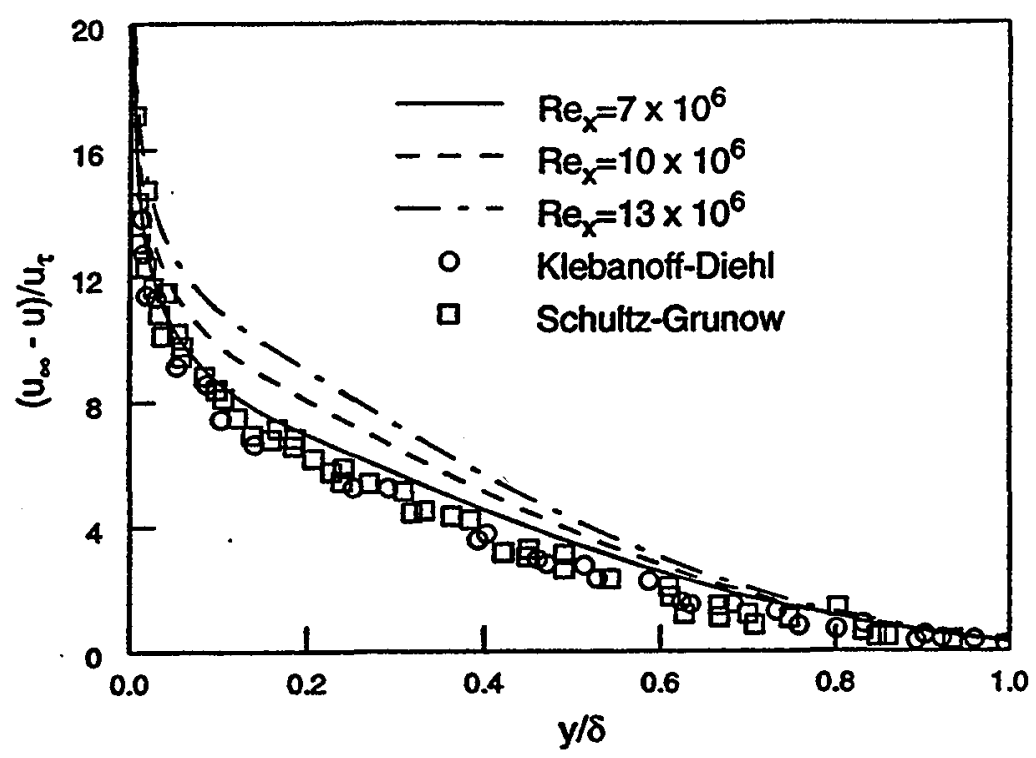

(a) MML

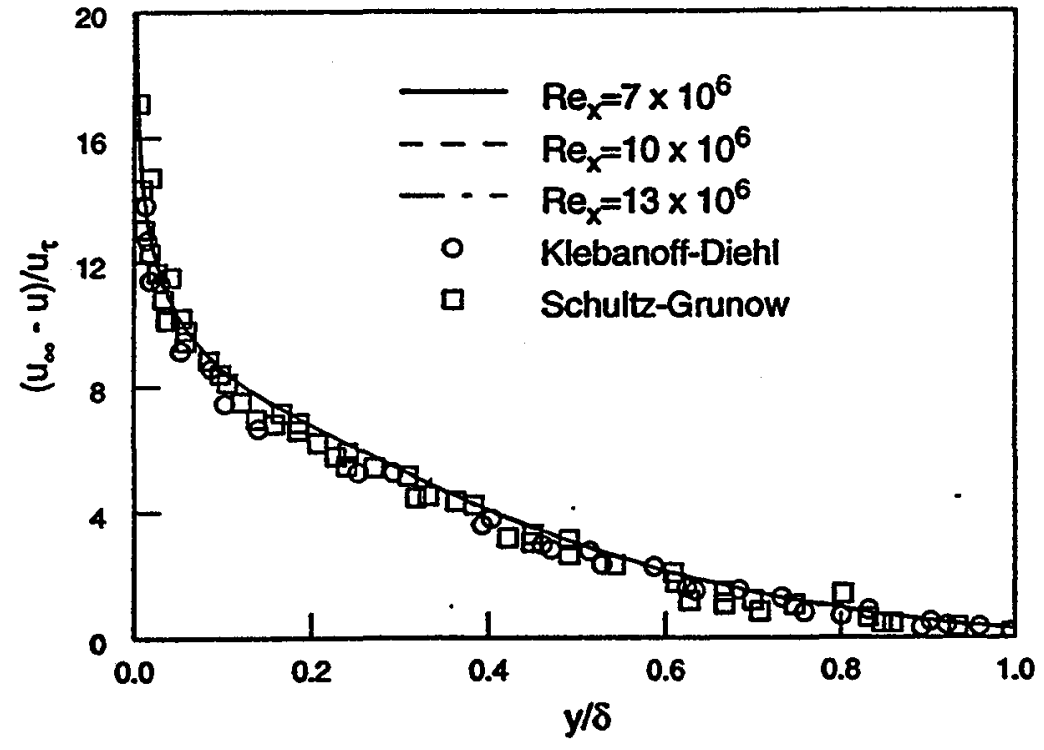

(b) BLM

Figure 9. Velocity-defect profiles for zero pressure gradient flat plate flow at three Reynolds numbers. 
flow over a flat plate, the boundary layer thickness increases with increasing $x$ distance along the plate. To accurately model this flow, the turbulent length scale must also increase proportionately with the boundary layer thickness. In MML, the outer length scale, as given in equation (2.10), is equal to a constant times the shear length scale, $\mathrm{y}^{*}$. The increase in $\mathrm{y}^{*}$ with $\mathrm{x}$-distance is negligible, resulting in an essentially constant value of the outer length scale for all Reynolds numbers. Plots of $\mu_{t}$, as shown in figure 10, illustrate that the turbulent viscosity profiles calculated with MML are nearly the same at all Reynold's numbers, but the BLM $\mu_{\mathrm{t}}$ profiles increase with increasing Reynolds number. Though MML produced the correct length scales for an airfoil near stall, ${ }^{5}$ modifications are needed to make it applicable to general boundary layer flows.

In order to make MML applicable over a range of Reynolds numbers, the optimal saturation lengths, or $\mathrm{C}_{1}$ values, were found at several Reynolds numbers. The following simplified formulas were used to calculate the inner and outer mixing lengths:

$$
\begin{array}{ll}
l^{+}=\mathrm{ky}^{+}\left(1-\mathrm{e}^{-\frac{\mathrm{y}^{+}}{\mathrm{A}^{+}}}\right), & \mathrm{C}_{\mathrm{l}}<\mathrm{y}^{+} \\
l_{\text {cap }}^{+}=\mathrm{kC}_{\mathrm{l}} & \cdot \mathrm{C}_{\mathrm{l}} \geq \mathrm{y}^{+}
\end{array}
$$

Here, $l^{+}$is the nondimensional form of the mixing length, equivalent to $l / \mathrm{y}^{*}$, and the outer length scale, $l_{\text {cap }}^{+}$, is simply the inner length scale evaluated at $y^{+}=C_{1}$. From these results, $l_{\text {cap }}^{+}$was found as a function of the skin friction, $c_{f}$, giving

$$
l_{\text {cap }}^{+}=1860-6.20 \times 10^{5} c_{f}
$$




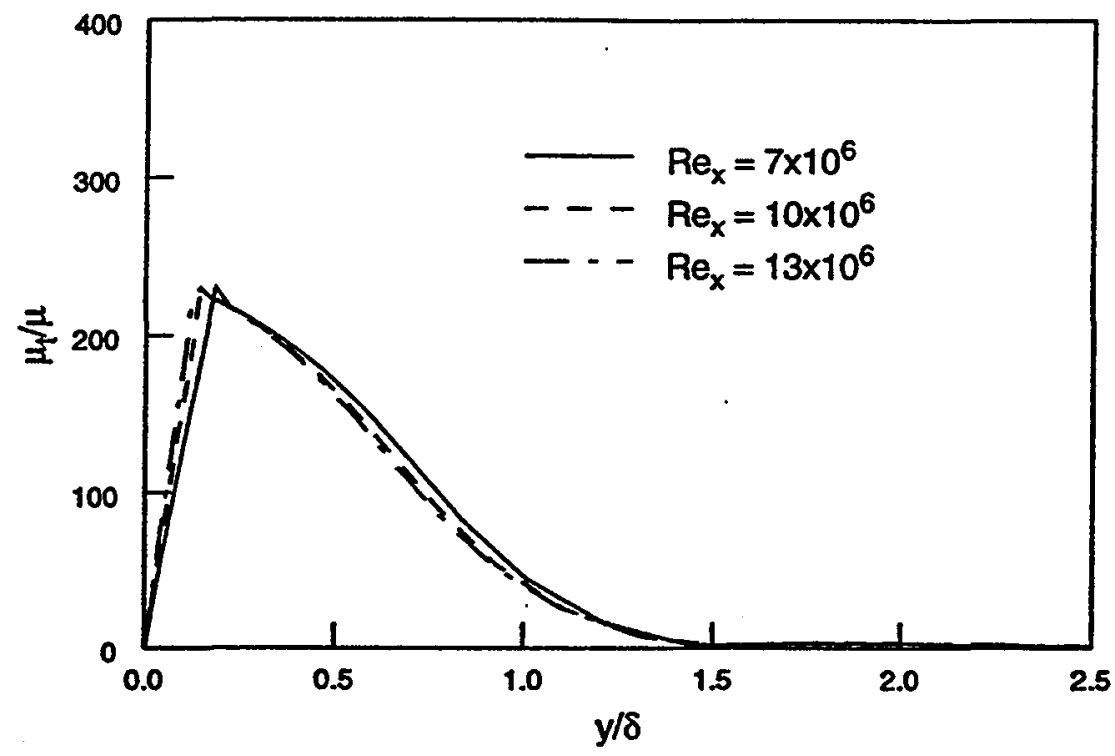

(a) $\mathrm{MML}$

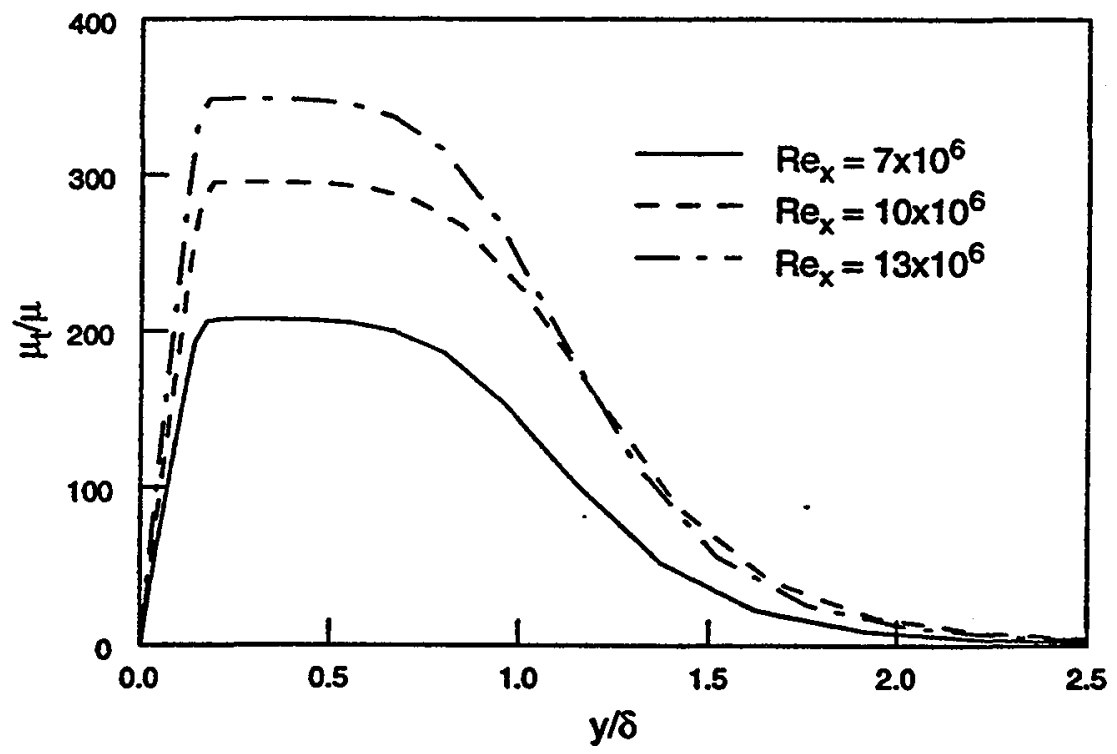

(b) BLM

Figure 10. Turbulent viscosity for zero pressure gradient flat plate flow at three Reynolds numbers. 
The velocity-defect profiles of figure 11 show that equations (3.10) and (3.12) with $l^{+}=\min \left(l^{+}, l_{\text {cap }}^{+}\right)$, allow the mixing length to grow proportionately with the boundary layer thickness. The modified MML is better than BLM at predicting the local skin friction coefficient, $c_{f}$, as shown in figure 12; the wiggles at the upstream boundary are a result of the imposed upstream boundary condition.

\subsection{Modifications for Adverse Pressure Gradient Flows}

Two equilibrium pressure gradient flows of Bradshaw ${ }^{25}$ were used to modify MML for adverse pressure gradients effects. Equilibrium turbulent flows are flows which have a constant value of Clauser's equilibrium parameter, ${ }^{2}$

$$
\beta=\frac{\delta_{1}}{\tau_{w}} \frac{\partial p_{e}}{\partial x}
$$

In addition, they correspond to a power-law velocity profile distribution, $u_{c} \propto x^{2}$, where the magnitude of the exponent, a, indicates the strength of the pressure gradient. They also exhibit similarity when plotted in velocity-defect coordinates. Three flows were examined in the experimental study of Bradshaw; ${ }^{25}$ these were flows with zero, mild, and strong pressure gradients. The corresponding values of the exponent, $a$, are $0,-0.15$, and -0.255 , respectively; the corresponding values of $\beta$ are 0,1 and 5 .

The modifications to the turbulence model are based on the trends exhibited in the mixing length at the three pressure gradients as shown in figure 13 taken from Bradshaw ${ }^{25}$. Note that for all three pressure gradients, the maximum mixing length is approximately $0.08 \delta$, the saturation distance from the wall is approximately $0.4 \delta$, and the slope of the curves near the wall increases with the strength of the pressure gradient. These three features were used to develop the following model: 


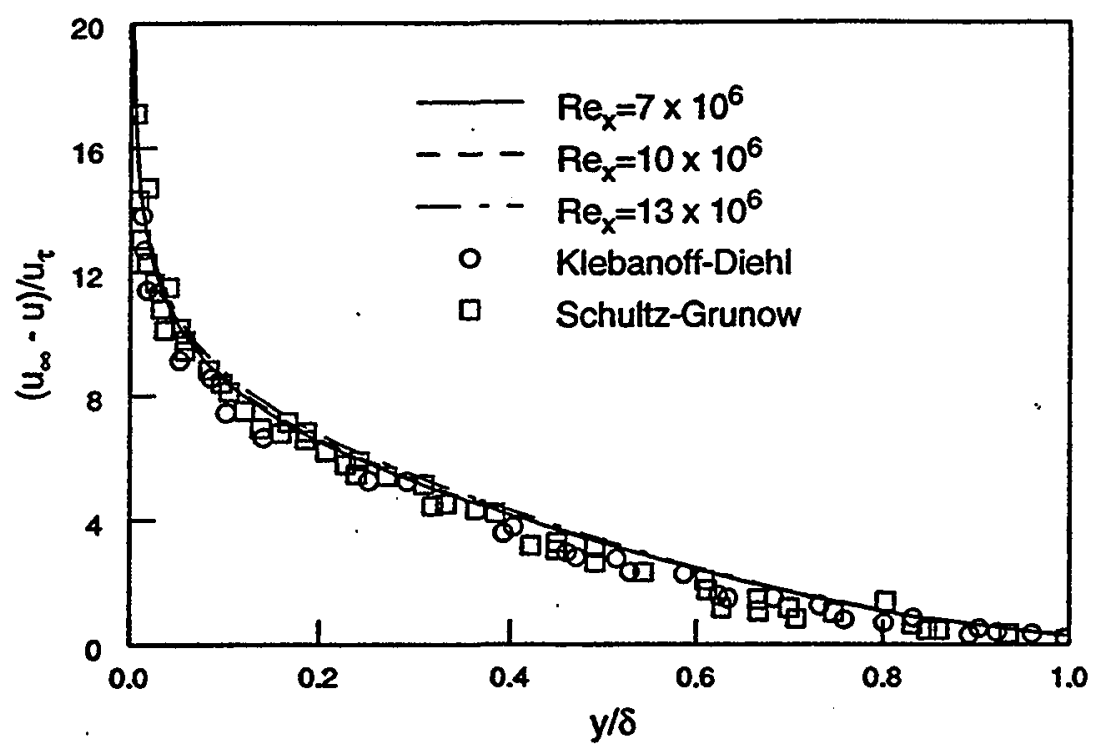

Figure 11. Velocity-defect for zero pressure gradient flat plate flow calculated using the modified MML of section 3.2. 


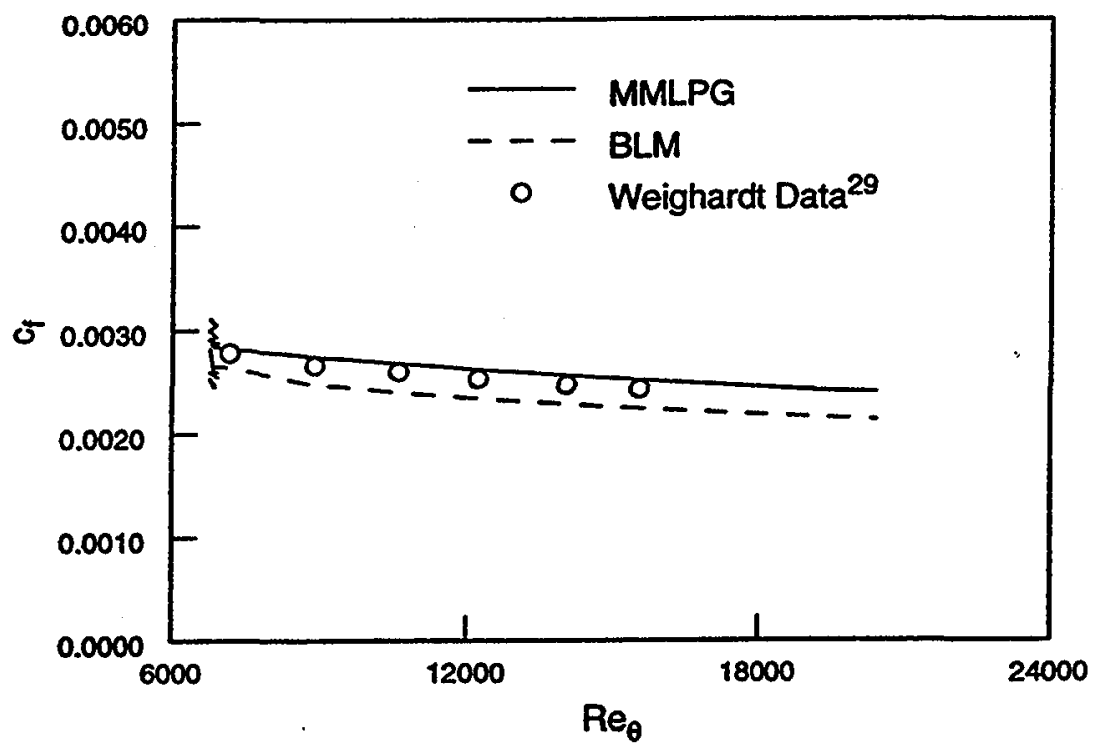

Figure 12. Local skin friction coefficient for zero pressure gradient flat plate flow; MML of section 3.2 used. 


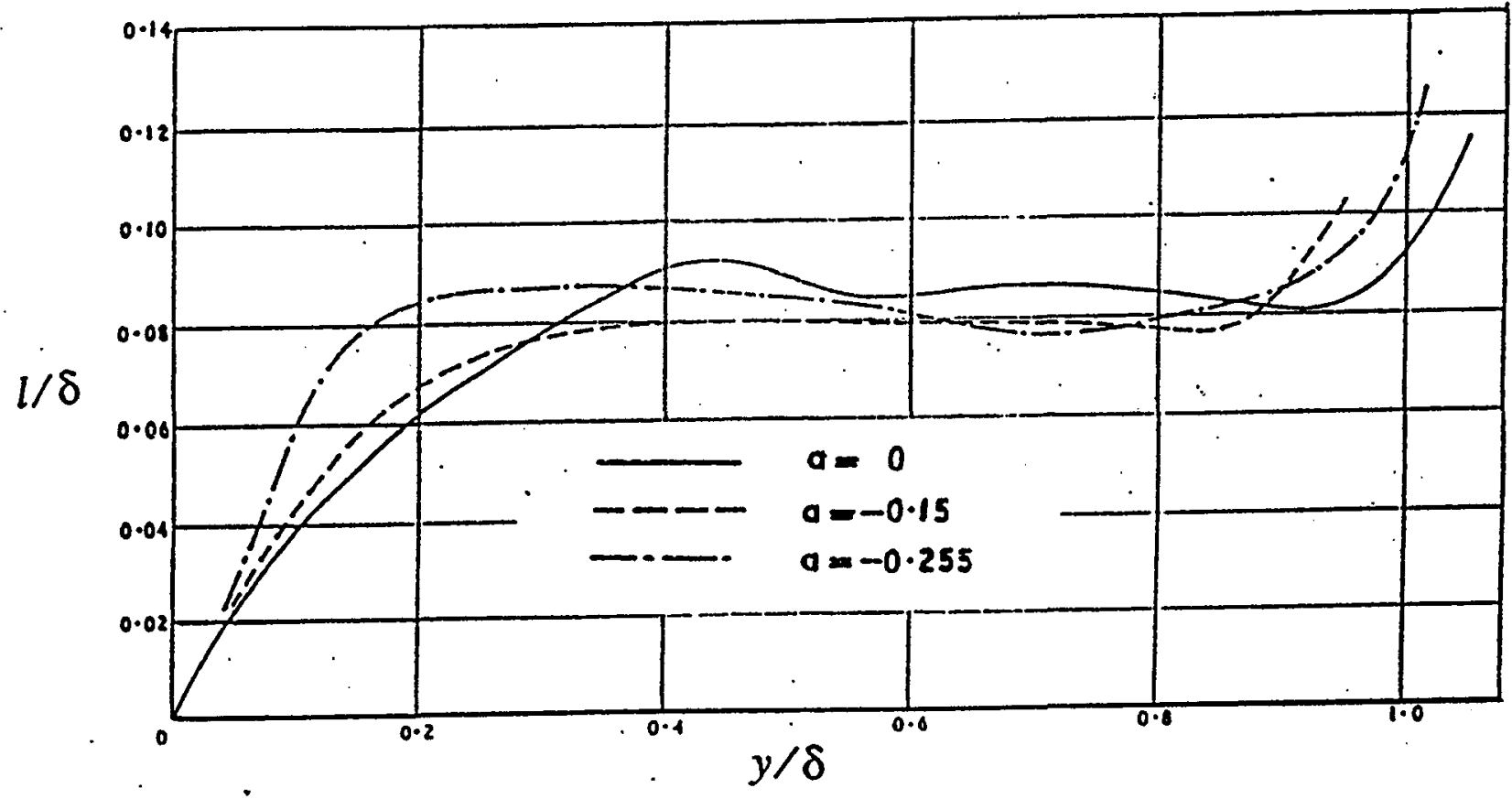

Figure 13. Mixing length profiles at three pressure gradients. ${ }^{25}$ 


$$
\begin{gathered}
l^{+}=k G_{3} \frac{G_{1}}{G_{2}}\left(1-\left(1-\frac{y^{+} G_{1} G_{2}}{G_{1}}\right)\left(1-e^{\left(\frac{y^{+}}{A^{+}}\right)}\right), \quad y^{+}<G_{1}\right. \\
l^{+}=k G_{3} \frac{G_{1}}{G_{2}} \quad y^{+}>G_{1}
\end{gathered}
$$

A new parameter, $G_{3}$, has been introduced and the constants $C_{1}$ and $C_{2}$ in the original MML model have been replaced by the functions $G_{1}$ and $G_{2}$, where

$$
\begin{aligned}
& \mathrm{G}_{1}=0.4 \mathrm{G}_{4} \\
& \mathrm{G}_{2}=5 \mathrm{G}_{3} \kappa
\end{aligned}
$$

Here, $G_{4}$ is essentially a nondimensional boundary layer thickness which is a function of $\beta$ and $c_{f}$, and $G_{3}$ controls the slope of mixing length curve and is a function of $\beta$. The following correlation was assumed for $\mathrm{G}_{4}$ :

$$
\mathrm{G}_{4}=\mathrm{G}_{5}+\mathrm{G}_{6} \mathrm{c}_{\mathrm{f}}
$$

Separate values of the parameters $G_{3}, G_{5}$, and $G_{6}$, corresponding to each of the three pressure gradients, were found and are given in table 1. This results in essentially three separate models, one for each pressure gradient, depending on which set of parameters is used. The results of these-modifications are compared with BaldwinLomax calculations in the velocity-defect plots of figures 14 through 16 . (Note: The Baldwin-Lomax results for the zero pressure gradient case are given in figure 9.) The reference conditions used are the same as those given in section 3.1. For the two adverse pressure gradient cases, the turbulent velocity profiles at the upstream boundary were computed using a cubic spline fit of the Bradshaw experimental data and held fixed; the appropriate pressure gradient was imposed at the freestream boundary. 
Table 1. Parameters used in pressure gradient modifications.

\begin{tabular}{|l|l|l|l|l|}
\hline $\begin{array}{l}\text { Pressure } \\
\text { Gradient } \\
\text { Strength }\end{array}$ & $\beta$ & $\mathrm{G}_{3}$ & $\mathrm{G}_{5}$ & $\mathrm{G}_{6}$ \\
\hline zero & 0 & 1.00 & 23,300 & $-7.75 \times 10^{6}$ \\
mild & 1 & 1.25 & 30,100 & $-1.16 \times 10^{7}$ \\
strong & 5 & 1.53 & 33,800 & $-2.09 \times 10^{7}$ \\
\hline
\end{tabular}

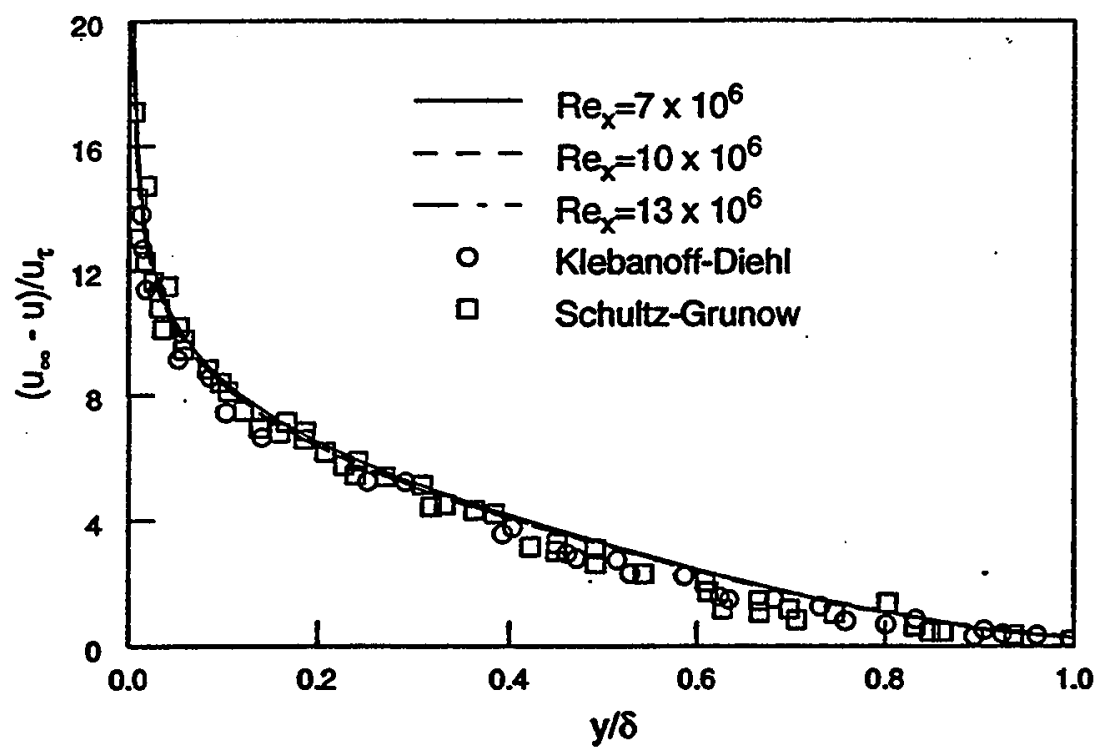

Figure 14. Velocity-defect for zero pressure gradient flow calculated using the modified MML of section 3.3. 


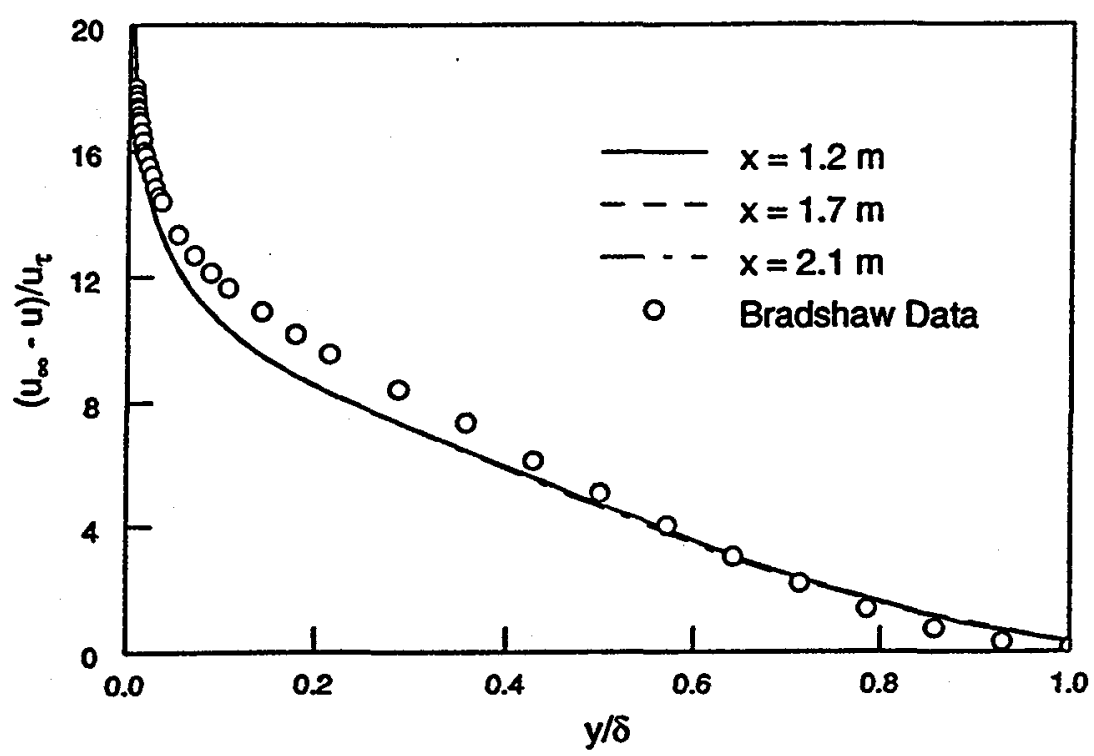

(a) Modified MML of section 3.3

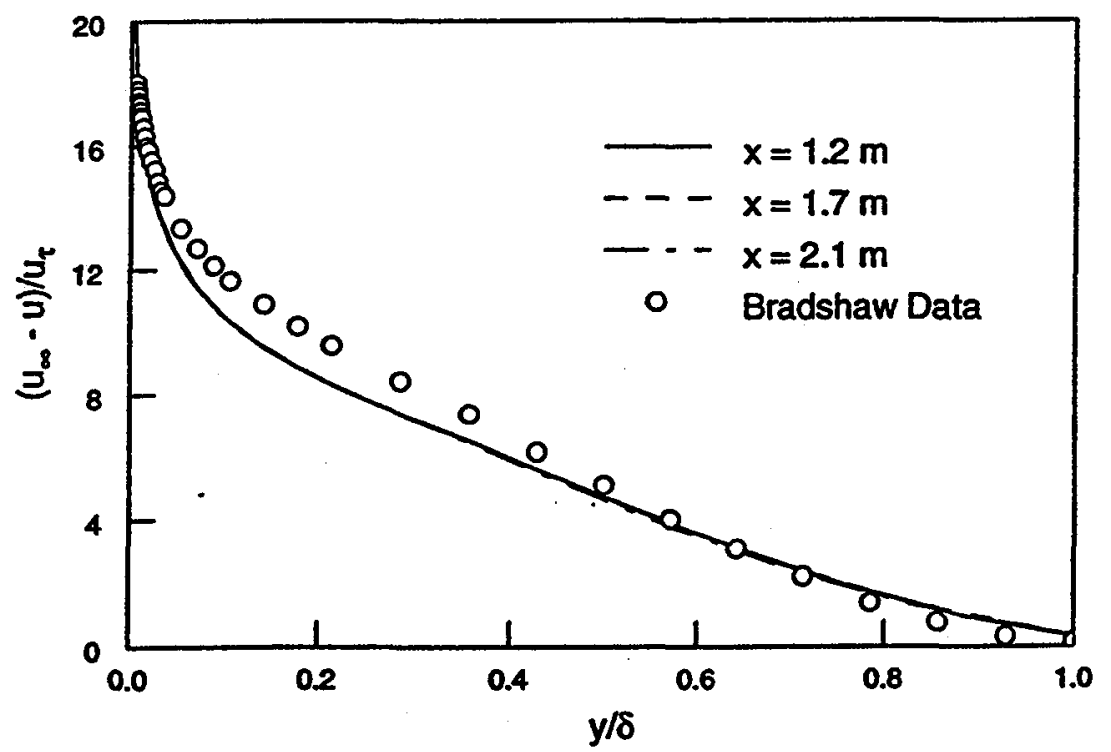

(b) BLM

Figure 15. Velocity-defect for mild pressure gradient flow. 


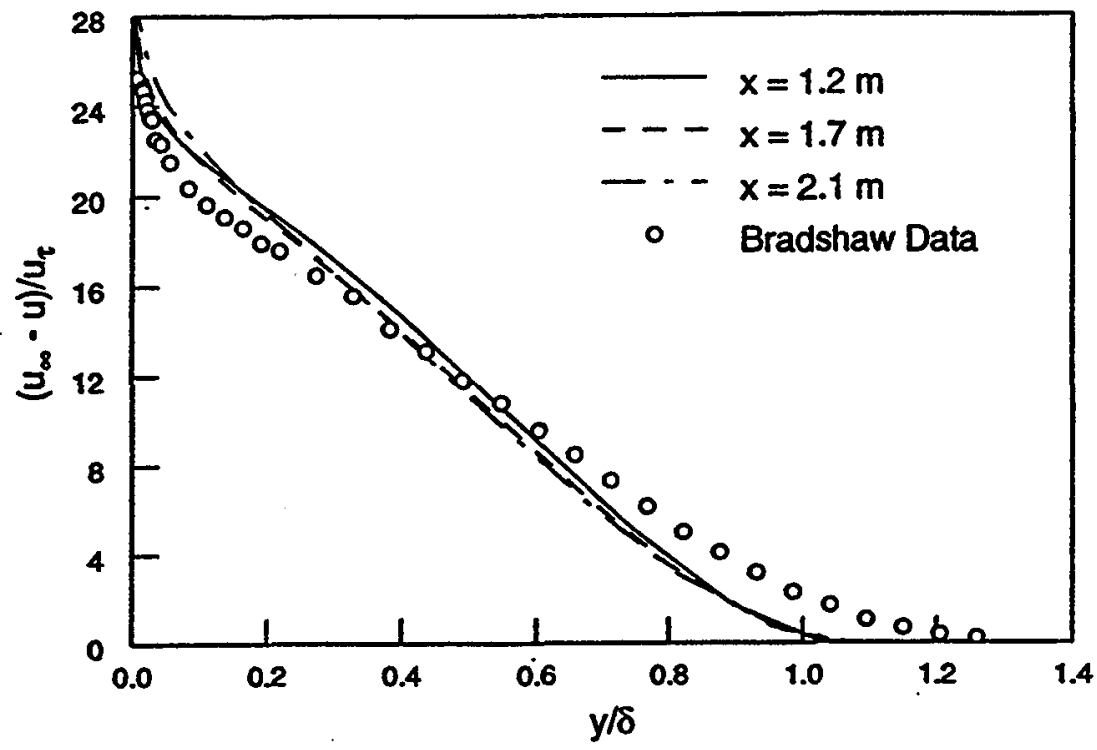

(a) Modified MML of section 3.3

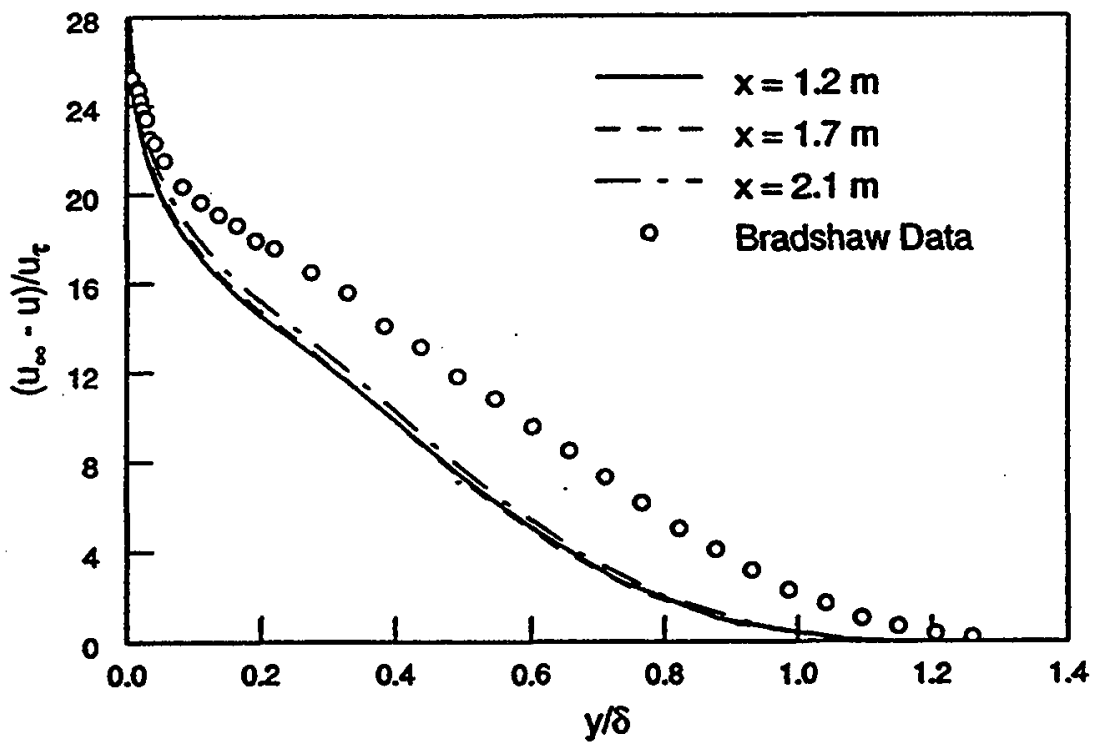

(b) BLM

Figure 16. Velocity-defect for strong pressure gradient flow. 
Both cases were computed using the grid of figure 6, but for the strong pressure gradient case, the number of grid points in the vertical direction was increased to 101.

\subsection{Final Model}

The final step in developing this turbulence model was to combine all of the above modifications to get one general turbulence model. To accomplish this, the following correlations were developed for the parameters $G_{3}, G_{5}$ and $G_{6}$ :

$$
\begin{gathered}
G_{3}=1.0 \quad \beta<0.0 \\
G_{3}=1.0+0.307 \beta-0.0391 \beta^{2} \quad 0.0 \leq \beta \leq 5.34 \\
G_{3}=1.52 \quad \beta>5.34 \\
G_{5}=23,300 \quad \beta<0.0 \\
G_{5}=23,300+8560 \beta-1230 \beta^{2} \quad 0.0 \leq \beta \leq 5.34 \\
G_{5}=33,900 \quad \beta>5.34 \\
G_{6}=-7.75 \times 10^{6}-4.51 \times 10^{6}+386,000 \beta^{2} \quad 0.0 \leq \beta \leq 5.34 \\
G_{6}=-20,900 \quad \beta>5.34
\end{gathered}
$$

The available experimental data is limited to only the three values of $\beta$ which are in the range $0 \leq \beta \leq 5.34$, and the quadratic correlations of equations (3.18b), (3.18e) and (3.18h) are based on this limited data. For $\beta<0$, the values in (3.18a), (3.18d) and $(3.18 \mathrm{~g})$, were obtained by evaluating the quadratic equations at $\beta=0$. Similarly, for 
$\beta>5.34$, the values in (3.18c), (3.18f) and (3.18i) were obtained by evaluating the quadratic equations at $\beta=5.34$.

Since $\beta$, which is defined in equation (3.13), is a function of the displacement thickness, $\delta_{1}$, a correlation was also developed to avoid the problem of calculating $\delta_{1}$ directly and thus having to define the edge of the boundary layer:

$$
\delta_{1}=\left(G_{7}+G_{8} c_{f}\right) y^{*}
$$

The parameters $G_{7}$ and $G_{8}$ were defined in a manner similar to $G_{3}, G_{5}$ and $G_{6}$ as given below.

$$
\begin{gathered}
G_{7}=2910 \quad \beta<0 \\
G_{7}=2910+2700 \beta-343 \beta^{2} \quad 0 \leq \beta \leq 5.34 \\
G_{7}=7560 \quad \beta \geq 5.34 \\
G_{8}=-96900 \quad \beta<0 \\
G_{8}=-988,000-1.15 \times 10^{6} \beta+89,000 \beta^{2} \quad 0 \leq \beta \leq 5.34 \\
G_{8}=-4.57 \times 10^{6} \quad \beta>5.34 .
\end{gathered}
$$

The value of $\beta$ used to define $G_{7}$ and $G_{8}$ is lagged in time.

The final model, called MMLPG, was developed using the equilibrium turbulent flows of Bradshaw and is defined by equations (3.14) through (3.19). The resulting velocity-defect profiles for all three pressure gradient flows are shown in figure 17 and exhibit good agreement with the experimental data, with the exception of the strong pressure gradient case. The calculations were performed on a CRAY Y-MP computer and the computational times are given in table 2 . The strong pressure gradi- 


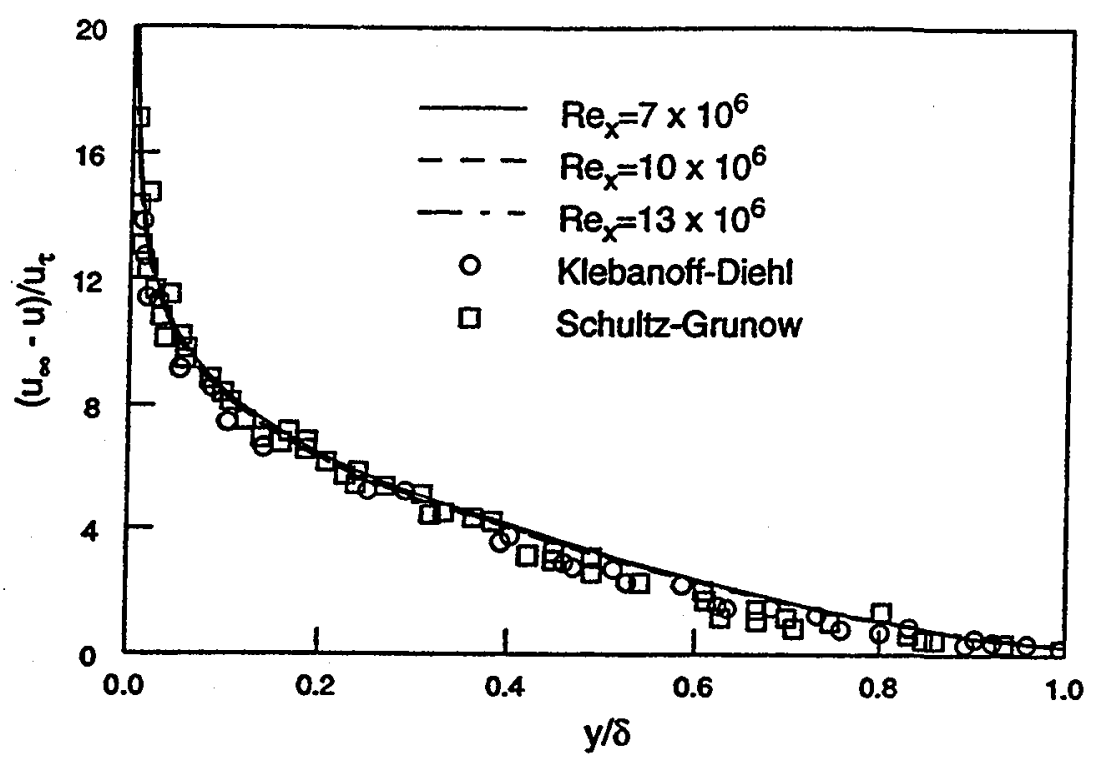

(a) Zero pressure gradient flow.

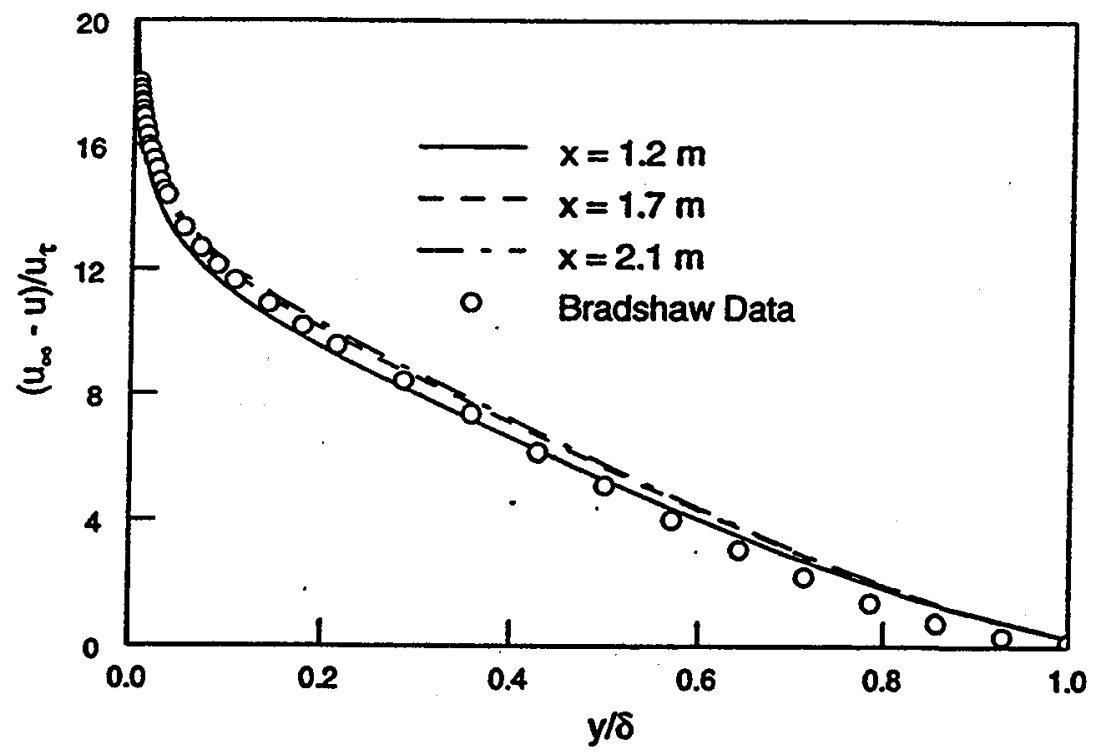

(b) Mild pressure gradient flow.

Figure 17. Velocity-defect profiles computed using MMLPG. 


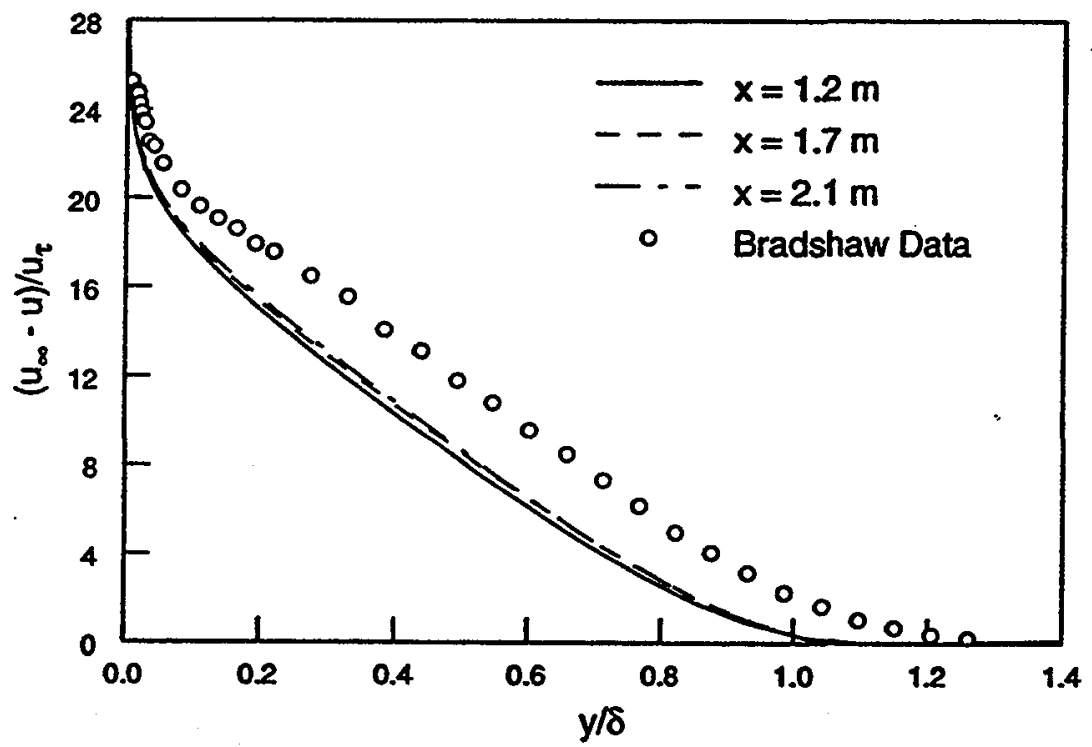

(c) Strong pressure gradient.

Figure 17. continued. 
Table 2. Computational times for flat plate flows.

(a) Zero Pressure Gradient

\begin{tabular}{|l|l|l|}
\hline Model & Iterations & $\begin{array}{l}\text { sec./iter./ } \\
\text { grid point }\end{array}$ \\
\hline BLM & 2000 & $2.02 \times 10^{-5}$ \\
MMLPG & 2000 & $2.00 \times 10^{-5}$ \\
\hline
\end{tabular}

(b) Mild Pressure Gradient

\begin{tabular}{|l|l|l|}
\hline Model & Iterations & $\begin{array}{l}\text { sec/iter./ } \\
\text { grid point }\end{array}$ \\
\hline BLM & 3000 & $2.14 \times 10^{-5}$ \\
MMLPG & 3000 & $2.17 \mathrm{z} 10^{-5}$ \\
\hline
\end{tabular}

(c) Strong Pressure Gradient

\begin{tabular}{|l|l|l|}
\hline Model & Iterations & $\begin{array}{l}\text { sec./iter./ } \\
\text { grid point }\end{array}$ \\
\hline BLM & 18,000 & $2.14 \times 10^{-5}$ \\
MMLPG & 10,000 & $1.96 \times 10^{-5}$ \\
\hline
\end{tabular}


ent case took considerably longer to reach convergence because the code had difficulties resolving oscillations induced at the upstream boundary, which was a fixed velocity profile as mentioned in section 3.3 .

\subsection{Averaging for Multiple Boundaries}

If both walls in a given coordinate direction are solid surfaces, the turbulent mixing lengths are computed separately at each surface and then averaged. The Sajben diffuser, which is described in Chapter IV, has solid walls at the upper and lower vertical boundaries, and is a typical example of a geometry which would require averaging of the mixing length. The averaging formula of Appendix 3 (equation C.9), which was used to average the $F_{\text {wake }}$ function in the Baldwin-Lomax model, is also used here to average the mixing length:

$$
l=\frac{l_{1} \mathrm{f}_{1}+l_{2} \mathrm{f}_{2}}{\mathrm{f}_{1}+\mathrm{f}_{2}}
$$

If the lower and upper boundaries in the vertical direction, are solid surfaces, as in the Sajben diffuser, then $l_{1}$ and $l_{2}$ are the mixing lengths at the lower and upper boundaries, respectively. The functions $f_{1}$ and $f_{2}$ are defined in equation C.10 of Appendix 3. 


\section{CHAPTER IV}

\section{ADVERSE PRESSURE GRADIENT TEST CASES}

To evaluate MMLPG for some typical propulsion flows, a converging-diverging duct, called the Sajben diffuser, was used. This duct is the diffuser portion of the inlet for a rocket/ramjet propulsion system; detailed experimental and computational data are available in the literature for flows both with and without external pressure pulse excitations. ${ }^{30-35}$ This study, however, dealt only with the unexcited flows. The geometry of the diffuser is given in figure 18: the throat height, $\mathrm{H}$, is $44 \mathrm{~mm}$; the entrance-to-throat ratio is 1.4 , and the exit-to-throat ratio is 1.5 . The grid, shown in figure 19 , is the same as that used by references 13 and 34 , and has 81 streamwise points and 51 vertical points. It was packed in the vertical direction near the walls in order to resolve the turbulent boundary layers and in the streamwise direction near the throat to resolve the normal shock. The reliability of this grid is discussed in Appendix 2. Three transonic flow cases were run. The flowfields were determined by setting $R$, the ratio of the exit static pressure to the inlet total pressure. The first case had a weak normal shock with $R=0.82$; the second case had subsonic flow throughout (no shock) with $R=0.862$, and the third case had a strong normal shock with $R=0.72$. The reference velocity, temperature, pressure and length used in Proteus were $4.72 \mathrm{~m} /$ $\mathrm{s}, 292 \mathrm{~K}, 135 \mathrm{kPa}$, and $.044 \mathrm{~m}$ respectively. These values match the values used in other numerical simulations of this flow. ${ }^{13,32,34}$ The initial conditions were zero velocity and constant temperature and pressure everywhere in the flowfield. Both 


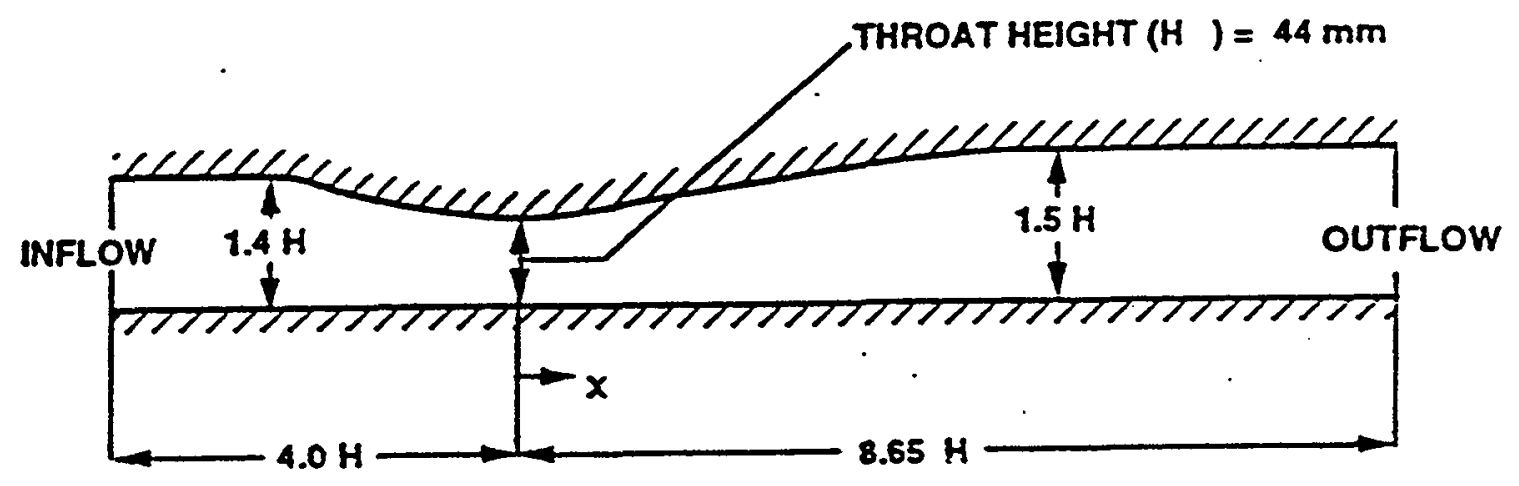

Figure 18. Illustration of the Sajben diffuser geometry.

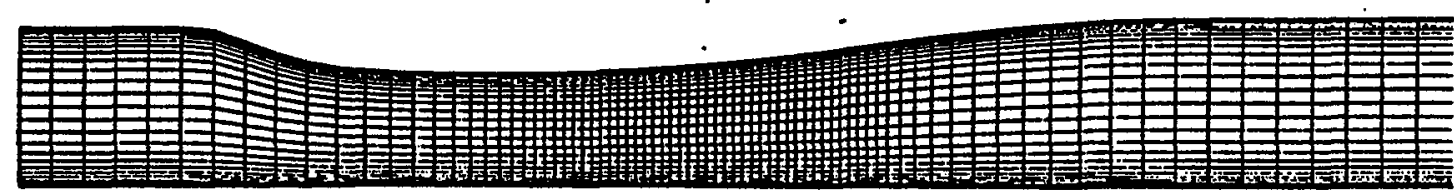

Figure 19. Computational grid for the Sajben diffuser. 
cases were run using MMLPG and two implementations of the Baldwin-Lomax model.

Two slightly different implementations of BLM were used because it was discovered, during the course of these calculations, that a slight change in the BLM coding, which occurred in the update of Proteus from Version $1.0^{14}$ to $2.0,^{13}$ can effect turbulent calculations. References 14 and 34 give results for the weak and no shock cases calculated with Version 1.0 of Proteus and using BLM. These calculations were repeated in the current study using the current version of Proteus, Version 2.0, and slightly different results were obtained. (These results will be presented later in this chapter.) Discrepancies in the results were caused by differences in the implementation of the BLM model, more specifically, in the $F_{\text {wake }}$ function. Version 2.0 of Proteus computes $F_{\text {wake }}$ using equation (C.6) in Appendix 3, and version 1.0 of Proteus computes $F_{\text {wake }}$ as

$$
F_{\text {wake }}=\min \left\{\begin{array}{c}
y_{\max } F_{\max } \\
C_{w k} V_{\text {diff }}^{2} \bar{F}_{\max }
\end{array}\right.
$$

which is the formulation stated in the original paper by Baldwin and Lomax. ${ }^{4}$ The BLM implementations using equations (4.1) and (C.6) will be referred to as BLM1 and BLM2, respectively.

\subsection{Weak Shock Case}

The weak shock case was used as an example case in the Proteus User's Manual, ${ }^{13,14}$ and therefore was run first in order to gain familiarity with running this type of flow. It was computed as described in reference 13: First the exit pressure was gradually reduced to $R=0.1338$ to establish supersonic flow throughout the diffuser; then it was gradually raised to $R=0.82$, the desired ratio to establish the 
weak normal shock, and iterated until the solution was no longer changing appreciably with time. A plot of the static pressure on the top wall at two locations, one upstream and one downstream of the normal shock, as the solution progresses is given in figure 20. This indicates that pressure reaches a steady state level, which, for practical engineering purposes, can be considered a converged solution. A closer examination of the results indicates that the solution oscillates slightly about a mean steady level. This may be caused by inherent unsteadiness in the flow; Salmon et al ${ }^{30}$ mention that very low-amplitude, self-sustaining oscillations were observed experimentally. It is more likely that the oscillations present in this calculation are numerical in nature, which is common for flows with shock waves. The oscillations originating at the shock may not be damped out by the artificial viscosity and therefore tend to migrate upstream. The artificial viscosity used in Proteus to calculate this flow was second- and fourth-order explicit, both using the nonlinear coefficient model of Jameson et al; ${ }^{19}$ the respective smoothing coefficients are $\kappa_{2}$ and $\kappa_{4}$, as given in Appendix 2. For the entire calculation, $\kappa_{2}$ was set to $0.1 ; \kappa_{4}$ was set to .005 for the first 6000 iterations, while the exit pressure was changing, and decreased to .0004 for the remaining 3000 iterations, which were at a constant exit pressure. More details about the effects of the artificial viscosity on this solution are included in Appendix 2. The static pressure distribution on the top and bottom walls is given in figure 21. The small discrepancies just downstream of the shock are due to insufficient streamwise grid distribution. The shock location on the upper wall and the shock Mach number at the edge of the upper wall boundary layer are given in table 3. Both MMLPG and BLM2 do a good job of predicting the pressure distribution on the wall and the location of the shock. Each case was run for 9000 iterations and calculations made using MMLPG, BLM1 and BLM2 required $3.44 \times 10^{-5}$ sec/iteration/grid point, 


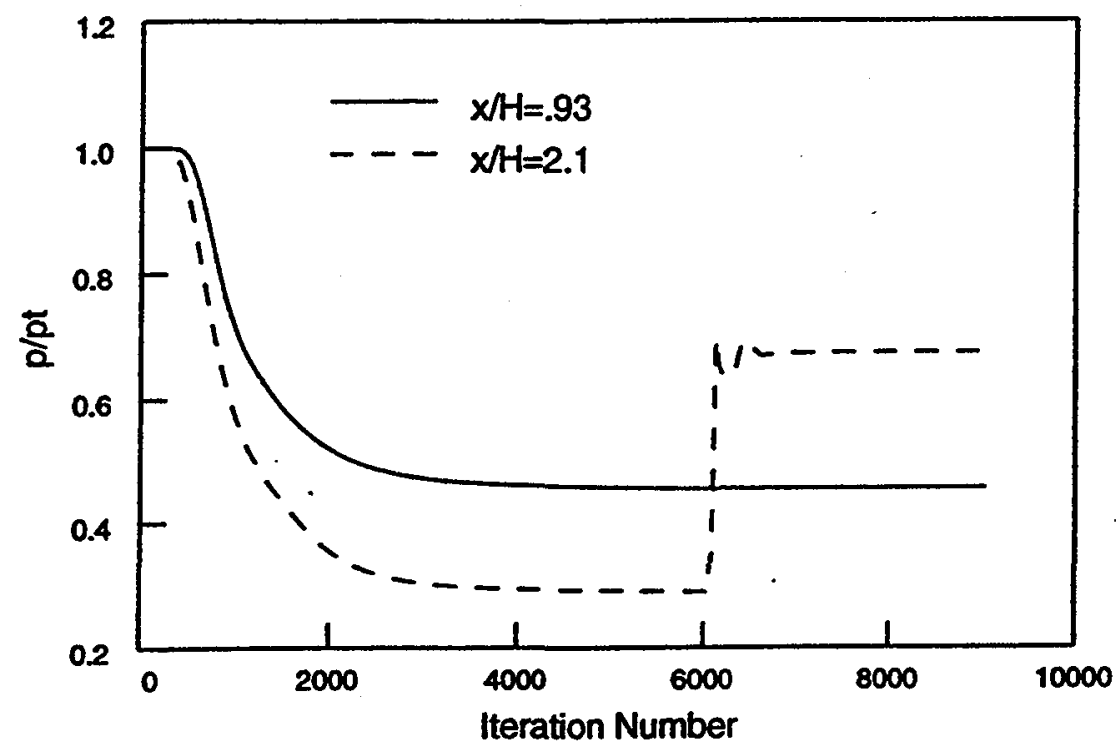

(a) MMLPG

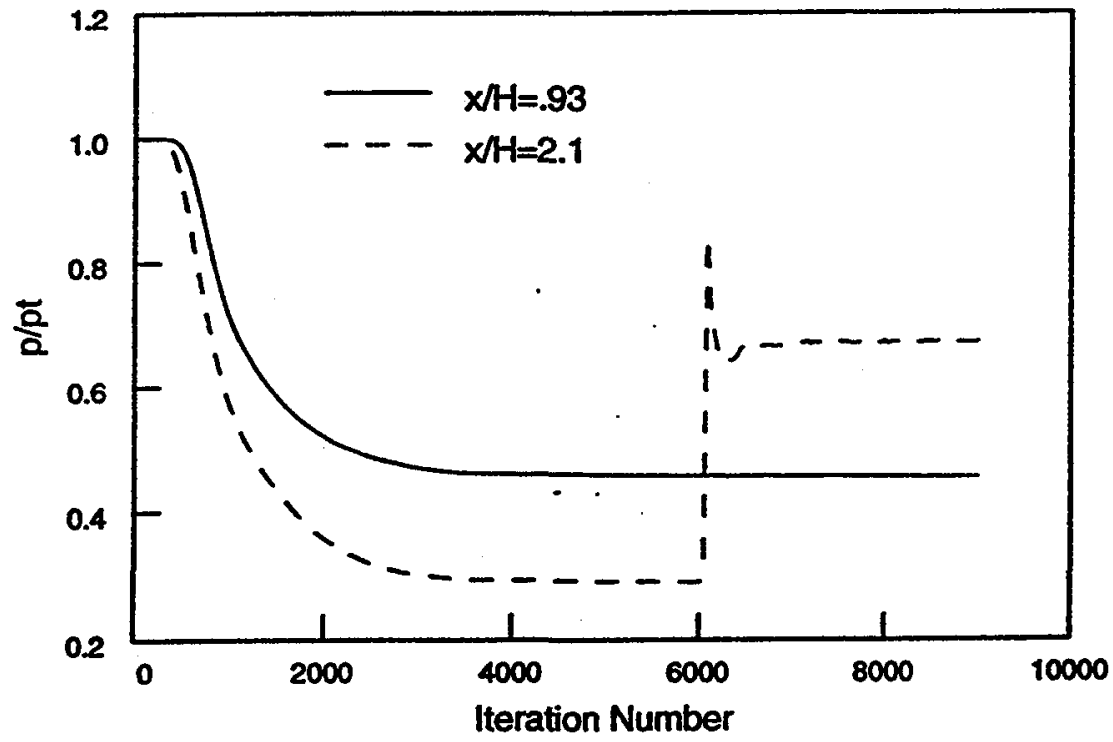

(b) BLM2

Figure 20. Static pressure history at two locations on the top wall: just upstream and just downstream of the normal shock. 


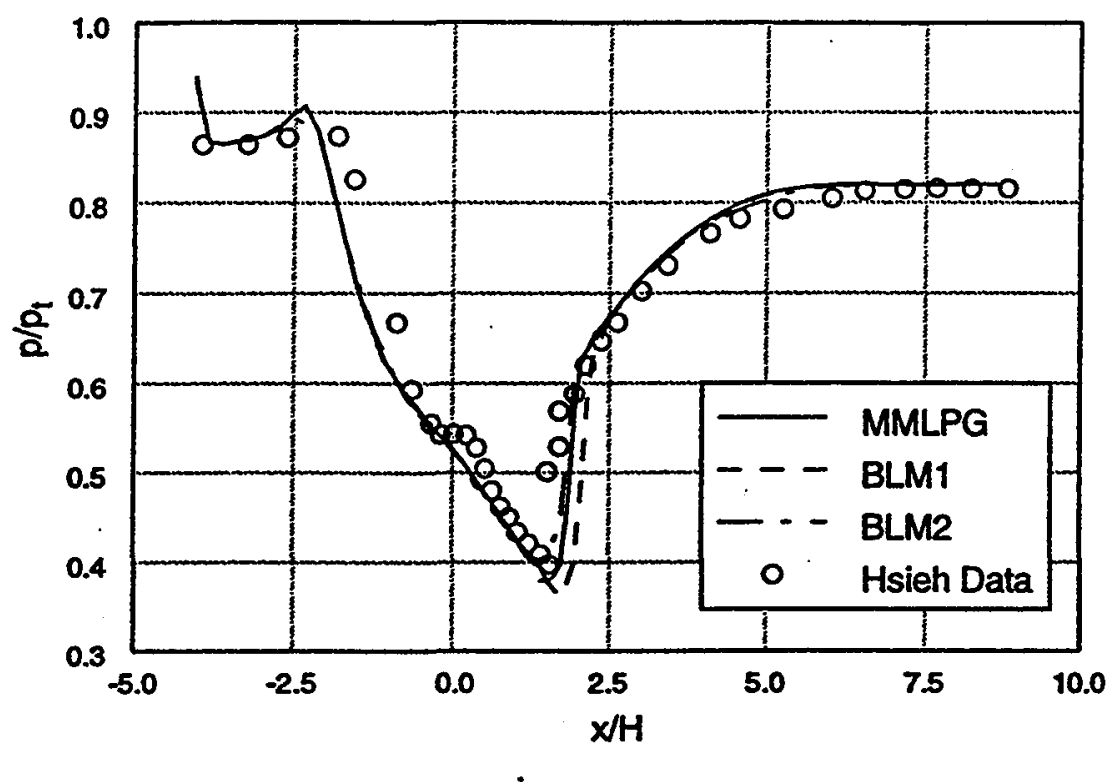

(a) Top wall

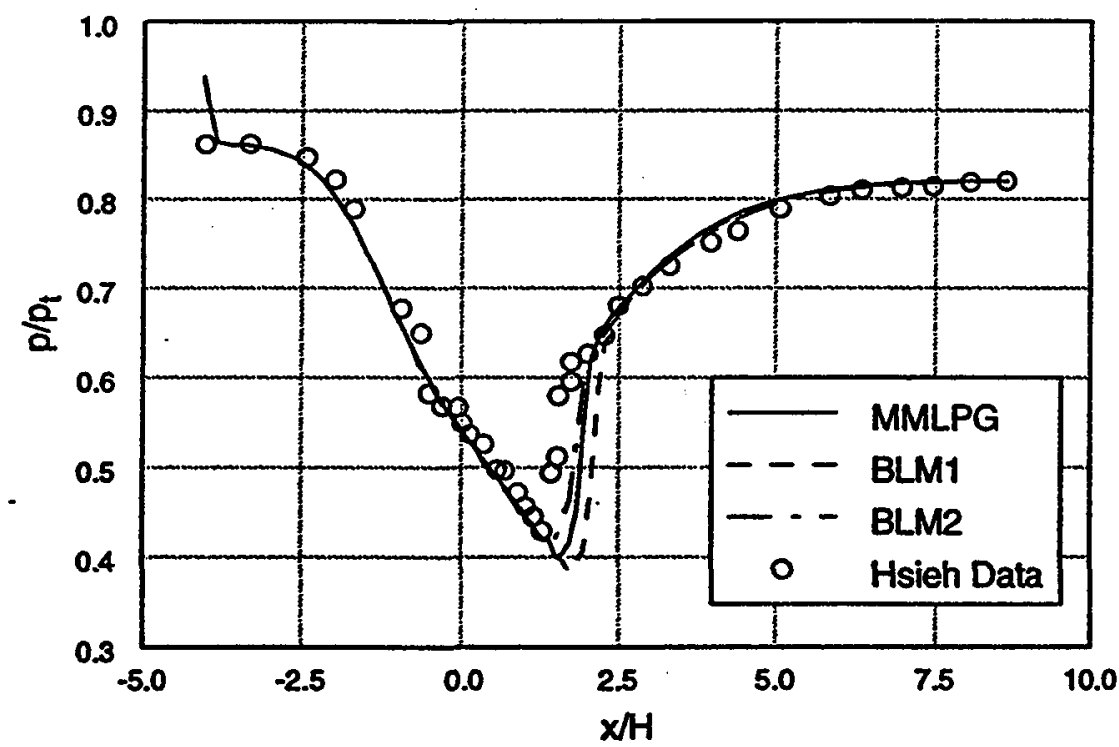

(b) Bottom wall

Figure 21. Static pressure distribution on the top and bottom walls of the Sajben diffuser, weak shock case. 
Table 3. Shock location and Mach number, weak shock case.

\begin{tabular}{|l|l|l|}
\hline $\begin{array}{l}\text { Turbulence } \\
\text { Model }\end{array}$ & $\begin{array}{l}\text { Shock } \\
\text { Mach } \\
\text { Number }\end{array}$ & $\begin{array}{l}\text { Shock } \\
\text { Location } \\
(\mathrm{x} / \mathrm{H})\end{array}$ \\
\hline MMLPG & 1.233 & 1.57 \\
BLM1 & 1.309 & 1.73 \\
BLM2 & 1.228 & 1.49 \\
Experiment $^{30}$ & 1.235 & 1.41 \\
\hline
\end{tabular}


$3.90 \times 10^{-5} \mathrm{sec} /$ iteration/grid point and $3.36 \times 10^{-5} \mathrm{sec} /$ iteration/grid point, respectively on the CRAY Y-MP computer.

\subsection{No Shock Case}

The second diffuser test case did not have a normal shock wave. To compute this case, the exit pressure was gradually lowered to $R=0.862$ then iterated until the solution stopped changing. A steady state solution was reached with subsonic flow throughout the entire diffuser. The Proteus default artificial viscosity, which uses the constant coefficient model of Steger ${ }^{18}$ with both fourth-order explicit and second- . order implicit artificial viscosity, was used; the smoothing coefficients, $\varepsilon_{E}{ }^{(4)}$ and $\varepsilon_{I}$ (defined in Appendix 2), had values of 1.0 and 2.0, respectively.

The static pressure distribution on the top and bottom walls is given in figure 22 and shows that MMLPG is clearly better than BLM1 and BLM2 at predicting the pressure distribution, though it still predicts a larger pressure drop than that given by the experimental data. The MMLPG results are similar to the calculations of Hseih et $\mathrm{al}^{33}$ who attributed the lower throat pressure to the fact that the experiment was highly sensitive to small perturbations in exit pressure. The maximum Mach numbers in the diffuser are given in table 4. Though no experimental data is available to compare these values, the MMLPG results are in best agreement with the calculations of Georgiadis $^{35}$ who used the PARC Navier-Stokes $\operatorname{code}^{36}$ for the same geometry. Each case was run for 9000 iterations and calculations using MMLPG, BLM1 and BLM2 required $3.45 \times 10^{-5} \mathrm{sec} /$ iteration/grid point, $2.90 \times 10^{-5} \mathrm{sec} /$ iteration/grid point and $3.36 \times 10^{-5}$ sec/iteration/grid point, respectively, on the CRAY Y-MP computer. 


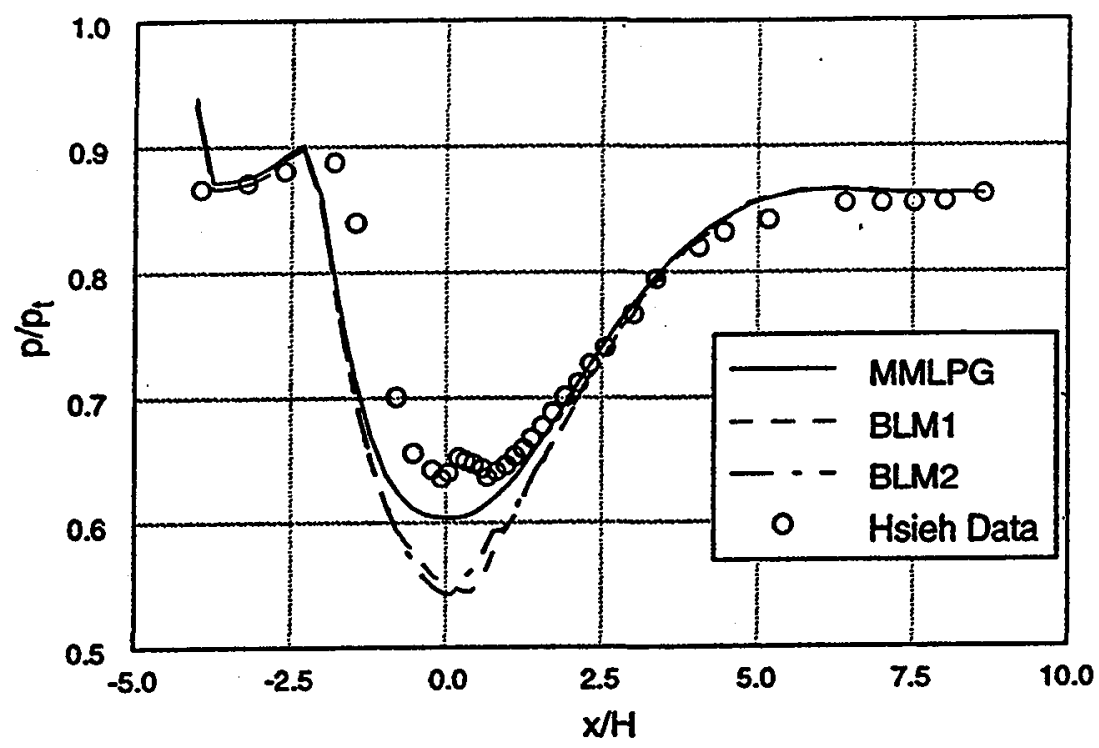

(a) Top wall

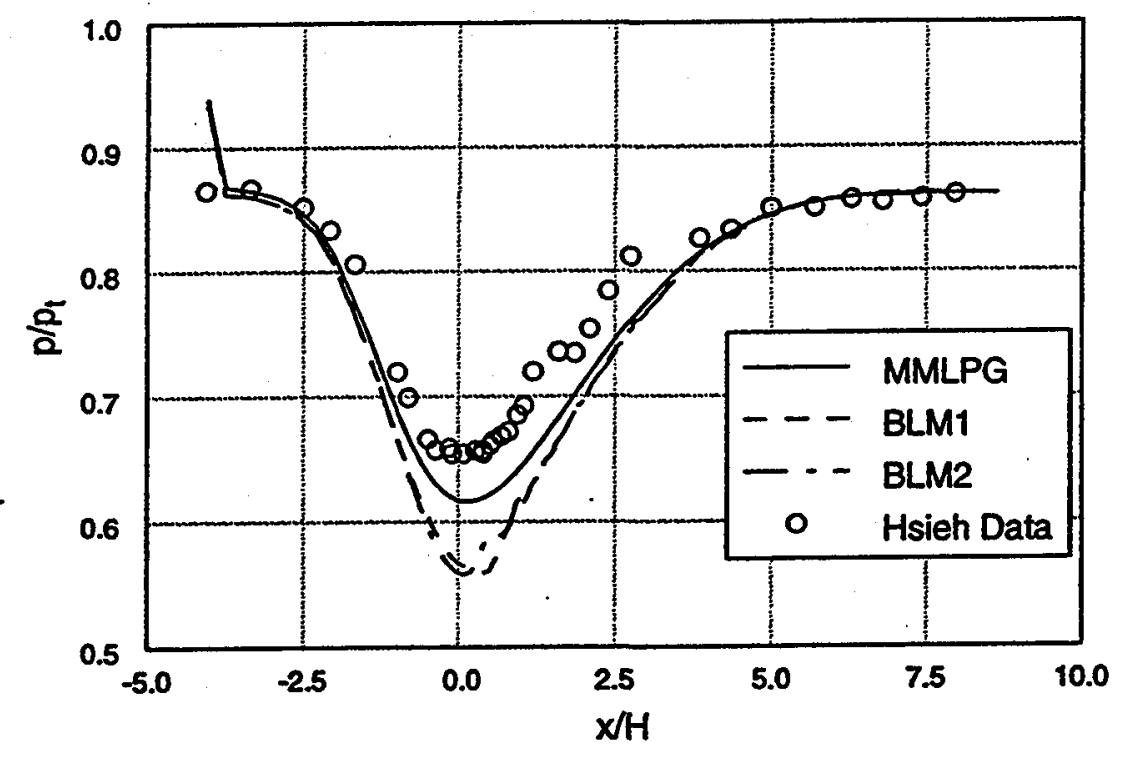

(b) Bottom wall

Figure 22. Static pressure distribution on the top and bottom walls of the Sajben diffuser, no shock case. 
Table 4. Maximum Mach number, no shock case.

\begin{tabular}{|l|l|}
\hline $\begin{array}{l}\text { Turbulence } \\
\text { Model }\end{array}$ & $\begin{array}{l}\text { Maximum } \\
\text { Mach } \\
\text { Number }\end{array}$ \\
\hline MMLPG & 0.881 \\
BLM1 & 0.972 \\
BLM2 & 0.976 \\
\hline
\end{tabular}




\subsection{Strong Shock Case}

The final diffuser flow computed was the case with a strong normal shock positioned in the throat. This case was run in a manner similar to the weak shock case: First the exit pressure was gradually lowered to $R=0.1338$ to achieve supersonic flow throughout the diffuser; then it was gradually raised to $R=0.72$ to establish the strong normal shock in the throat region, then iterated there until the solution stopped changing appreciably with time. Proteus was run in both steady and unsteady modes to try to simulate the experimentally observed self-excited oscillations of $217 \mathrm{~Hz} .{ }^{30}$ Unsteady mode in Proteus is achieved by calculating a global time step whereas steady mode uses a local time step to speed up the computation. Neither calculation simulated the experimentally observed oscillatory behavior, but instead produced very small numerical oscillations in the flow properties. (The artificial viscosity used for the strong shock calculations was the same as that used for the weak shock calculation.) Figure 23 shows the static pressure on the top wall at the experimental shock location and illustrates the behavior of these small oscillations; the calculation shown was run in unsteady mode with MMLPG.

The static pressure on the top and bottom walls are presented in figure 24 and the shock location and Mach number at the edge of the top wall boundary layer are given in table 5. Both BLM2 and MMLPG predicted the shock location too far downstream, while BLM1 predicted it too far upstream. The experiment predicted a region of separation on the top wall just downstream of the shock with the flow reattaching at $x / H=6.0$. MMLPG predicted a very small region of separation on the top wall which reattached at $\mathrm{x} / \mathrm{H}=3.6$. BLM2 predicted very small regions of separation on both the top and bottom walls which reattached at $x / H=3.8$ and $x / H=6.2$, respectively, and BLM1 predicted a separation along the bottom wall that did not 


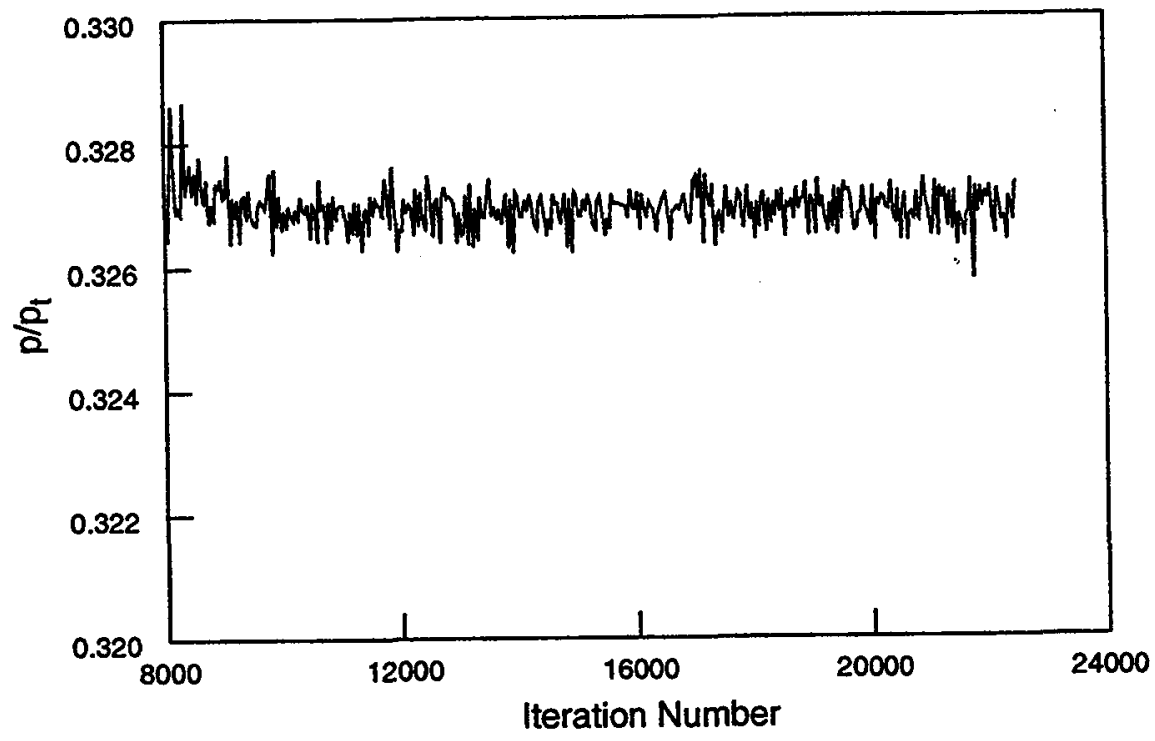

Figure 23. Shock static pressure on top wall for the Sajben diffuser, strong shock case. 


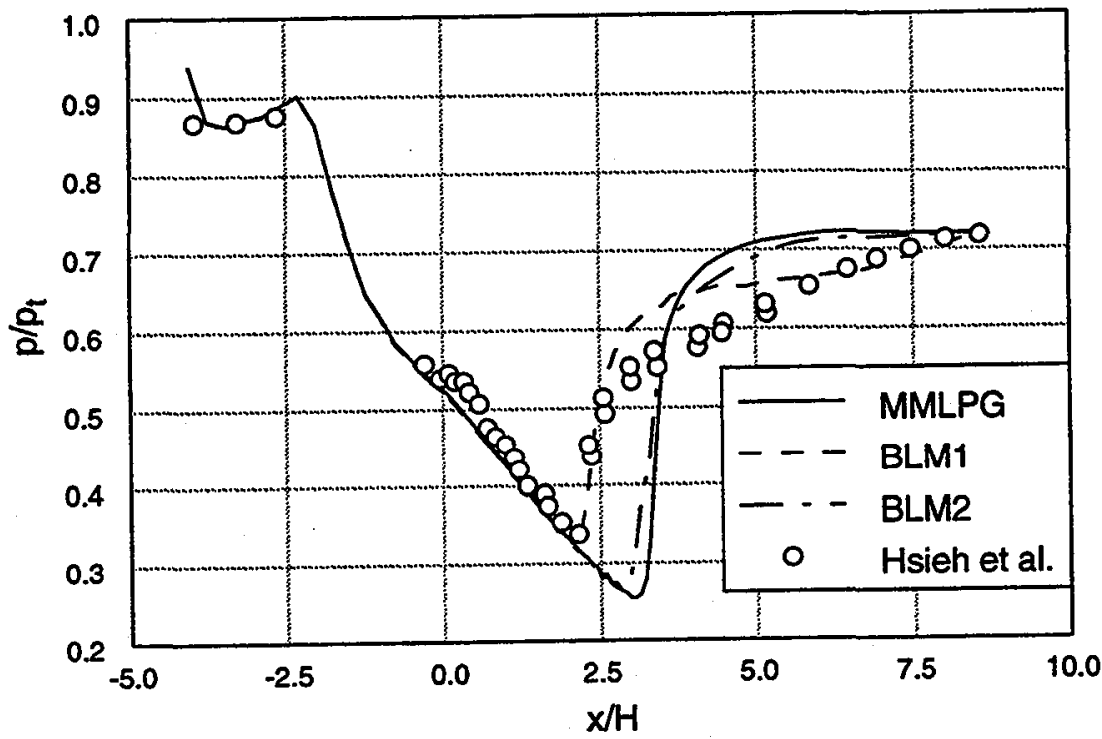

(a) Top wall

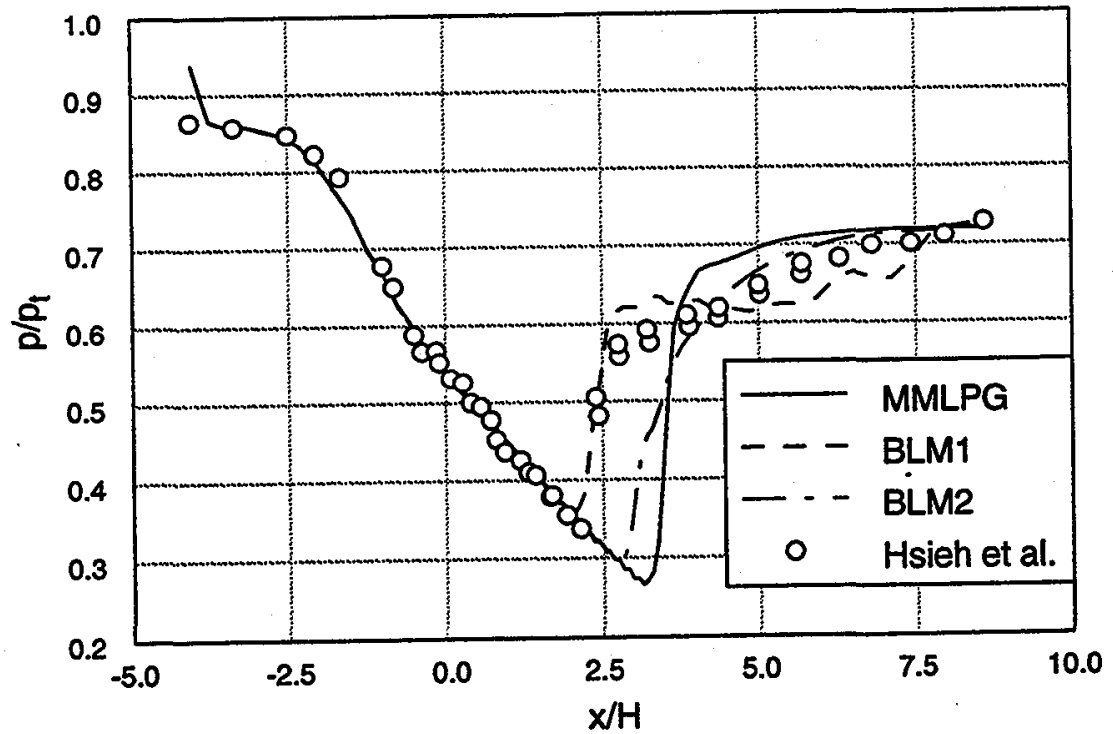

(b) Bottom wall

Figure 24. Static pressure distribution on the top and bottom walls of the Sajben diffuser, strong shock case. 
Table 5. Shock location and Mach number, strong shock case

\begin{tabular}{|l|l|l|}
\hline $\begin{array}{l}\text { Turbulence } \\
\text { Model }\end{array}$ & $\begin{array}{l}\text { Shock } \\
\text { Mach } \\
\text { Number }\end{array}$ & $\begin{array}{l}\text { Shock } \\
\text { Location } \\
(\mathrm{x} / \mathrm{H})\end{array}$ \\
\hline MMLPG & 1.626 & 3.13 \\
BLM1 & 1.411 & 2.11 \\
BLM2 & 1.665 & 2.90 \\
Experiment $^{30}$ & 1.353 & 1.98 \\
\hline
\end{tabular}


reattach. The separated behavior is illustrated in figure 25 , which gives the velocity profiles at four locations downstream of the shock. These peculiar results can be attributed to the behavior of the turbulent viscosity as shown in figure 26. MMLPG and BLM2 compute much higher values of $\mu_{\mathrm{t}}$ than does BLM1; this is due to the large increase in vorticity downstream of the shock. In BLM1, as given in equation (4.1), the second formula results in $F_{w a k e}$ being inversely proportional to the vorticity magnitude, and this helps to reduce the value of $\mu_{t}$ for this model. Each case was run for 10,000 iterations and the steady calculations using MMLPG, BLM1 and BLM2 required $3.54 \times 10^{-5} \mathrm{sec} /$ iteration/grid point, $3.83 \times 10^{-5} \mathrm{sec} /$ iteration/grid point, and $3.82 \times 10^{-5} \mathrm{sec} /$ iteration/grid point, respectively, on the CRAY Y-MP computer. 


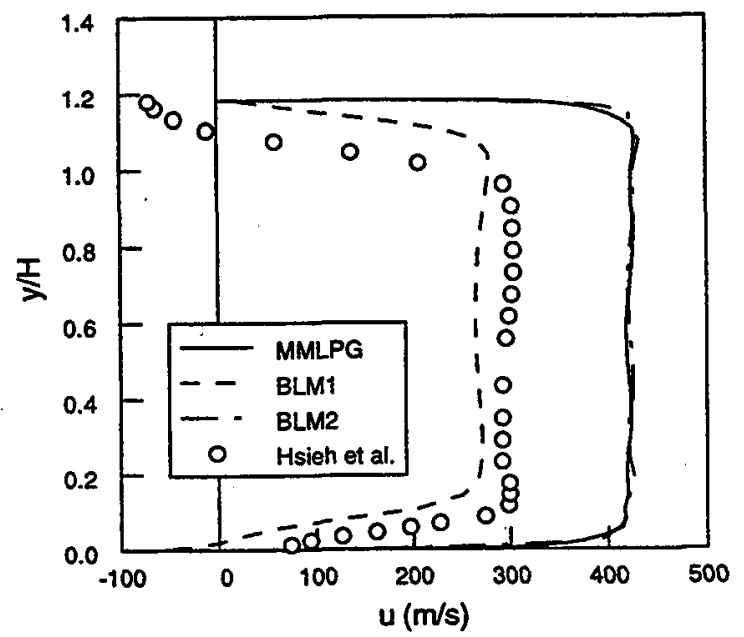

(a) $\mathrm{x} / \mathrm{H}=2.88$

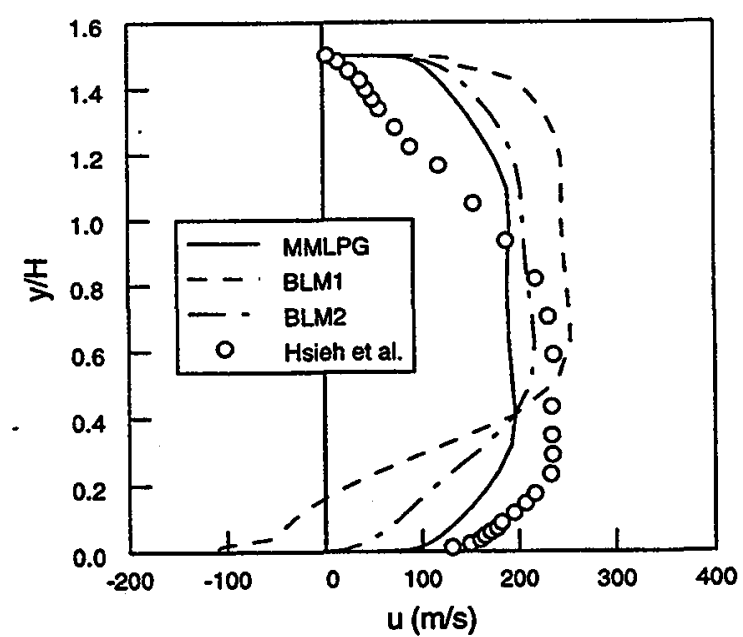

(c) $\mathrm{x} / \mathrm{H}=6.34$

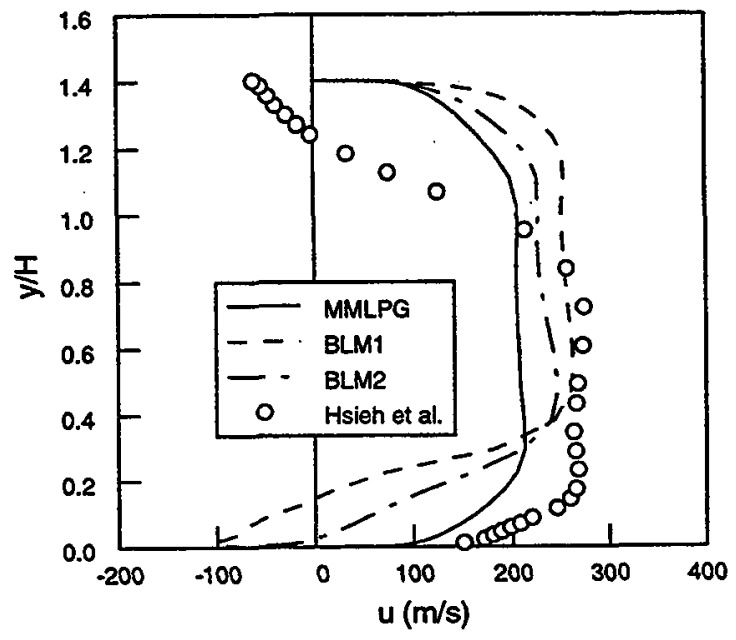

(b) $\mathrm{x} / \mathrm{H}=4.61$

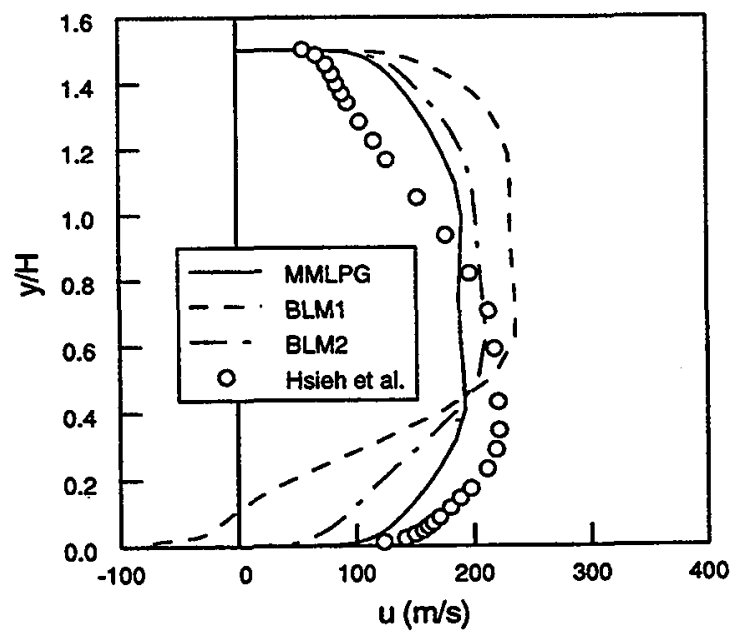

(d) $\mathrm{x} / \mathrm{H}=7.49$

Figure 25. Velocity profiles for the strong shock case. 


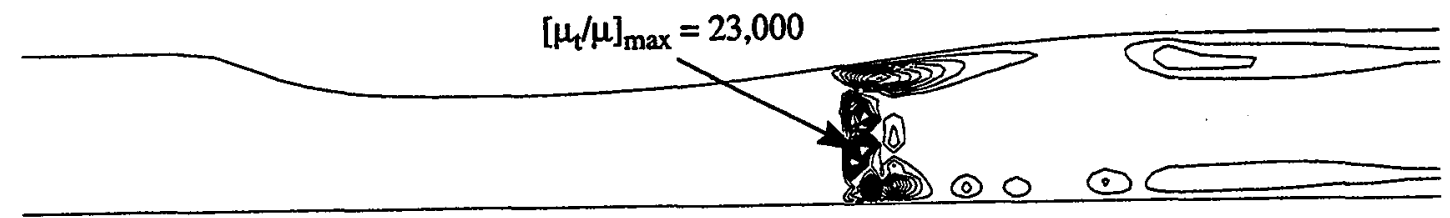

(a) MMLPG

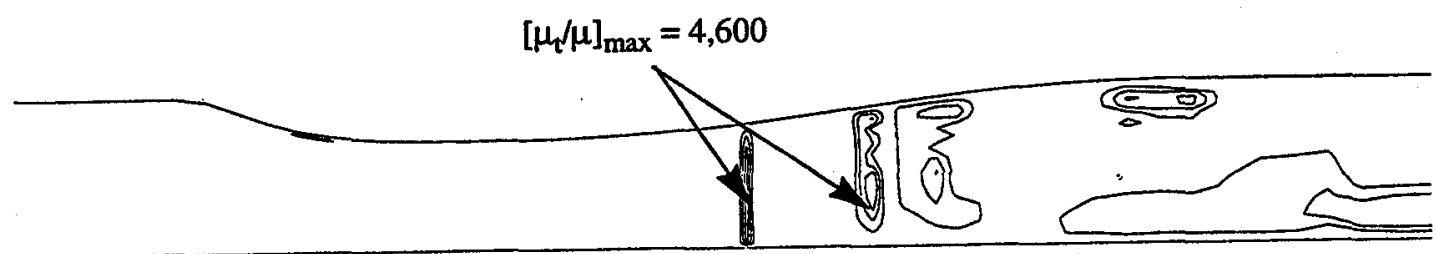

(b) BLM1

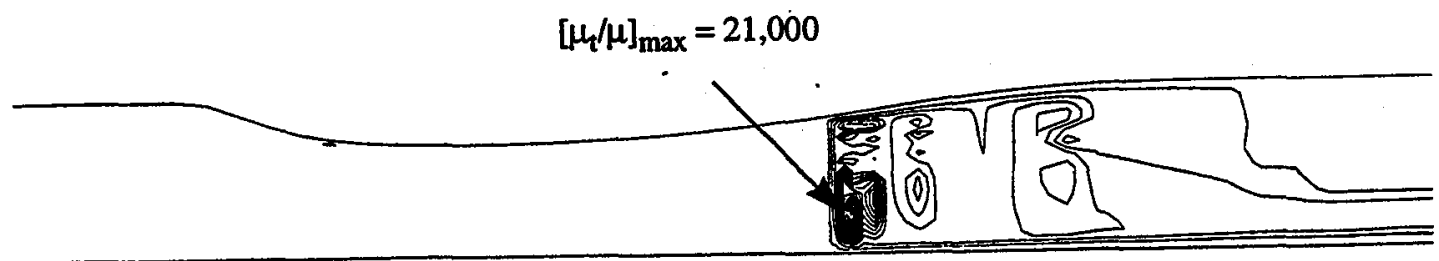

(c) BLM2

Figure 26. Turbulent viscosity ratio, $\mu_{\mathrm{t}} / \mu$, for the Sajben diffuser, strong shock case. 


\section{CHAPTER V \\ SUMMARY AND CONCLUSIONS}

The objective of this work was to modify the MML algebraic turbulence model to increase its range of applicability to include zero and adverse pressure gradient boundary layer flows. To accomplish this objective, modifications were made based on experimental data for zero and adverse pressure gradient flat plate flows. The resulting model, called MMLPG, successfully predicted the flat plate flows and also successfully predicted three transonic diffuser flows. This indicates that the objective of this work has been met.

In order to provide meaningful solutions for turbulent flows, CFD codes require good turbulence models. Algebraic models are the simplest and the most computationally inexpensive of turbulence models, and so were chosen as the focus of this study. Proteus, which was used to make all of the calculations in this work, is a Reynolds averaged Navier-Stokes code for aerospace propulsion flows and contains the Baldwin-Lomax algebraic turbulence model as a default. The Baldwin-Lomax model is known to have problems calculating certain flowfields, namely flows with strong pressure gradients and large separated regions. A promising newer model, the MML model, produced significantly better results than the Baldwin-Lomax model for separated airfoil flows, ${ }^{5}$ but it was not evaluated for other types of flows. The objective of the current work was to continue development of MML to increase its range of applicability to include boundary layer flows with zero and adverse pressure gradients. 
To accomplish this objective, MML was installed in Proteus and first used to calculate zero pressure gradient flow over a flat plate. These results indicated that the original MML model was not allowing for the proper boundary layer growth with increasing Reynolds number. To remedy this behavior, a relationship was found for the saturation length scale as a function of the local skin friction coefficient. This modified version of MML allowed for the proper boundary layer growth and therefore produced the correct velocity-defect profiles. Next, MML was modified to calculate adverse pressure gradient flows using the experimental data of Bradshaw for zero, mild and strong adverse pressure gradient flows. These modifications were combined into one generalized model, called MMLPG. This new model accurately predicted the zero and adverse pressure gradient flows and exhibited better agreement with experimental data than the Baldwin-Lomax model.

To more thoroughly evaluate MMLPG for other adverse pressure gradient flows, this model was also used to calculate three transonic diffuser flow cases: flow with a weak shock, flow with no shock, and flow with a strong shock. These are flows typically encountered in aerospace propulsion applications. The MMLPG results were compared with results calculated using two slightly different implementations of the Baldwin-Lomax model, referred to as BLM1 and BLM2. The differences in the two models arise from the calculation of the $F_{w a k e}$ function, as discussed in Chapter IV.

For the weak shock case, MMLPG and BLM2 did equally well in predicting the shock Mach Number and location, and also in predicting the static pressure distribution on the top and bottom walls. However, BLM1 over-predicted the shock Mach number and location and did not match the wall static pressures in the throat region of the diffuser. For the no shock case, MMLPG was significantly better than either of the 
Baldwin-Lomax models at predicting the static pressures on the walls and MMLPG also predicted a maximum Mach number that was in close agreement with the results of Georgiadis. ${ }^{35}$

The strong shock diffuser flow was beyond the capabilities of all three models. Both MMLPG and BLM2 over-predicted the shock Mach number and location, as well as the pressure distribution on the walls, while the BLM1 results were in reasonable agreement for these quantities. None of the models were able to correctly predict the shock-induced separation on the top wall; in fact, BLM1 predicted no separation at all on the top wall yet predicted a very large, unattached separation on the bottom wall. The primary reason the MMLPG and BLM2 results differ greatly from the BLM1 results is explained by the turbulent viscosity values. MMLPG and BLM2 gave maximum turbulent viscosity values of 23,000 and 21,000 times the molecular viscosity, respectively, while BLM1 gave a maximum turbulent viscosity of only 4,600 times the molecular viscosity. The turbulent viscosity is proportional to the vorticity, which becomes very large just downstream of the normal shock, however, the $F_{\text {wake }}$ function used in BLM1 is inversely proportional to the vorticity resulting in a lower overall turbulent viscosity. The poor performance of all of the models for this case can also be attributed to the fact that all of the models are equilibrium turbulence models being used to calculate a flow which is clearly nonequilibrium. The poor performance of MMLPG for the strong shock case is also explained by the derivation of the model, which is based on experimental data for $\beta$ values between 0 and 5, while this flow encountered $\beta$ values as high as 12,000 . Considering that MMLPG did well at calculating the less severe no shock and weak shock flows indicates that it is most likely applicable to other propulsion flows at these less severe types of conditions. 
The flat plate and transonic diffuser results indicate that the modified version of the MML model, MMLPG, is capable of accurately predicting turbulent flows with and without adverse pressure gradients. Thus, the objective of this work, which was to evaluate the original MML model and modify it to increase its range of applicability to include adverse pressure gradient flows, has been met. Future work should include continued validation of the model for these types of flows as well as continued development of the model to better account for stronger adverse pressure gradient flows both with and without separation. 


\section{REFERENCES}

1. Rodi, W., Turbulence Models and Their Application in Hydraulics, Brookfield Publishing, Brookfield, Vermont, 1984.

2. White, F. M., Viscous Fluid Flow, McGraw-Hill, Inc., New York, 1991.

3. Anderson, D. A., Tannehill, J. C., and Pletcher, R. H., Computational Fluid Mechanics and Heat Transfer, McGraw-Hill, New York, 1984.

4. Baldwin, B. and Lomax, H., "Thin Layer Approximation and Algebraic Model for Separated Turbulent Flows," AIAA Paper 78-257, January 1978.

5. Potapczuk, M. G., "Navier-Stokes Analysis of Airfoils with Leading Edge Ice Accretions," Ph.D. Dissertation, University of Akron, May 1989.

6. Yu, N. J., Allmaras, S. R., and Moschetti, K. G., "Navier-Stokes Calculations for Attached and Separated Flows Using Different Turbulence Models," AIAA Paper 91-1791, June 1991.

7. Visbal, M. and Knight, D., "The Baldwin-Lomax Turbulence Model for TwoDimensional Shock-Wave/Boundary-Layer Interactions," AIAA Journal, Vol. 22, No. 7, July 1984, pp. 921-928.

8. Degani, D. and Schiff, L. B., "Computation of Turbulent Supersonic Flows around Pointed Bodies Having Crossflow Separation," Journal of Computational Physics, Vol. 66, 1986, pp. 173-196.

9. Menter, F. R., "Performance of Popular Turbulence Models for Attached and Separated Adverse Pressure Gradient Flows," AIAA Journal, Vol. 30, No. 8, August 1992, pp. 2066-2072.

10. Stock, H. W. and Haase, W., "The Determination of Turbulent Length Scales in Algebraic Turbulence Models for Attached and Slightly Separated Flows Using Navier-Stokes Methods," AIAA Paper 87-1302, June 1987.

11. Sakowski, B., Darling, D., Roach, R. L. and van de Wall, A., "Evaluation and Application of the Baldwin-Lomax Turbulence Model in Two-Dimensional, 
Unsteady, Compressible Boundary Layers with and without Separation in Engine Inlets," AIAA Paper 92-3676, July 1992.

12. Chima, R. V., Giel, P. W. and Boyle, R. J., “An Algebraic Turbulence Model for Three-Dimensional Viscous Flows," NASA TM 105931, January 1993.

13. Towne, C. E., Schwab, J. R. and Bui, T. T., "Proteus Two-Dimensional NavierStokes Computer Code, Version 2.0, Vols. 1-3," NASA TM 106336, 106337, 106339, October 1993.

14. Towne, C. E., Schwab, J. R., Benson, T. J. and Suresh, A., "PROTEUS TwoDimensional Navier-Stokes Computer Code, Version 1.0, Vols. 1-3," NASA TM 102551-102553, March 1990.

15. Briley, W. R., McDonald, H., "Solution of the Multidimensional Compressible Navier-Stokes Equations by a Generalized Implicit Method," Journal of Computational Physics, Vol. 24, 1977, pp. 373-397.

16. Beam, R. M. and Warming, R. F., "An Implicit Factored Scheme for the Compressible Navier-Stokes Equations," AIAA Journal, Vol. 16, No. 4, April 1978, pp. 393-402.

17. Chien, K. Y., "Prediction of Channel and Boundary-Layer Flows with a LowReynolds-Number Turbulence Model," AIAA Journal, Vol. 20, No. 1, January 1982, pp. 33-38.

18. Steger, J. L., "Implicit Finite-Difference Simulation of Flow about Arbitrary TwoDimensional Geometries," AIAA Journal, Vol. 16, No. 7, July 1978, pp. 679-686.

19. Jameson, A., Schmidt, W. and Turkel, E., "Numerical Solutions of the Euler Equations by Finite Volume Methods Using Runge-Kutta Time-Stepping Schemes," AIAA Paper 81-1259, June 1981.

20. Cebeci, T. and Smith, A. M. O., Analysis of Turbulent Boundary Layers, Academic Press, New York, 1974.

21. Samuel, A. E. and Joubert, P. N., "A boundary layer developing in an increasingly adverse pressure gradient," Journal of Fluid Mechanics, Vol. 66, Part 3, 1974, pp. 481-505.

22. Driver, D. M., "Reynolds Shear Stress Measurements in a Separated Boundary Layer," AIAA Paper 91-1787, 1991. 
23. Kirtley, K. R., “A Coupled, Parabolic-Marching Method for the Prediction of Three-Dimensional Viscous Incompressible Turbomachinery Flows," Ph. D. Thesis, Pennsylvania State University, December, 1987.

24. Launder, B. E. and Priddin, C. H., "A Comparison of Some Proposals for the Mixing Length Near a Wall," International Journal of Heat and Mass Transfer, Vol. 16, 1973, pp. 700-702.

25. Bradshaw, P., "The Turbulence Structure of Equilibrium Boundary Layers," NPL Aero Report 1184, January, 1966.

26. Fletcher, C. A. J., Computational Techniques of Fluid Dynamics, Vol. 1, SpringerVerlag, Berlin, 1985.

27. Musker, A. J., "Explicit Expression for the Smooth Wall Velocity Distribution in a Turbulent Boundary Layer," AIAA Journal, Vol. 17, No. 6, June 1979, pp. 655657.

28. Clauser, F. H., "Turbulent Boundary Layers in Adverse Presșure Gradients," Journal of Aeronautical Sciences, February 1954, pp. 91-108.

29. Weighardt, K., "Flat Plate Flow. $\mathbf{u}_{\infty}=33 \mathrm{~m} / \mathrm{sec}$," Proceedings, AFOSR-IFPStanford Conference on Computation of Turbulent Boundary Layers-1968, Vol. II, Ed. by Coles, D.E. and Hirst, E. A., 1968, pp. 98-123.

30. Salmon, J. T., Bogar, T. J. and Sajben, M., "Laser Doppler Velocimeter Measurements in Unsteady, Separated, Transonic Diffuser Flows," AIAA Journal, Vol. 21, No. 12,1983 , pp. 1690-1697.

31. Bogar, T. J., Sajben, M. and Kroutil, J. C., "Characteristic Frequencies of Transonic Diffúser Flow Oscillations," AIAA Journal, Vol. 21, No. 9, 1983, pp. $1232-1240$.

32. Hsieh, T., Bogar, T. J. and Coakley, T. J., "Numerical Simulation and Comparison with Experiment for Self-Excited Oscillations in a Diffuser Flow," AIAA Journal, Vol. 25, No. 7, 1987, pp. 936-943.

33. Hsieh, T., Wardlaw, A. B. Jr., Collins, P. and Coakley, T., "Numerical Investigation of Unsteady Inlet Flowfields," AIAA Journal, Vol. 25, No. 1, January 1987, pp. 75-81.

34. Bui, T. T., "Implementation/Validation of a Low Reynolds Number Two-Equation Turbulence Model in the Proteus Navier-Stokes Code - Two-Dimensional/ Axisymmetric," NASA TM 105619, April 1992. 
35. Georgiadis, N. J., "An Evaluation of Turbulence Models for Propulsion Flows," Master's Thesis, University of Akron, May 1993.

36. Cooper, G. K. and Sirbaugh, J. R., "PARC Code: Theory and Usage," Arnold Engineering Development Center Report AEDC-TR-89-15, December 1989.

37. Wassel, A. T., and Catton, I., "Calculation of Turbulent Boundary Layers Over Flat Plates With Different Phenomenological Theories of Turbulence and Variable Turbulent Prandtl Number," International Journal of Heat and Mass Transfer, Vol. 16,1973, pp. 1547-1563.

38. Schlicting, H., Boundary-Layer Theory, McGraw-Hill Book Company, New York, 1968.

39. Hoffman, K. A., Computational Fluid Dynamics for Engineers, Engineering Education System, Austin, Texas, 1989.

40. Pulliam, T. H., “Artificial Dissipation Models for the Euler Equations," AIAA Journal, Vol. 24, No. 12, December 1986, pp. 1931-1940. 
APPENDICES 


\section{APPENDIX 1 GOVERNING EQUATIONS OF PROTEUS}

The governing equations of Proteus are the compressible Navier-Stokes equations. The equations given below are taken from reference 13 , but may also be found in several references. ${ }^{2,3,38}$ Since the two-dimensional/axisymmetric version of the Proteus code was used for all calculations discussed in this work, the two-dimensional, planar equations are given here. (For the axisymmetric version of the equations, which are somewhat more complex, consult reference 13.)

\section{Cartesian Coordinates}

In Cartesian coordinates, the continuity, $x$-momentum, $y$-momentum and energy equations are written in strong conservation law form, using vector notation:

$$
\frac{\partial \mathbf{Q}}{\partial \mathrm{t}}+\frac{\partial \mathbf{E}}{\partial \mathrm{x}}+\frac{\partial \mathbf{F}}{\partial \mathrm{y}}=\frac{\partial \mathbf{E}_{v}}{\partial \mathrm{x}}+\frac{\partial \mathbf{F}_{V}}{\partial \mathrm{y}}
$$

where

$$
Q=\left[\begin{array}{c}
\rho \\
\rho u \\
\rho v \\
E_{\tau}
\end{array}\right]
$$




$$
\begin{gathered}
\mathbf{E}=\left[\begin{array}{c}
\rho u \\
\rho u^{2}+p \\
\rho u v \\
\left(E_{T}+p\right) u
\end{array}\right] \\
\mathbf{F}=\left[\begin{array}{c}
\rho v \\
\rho u v \\
\rho v^{2}+p \\
\left(E_{T}+p\right) v
\end{array}\right] \\
\mathbf{E}_{V}=\left[\begin{array}{c} 
\\
0 \\
\tau_{x x} \\
\tau_{x y} \\
u \tau_{x x}+v \tau_{x y}-q_{x}
\end{array}\right] \\
F_{V}=\left[\begin{array}{c} 
\\
0 \\
\tau_{x y} \\
\tau_{y y} \\
u \tau_{x y}+v \tau_{y y}-q_{y}
\end{array}\right]
\end{gathered}
$$

In equation (A.2), the dependent variables are $\rho, \rho u, \rho v$ and $E_{T}$, the inviscid fiux vectors are $\mathbf{E}$ and $\mathbf{F}$, and the viscous flux vectors are $\mathbf{E}_{V}$ and $\mathbf{F}_{V}$. The normal and shear stresses, and the heat flux are given by

$$
\begin{aligned}
\tau_{x x} & =2 \mu \frac{\partial u}{\partial x}+\lambda\left(\frac{\partial u}{\partial x}+\frac{\partial v}{\partial y}\right) \\
\tau_{y y} & =2 \mu \frac{\partial v}{\partial y}+\lambda\left(\frac{\partial u}{\partial x}+\frac{\partial v}{\partial y}\right) \\
\tau_{x y} & =\mu\left(\frac{\partial u}{\partial y}+\frac{\partial v}{\partial x}\right)
\end{aligned}
$$




$$
\begin{aligned}
& q_{x}=-k \frac{\partial T}{\partial x} \\
& q_{y}=-k \frac{\partial T}{\partial y}
\end{aligned}
$$

\section{Equation of State}

In addition to the above equations, an equation of state is needed to relate the pressure to the dependent variables. Proteus contains the equation of state for an ideal gas:

$$
p=\rho R T
$$

where $\mathrm{R}$ is the ideal gas constant. For a calorically perfect gas, this is equivalent to

$$
p=(\gamma-1)\left[E_{T}-\frac{1}{2} \rho\left(u^{2}+v^{2}\right)\right]
$$

\section{Generalized Grid Transformation}

The governing equations in section 1.0 are written in Cartesian coordinates and are not well-suited for nonrectangular geometries and grids with unequal spacing. 13,39 To overcome these difficulties, the following generalized grid transformation is used to transform the governing equations from physical $(x, y)$ coordinates to rectangular orthogonal computational $(\xi, \eta)$ coordinates.

$$
\begin{aligned}
& \xi=\xi(x, y) \\
& \eta=\eta(x, y)
\end{aligned}
$$

The resulting spatial computational domain is square, and has uniform spacing. The chain rule is used to transform the partial derivatives in the Cartesian form of the 
governing equations, (A.1)-(A.3); for details, refer to Towne et al. ${ }^{13}$ The transformed equations are written as

$$
\frac{\partial \hat{\mathbf{Q}}}{\partial \mathrm{t}}+\frac{\partial \hat{\mathbf{E}}}{\partial \xi}+\frac{\partial \hat{\mathbf{F}}}{\partial \eta}=\frac{\partial \hat{\mathbf{E}}_{V}}{\partial \xi}+\frac{\partial \hat{\mathbf{F}}_{V}}{\partial \eta}
$$

where

$$
\begin{gathered}
\hat{\mathbf{Q}}=\frac{\mathbf{Q}}{J} \\
\hat{\mathbf{E}}=\frac{1}{J}\left(\mathbf{E} \xi_{\mathrm{x}}+\mathbf{F} \xi_{\mathrm{y}}+\mathbf{Q} \xi_{\mathrm{t}}\right) \\
\hat{\mathbf{F}}=\frac{1}{J}\left(\mathbf{E} \eta_{\mathrm{x}}+\mathbf{F} \eta_{\mathrm{y}}+\mathbf{Q} \eta_{\mathrm{t}}\right) \\
\hat{\mathbf{E}}_{V}=\frac{1}{J}\left(\mathbf{E}_{v} \xi_{\mathrm{x}}+\mathbf{F} \xi_{\mathrm{y}}\right) \\
\hat{\mathbf{F}}_{V}=\frac{1}{J}\left(\mathbf{E}_{v} \eta_{\mathrm{x}}+\mathbf{F} \eta_{\mathrm{y}}\right)
\end{gathered}
$$

and $J$ is the Jacobian of the transformation,

$$
J=\xi_{x} \eta_{y}-\xi_{y} \eta_{x}
$$

4. Time Differencing

The generalized time differencing scheme of Beam \& Warming $^{16}$ is used to approximate the time derivative in equation (A.7): 


$$
\begin{aligned}
\frac{\partial \hat{\mathbf{Q}}}{\partial \mathrm{t}} \approx \frac{\Delta \hat{\mathbf{Q}}^{\mathrm{n}}}{\Delta \mathrm{t}}= & \frac{\theta_{1}}{1+\theta_{2}} \frac{\partial\left(\Delta \hat{\mathbf{Q}}^{\mathrm{n}}\right)}{\partial \mathrm{t}}+\frac{1}{1+\theta_{2}} \frac{\partial \hat{\mathbf{Q}}^{\mathrm{n}}}{\partial \mathrm{t}}+\frac{\theta_{2}}{1+\theta_{2}} \frac{\Delta \hat{\mathbf{Q}}^{\mathrm{n}-1}}{\Delta \mathrm{t}} \\
& +O\left[\left(\theta_{1}-\frac{1}{2}-\theta_{2}\right) \Delta \mathrm{t},\left(\Delta \mathrm{t}^{2}\right)\right]
\end{aligned}
$$

where $\Delta \hat{\mathbf{Q}}^{\mathrm{n}}=\hat{\mathbf{Q}}^{\mathrm{n}+1}-\hat{\mathbf{Q}}^{\mathrm{n}}$, and the superscripts $\mathrm{n}$ and $\mathrm{n}+1$ denote the known and unknown time levels, respectively.

The parameters $\theta_{1}$ and $\theta_{2}$ determine the type of time differencing used. Table 6 summarizes the available schemes.

Table 6. Time differencing schemes in Proteus

\begin{tabular}{|c|c|c|c|}
\hline$\theta_{1}$ & $\theta_{2}$ & Method & Truncation Error \\
\hline 1 & 0 & Euler implicit & $O(\Delta \mathrm{t})$ \\
\hline $1 / 2$ & 0 & Trapezoidal implicit & $O(\Delta \mathrm{t})^{2}$ \\
\hline 1 & $1 / 2$ & 3-point backward implicit & $O(\Delta \mathrm{t})^{2}$ \\
\hline
\end{tabular}

The Euler implicit method is recommended for steady flows and the 3-point backward implicit method is recommended for unsteady flows.

\section{Space Differencing}

Spacial first derivatives in the $\xi$ direction are approximated using the following second-order central difference formula.

$$
\left(\frac{\partial f}{\partial \xi}\right)_{i, j} \approx \delta_{\xi} f_{i, j}=\frac{f_{i+1, j}-f_{i-1, j}}{2 \Delta \xi}
$$

The computational grid spacing, $\Delta \xi$, is constant. A similar formula is used for first derivatives in the $\eta$ direction. 


\section{APPENDIX 2}

\section{ARTIFICIAL VISCOSITY AND GRID CONVERGENCE}

High frequency nonlinear instabilities can appear as the Proteus solution develops. For example, physical phenomena, such as shock waves, can cause instabilities when they are captured by the finite difference algorithm. In addition, high Reynolds number flows may have oscillations resulting from the odd-even decoupling inherent in the use of central spatial differencing of the convective terms. Artificial viscosity may be used to suppress these oscillations. The two artificial viscosity models in Proteus are the constant coefficient model of Steger ${ }^{18}$ and the nonlinear coefficient model of Jameson et al. ${ }^{19}$ The implementation of these models in generalized nonorthogonal coordinates was taken from Pulliam. ${ }^{40}$

\section{Constant Coefficient Model}

The constant coefficient model uses a combination of explicit and implicit smoothing. The standard explicit artificial viscosity uses fourth-order differences. Second-order explicit artificial viscosity, which provides more smoothing, is also available in Proteus, however it is rarely used because it introduces a large error. The implicit smoothing is second order and is used to extend the linear stability bound of the fourth-order explicit smoothing.

The explicit artificial viscosity is implemented in the Proteus alternating direction implicit (ADI) algorithm ${ }^{15}$ by adding the following terms to the right-hand side source term for the first ADI sweep. 


$$
\frac{\varepsilon_{E}^{(2)} \Delta \mathrm{t}}{J}\left(\nabla_{\xi} \Delta_{\xi} \mathbf{Q}+\nabla_{\eta} \Delta_{\eta} \mathbf{Q}\right)-\frac{\varepsilon_{E}^{(4)} \Delta \mathrm{t}}{J}\left[\left(\nabla_{\xi} \Delta_{\xi}\right)^{2} \mathbf{Q}+\left(\nabla_{\eta} \Delta_{\eta}\right)^{2} \mathbf{Q}\right]
$$

where $\varepsilon_{E}{ }^{(2)}$ and $\varepsilon_{E}{ }^{(4)}$ are the second- and fourth-order explicit artificial viscosity coefficients. The symbols $\nabla$ and $\Delta$ are the backward and forward first difference operators for the first ADI sweep such that

$$
\begin{aligned}
& \nabla_{\xi} \mathbf{Q}_{\mathbf{i}}=\mathbf{Q}_{\mathbf{i}}-\mathbf{Q}_{\mathbf{i}-1} \\
& \Delta_{\xi} \mathbf{Q}_{\mathbf{i}}=\mathbf{Q}_{\mathbf{i}+1}-\mathbf{Q}_{\mathbf{i}} \\
& \nabla_{\xi} \Delta_{\xi} \mathbf{Q}_{i}=\mathbf{Q}_{\mathbf{i}+1}-2 \mathbf{Q}_{\mathrm{i}}+\mathbf{Q}_{\mathrm{i}-1} \\
& \left(\nabla_{\xi} \Delta_{\xi}\right)^{2} \mathbf{Q}_{i}=\mathbf{Q}_{i+2}-4 \mathbf{Q}_{i+1}+6 \mathbf{Q}_{\mathrm{i}}-4 \mathbf{Q}_{\mathrm{i}-1}+\mathbf{Q}_{\mathrm{i}-2}
\end{aligned}
$$

Similar formulas are used in the $\eta$ direction.

The implicit artificial viscosity is implemented by adding the following terms to the left-hand side of the governing equation.

$$
\begin{aligned}
& -\frac{\varepsilon_{l} \Delta \mathrm{t}}{J}\left[\nabla_{\xi} \Delta_{\xi}\left(J \Delta \hat{\mathbf{Q}}^{*}\right)\right] \\
& -\frac{\varepsilon_{l} \Delta \mathrm{t}}{J}\left[\nabla_{\eta} \Delta_{\eta}\left(J \Delta \hat{\mathbf{Q}}^{\mathrm{n}}\right)\right]
\end{aligned}
$$

Equation (B.3a) is added for the first ADI sweep and equation (B.3b) is added for the second ADI sweep. The constant $\varepsilon_{I}$ is the implicit artificial viscosity coefficient.

The optimum values of the coefficients $\varepsilon_{E}{ }^{(2)}, \varepsilon_{E}{ }^{(4)}$ and $\varepsilon_{I}$ vary from problem to problem. They should be small so as not to corrupt the physical solution, yet large enough to damp any instabilities. The Proteus User's Guide ${ }^{13}$ recommends starting values of $\varepsilon_{E}^{(4)}=1.0, \varepsilon_{E}^{(2)}=1.0$ and $\varepsilon_{I}=2.0$. 
2. Nonlinear Coefficient Model

The nonlinear coefficient artificial viscosity is explicit and contains second and fourth-order differences. The following terms are added to the right-hand side of the governing equations.

$$
\begin{aligned}
& \nabla_{\xi}\left\{\left[\left(\frac{\Psi}{J}\right)_{i+1}+\left(\frac{\Psi}{J}\right)_{i}\right]\left(\varepsilon_{\xi}^{(2)} \Delta_{\xi} \mathbf{Q}-\varepsilon_{\xi}^{(4)} \Delta_{\xi} \nabla_{\xi} \Delta_{\xi} \mathbf{Q}\right)_{i}\right\} \\
& +\nabla_{\eta}\left\{\left[\frac{\Psi}{J_{j+1}}+\frac{\Psi}{J_{j}}\right]\left(\varepsilon_{\eta}^{(2)} \Delta_{\eta} \mathbf{Q}-\varepsilon_{\eta}^{(4)} \Delta_{\eta} \nabla_{\eta} \Delta_{\eta} \mathbf{Q}\right)_{j}\right\}
\end{aligned}
$$

The difference operator $\Delta_{\xi} \nabla_{\xi} \Delta_{\xi} \mathbf{Q}_{i}$ is defined by

$$
\Delta_{\xi} \nabla_{\xi} \Delta_{\xi} \mathbf{Q}_{i}=\mathbf{Q}_{i+2}-3 \mathbf{Q}_{i+1}+\mathbf{Q}_{\mathrm{i}-1}
$$

and the expression $\psi$ is given by

$$
\psi=\psi_{x}+\Psi_{y}
$$

where $\psi_{x}$ and $\psi_{y}$ are spectral radii defined by

$$
\begin{aligned}
& \Psi_{\mathrm{x}}=\frac{|\mathrm{U}|+\mathrm{a} \sqrt{\xi_{\mathrm{x}}^{2}+\xi_{\mathrm{y}}^{2}}}{\Delta \xi} \\
& \Psi_{\mathrm{y}}=\frac{|\mathrm{V}|+\mathrm{a} \sqrt{\eta_{\mathrm{x}}^{2}+\eta_{\mathrm{y}}^{2}}}{\nabla \eta}
\end{aligned}
$$

The second- and fourth- order nonlinear artificial viscosity coefficients are a function of the pressure field. In the $\xi$ direction, they are given by

$$
\begin{aligned}
& \left(\varepsilon_{\xi}^{(2)}\right)_{i}=\kappa_{2} \Delta t \max \left(\sigma_{i+1}, \sigma_{i}, \sigma_{i-1}\right) \\
& \left(\varepsilon_{\xi}^{(4)}\right)_{i}=\max \left[0, \kappa_{4} \Delta t-\left(\varepsilon_{\xi}^{(2)}\right)_{i}\right]
\end{aligned}
$$

where 


$$
\sigma_{i}=\left|\frac{p_{i+1}-2 p_{i}+p_{i-1}}{p_{i+1}+2 p_{i}+p_{i-1}}\right|
$$

Similar formulas are used in the $\eta$ direction.

The parameter $\sigma$ is a pressure gradient scaling parameter which increases the amount of second-order smoothing relative to fourth-order near shock waves. The parameters $\kappa_{2}$ and $\kappa_{4}$ are user-specified constants. As with the constant coefficient model, the optimum values of $\kappa_{2}$ and $\kappa_{4}$ are problem dependent. Typical values range from $\kappa_{4}=0.005$ and $\kappa_{2}=0.01$ for flows with no shocks, to $\kappa_{4}=0.0004$ and $\kappa_{2}=0.1$ for flows with shocks. ${ }^{13}$ Pulliam gives $\kappa_{2}=0.25$ and $\kappa_{4}=0.01$ as typical values for an Euler analysis. ${ }^{13,40}$

\section{Comments on Artificial Viscosity}

As previously mentioned, artificial viscosity is generally used to minimize oscillations which occur when computing high Reynolds number flows and flows with shock waves. Since the artificial viscosity terms do not represent anything physical, the coefficients should be as small as possible so as not to corrupt the solution, yet large enough to damp the nonphysical instabilities. Optimum values of the artificial viscosity coefficients vary from problem to problem; the coefficients used to calculate the flows presented in Chapters III and IV were selected based on values used for similar cases, as given in the Proteus User's Manual. ${ }^{13}$ Some representative test cases were evaluated to insure that the chosen artificial viscosity did not corrupt the physical characteristics of the flow.

The flat plate flows presented in Chapter III were run using the constant

coefficient model with $\varepsilon_{E}{ }^{(4)}=1.0, \varepsilon_{E}{ }^{(2)}=0.0$ and $\varepsilon_{I}=2.0$. For these flows, it was possible to run Proteus with zero artificial viscosity, however the solutions took two to four times longer to "converge," or reach a point where the solution stopped changing 
appreciably with time. Upon close examination, these solutions did not agree as closely with experimental data as the solutions computed using artificial viscosity.

For the diffuser flows computed in Chapter IV, the artificial viscosity effects were examined for the weak shock case. As mentioned in Chapter IV, the nonlinear coefficient model was used. A value of $\kappa_{2}=0.1$ was used for the entire calculation, with $\kappa_{4}=0.005$ while the exit pressure was changing (i.e, for the first 6000 iterations), and $\kappa_{4}=0.0004$ for the remaining 3000 iterations, which were at a constant exit pressure. It was not possible to compute this flow without artificial viscosity, so the effects of doubling and halving the smoothing coefficients was examined. The static pressure distribution on the top and bottom walls for this comparison (computed using MMLPG) is given in figure 27. The solution computed using half of the original artificial viscosity was nearly identical to the original solution, indicating that the originally chosen artificial viscosity is reasonable for this flow. Doubling the artificial viscosity gave a less desirable result in that the normal shock was smeared over a greater number of grid points.

\section{Grid Convergence}

Grid convergence is an important factor in the accuracy of a CFD calculation. The grids used to make the flat plate and transonic diffuser calculations were assessed to insure their grid independence. For the zero pressure gradient flat plate calculations, a $101 \times 101$ grid was initially chosen. The size of this grid was systematically reduced in each direction in order to find the coarsest grid that would give a solution which would not change if additional grid points were added. The $51 \times 51$ grid described in Chapter III was chosen based on this study.

The grid used to make the transonic diffuser calculations had been used previously by others, ${ }^{13,34}$ so it is probable that this grid gives a reliable solution. As an 


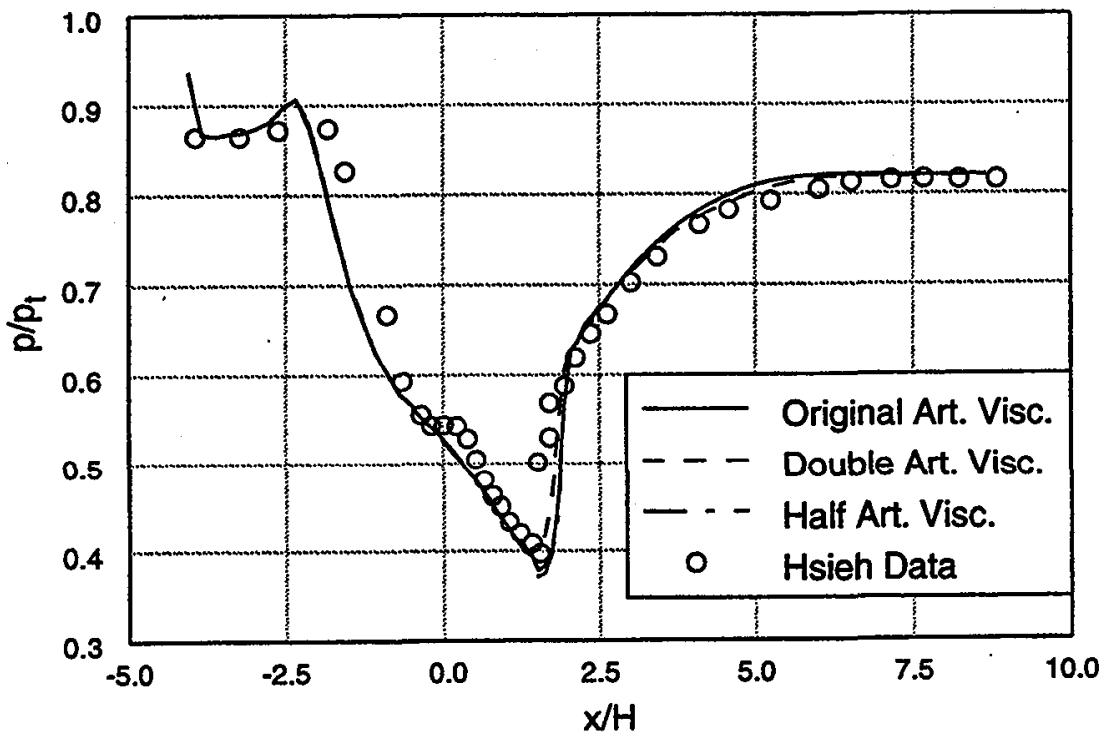

(a) Top Wall

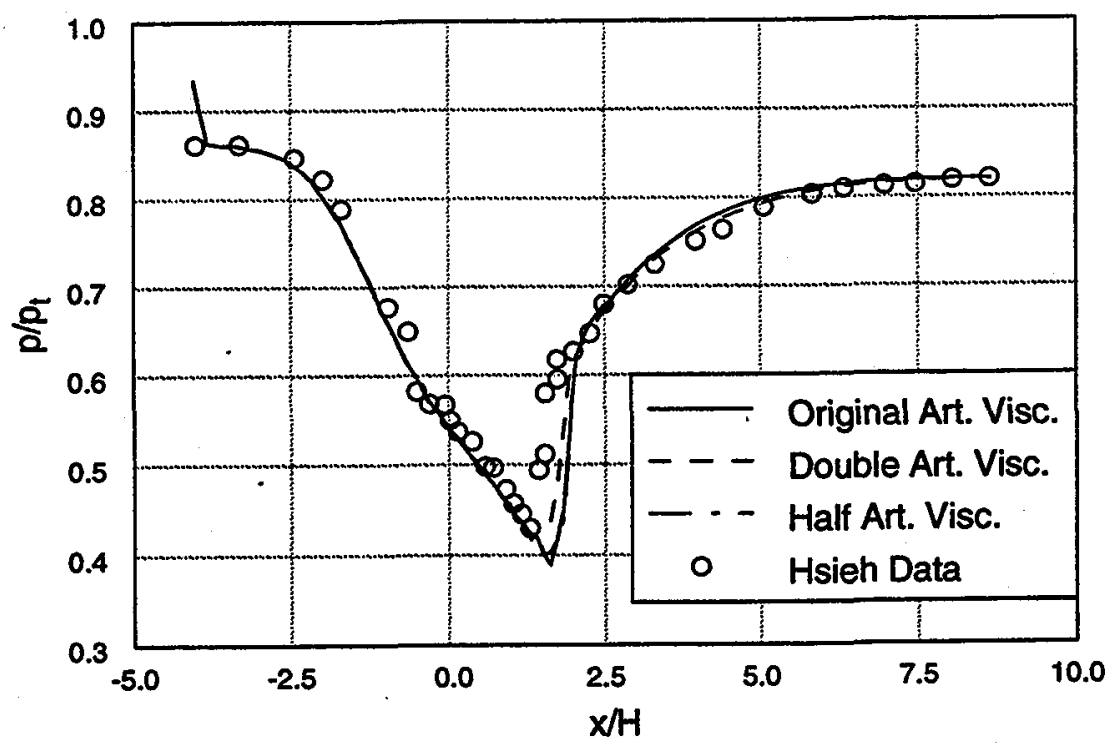

(b) Bottom Wall

Figure 27. Comparison of weak shock static pressure distributions, computed using MMLPG and three different amounts of artificial viscosity. 
added check, the number of grid points in each direction was doubled, and the resulting $162 \times 101$ grid was used to compute the no shock flow using MMLPG. A comparison of these results with the results obtained using the $81 \times 51$ grid of Chapter IV is given in figure 28 and indicates that the $81 \times 51$ grid is reliable. 


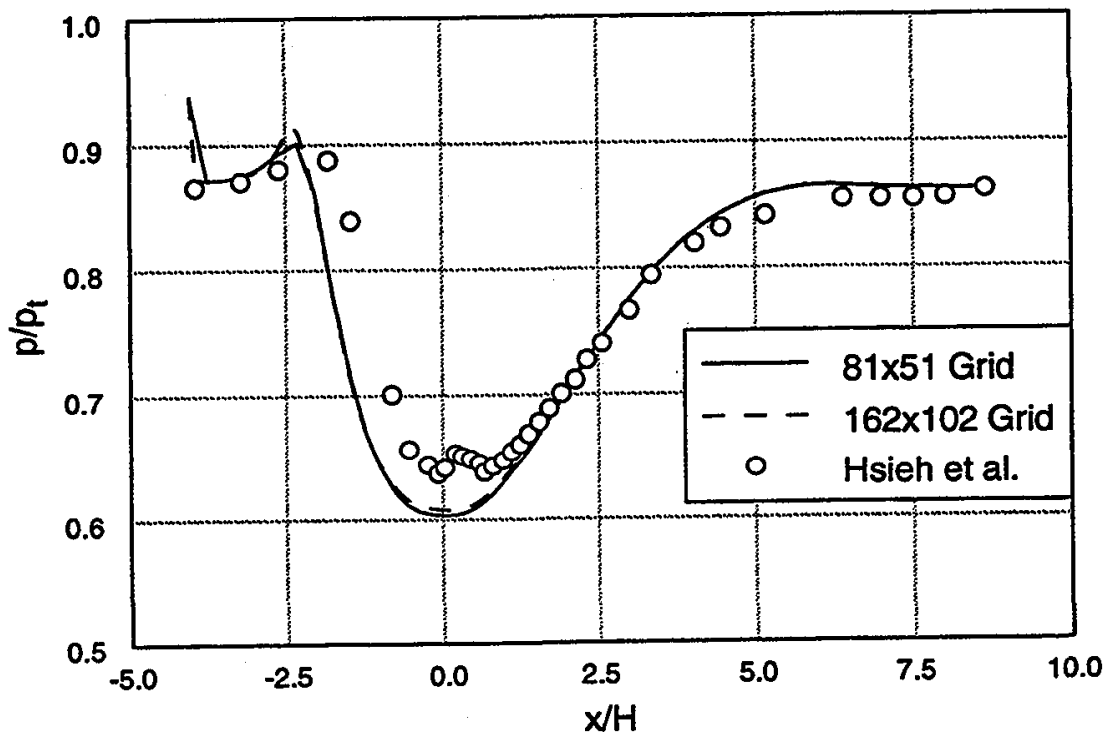

(a) Top Wall

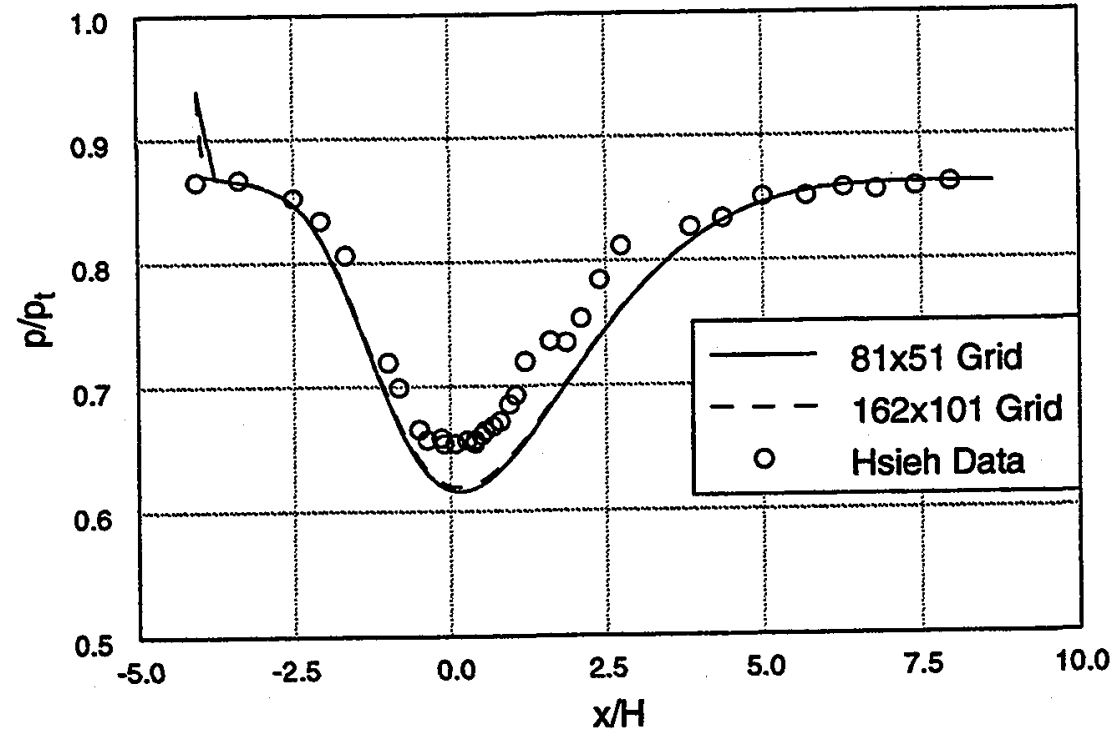

(b) Bottom Wall

Figure 28. Comparison of no shock static pressure distributions, computed using MMLPG and two different grids. 


\section{APPENDIX 3 \\ THE BALDWIN-LOMAX TURBULENCE MODEL}

A generalized version of the Baldwin-Lomax algebraic turbulence model ${ }^{4}$ is available in Proteus. ${ }^{13}$ As mentioned in chapter in Chapter II, the turbulent shear and normal stresses and the turbulent heat flux are modeled using the Boussinesq approach, where the effective viscosity is defined as $\mu_{\text {eff }}=\mu+\mu_{t}$, the second coeffcient of viscosity is defined as $\lambda_{\text {eff }}=\lambda+\lambda_{t}$, and the effective thermal conductivity coefficient is defined as $k_{e f f}=k+k_{\imath}$.

For wall bounded flows, the Baldwin-Lomax model is a two-layer model:

$$
\mu_{\mathrm{t}}= \begin{cases}\left(\mu_{\mathrm{t}}\right)_{\text {inner }}, & \mathrm{y} \leq \mathrm{y}_{\text {crossover }} \\ \left(\mu_{\mathrm{t}}\right)_{\text {outer }}, & \mathrm{y}>\mathrm{y}_{\text {crossover }}\end{cases}
$$

where $y_{\text {crossover }}$ is smallest value of $y$ at which the inner and outer region values of $\mu_{t}$ are equal. For free turbulent flows, $\mu_{t}=\left(\mu_{t}\right)_{\text {outer }}$.

\section{Inner Region}

The inner region turbulent viscosity is computed from

$$
\left(\mu_{\mathrm{t}}\right)_{\text {inner }}=\rho l^{2}|\omega|
$$

where $l$ is the mixing length given by 


$$
l=\kappa y\left(1-\mathrm{e}^{-\frac{\mathrm{y}^{+}}{\mathrm{A}^{+}}}\right)
$$

The quantity $|\omega|$ is the magnitude of the total vorticity, defined for two-dimensional planar flow as

$$
|\omega|=\left|\frac{\partial v}{\partial x}-\frac{\partial u}{\partial y}\right|
$$

\section{Outer Region}

In the outer region, the turbulent viscosity is given by

$$
\left(\mu_{\mathrm{t}}\right)_{\text {outer }}=K \mathrm{C}_{\mathrm{cp}} \rho \mathrm{F}_{\mathrm{Kleb}} \mathrm{F}_{\text {wake }}
$$

where $K$ is the Clauser constant, taken as 0.0168 and $C_{c p}$ is a constant taken as 1.6. The quantity $F_{\text {wake }}$ is computed from

$$
F_{\text {wake }}= \begin{cases}y_{\max } F_{\max }, & \text { for wall bounded flows } \\ C_{w k} V_{d i f f}^{2} \frac{y_{\max }}{F_{\text {max }}}, & \text { for free turbulent flows }\end{cases}
$$

where the constant $C_{w k}$ is 0.25 and

$$
V_{\text {diff }}=|\vec{V}|_{\max }-|\vec{V}|_{\min }
$$

where $\vec{V}$ is the total velocity vector. The quantity $F_{\max }$ is the maximum value of

$$
F(y)= \begin{cases}y|\omega|\left(1-e^{-\frac{y^{+}}{A^{+}}}\right), & \text {for wall bounded flows } \\ y|\omega|, & \text { for free turbulent flows }\end{cases}
$$


and $y_{\max }$ is the value of $y$ corresponding to $F_{\max } . F_{K l e b}$ is the Klebanoff intermittency factor which accounts for the experimentally observed phenomenon that as the free stream is approached, the fraction of time the flow is turbulent decreases. It is given by

$$
\mathrm{F}_{\mathrm{Kleb}}=\left[1-5.5\left(\frac{\mathrm{C}_{\mathrm{Kleb}} \mathrm{y}}{\mathrm{y}_{\max }}\right)^{6}\right]^{-1}
$$

where $\mathrm{C}_{\mathrm{Kleb}}$ is a constant taken as 0.3 .

\section{Multiple Boundaries}

If both walls in a given coordinate direction are solid surfaces, the turbulence model equations are applied separately at each surface and then averaged. The two outer regions overlap, and it assumed that the two inner regions do not overlap. The averaging procedure deals with the $F_{\text {wake }}$ function. For example, in the vertical direction, if the upper and lower boundaries are both solid surfaces, the two values of $F_{w a k e}$ at a particular streamwise station are combined using the following averaging formula:

$$
F_{\text {wake }}=\frac{\left(F_{\text {wake }}\right)_{1} f_{1}+\left(F_{\text {wake }}\right)_{2} f_{2}}{f_{1}+f_{2}}
$$

The quantities $\left(\mathrm{F}_{\text {wake }}\right)_{1}$ and $\left(\mathrm{F}_{\text {wake }}\right)_{2}$ are the separate values computed at the lower and upper boundaries using equation (C.6). The functions $f_{1}$ and $f_{2}$ are defined by

$$
\begin{aligned}
& f_{1}=\left(\frac{2 D_{1}}{y_{1}}\right)^{n} \\
& f_{2}=\left(\frac{2 D_{2}}{y_{2}}\right)^{n}
\end{aligned}
$$


The constant $\mathrm{n}$ is set equal to $2.0, \mathrm{y}_{1}$ and $\mathrm{y}_{2}$ are the normal distances to the bottom and top surfaces, respectively, and $D_{1}$ and $D_{2}$ are the normal distances from the two surfaces to the location of $|\vec{V}|_{\max }$. In addition, the $y / y_{\max }$ value used in equation (C.8) for $\mathrm{F}_{\mathrm{Kleb}}$ is computed for both surfaces and the minimum value is used. These values of $F_{K l e b}$ and $F_{w a k e}$ are then used in equation (C.5) to compute $\left(\mu_{t}\right)_{\text {outer }}$.

4. Turbulent Values of $\lambda$ and $k$

The turbulent second coefficient of viscosity is defined as

$$
\lambda_{\mathrm{t}}=-\frac{2}{3} \mu_{\mathrm{t}}
$$

The turbulent thermal conductivity coefficient is defined using the Reynolds analogy as

$$
\mathrm{k}_{\mathrm{t}}=\frac{\mathrm{c}_{\mathrm{p}} \mu_{\mathrm{t}}}{P r_{\mathrm{t}}}
$$

and $\mathrm{c}_{\mathrm{p}}$ is the specific heat at constant pressure and $\operatorname{Pr}_{t}$ is the turbulent Prandtl number. In Proteus, the turbulent Prandtl number may be equal to a constant or computed using the empirical formula of Wassel and Catton. ${ }^{37}$ For the cases described herin, $\operatorname{Pr}_{t}$ was constant with the Proteus default value of 0.91 . 
Public reporting burden for this collection of information is estimated to average 1 hour per response, including the time for reviewing instructions, searching existing data sources, gathering and maintaining the data needed, and completing and reviowing the collection of information. Send comments regarding this burden estimate or any other aspect of this Davis Highway, Suite 1204, Arlington, VA 22202-4302, and to the Office of Management and Budget, Paperwork Reduction Project (0704-0188). Washington, DC 20503.

\begin{tabular}{|l|c|r|}
\hline 1. AGENCY USE ONLY (Leave blank) & $\begin{array}{r}\text { 2. REPOAT DATE } \\
\text { April } 1994\end{array}$ & $\begin{array}{r}\text { 3. REPOAT TYPE AND DATES COVERED } \\
\text { Technical Memorandum }\end{array}$ \\
\hline
\end{tabular}

4. TITLE AND SUBTITLE

Modification of the MML Turbulence Model for Adverse Pressure

Gradient Flows

\section{AUTHOR(S)}

Julianne M. Conley
8. PERFORMING ORGANIZATION REPORT NUMBER

E-8690

National Aeronautics and Space Administration

Lewis Research Center

WU-505-62-52

Cleveland, Ohio 44135-3191

9. SPONSORING/MONITORING AGENCY NAME(S) AND ADDRESS(ES)

National Aeronautics and Space Administration

Washington, D.C. 20546-0001

10. SPONSORING/MONITORING AGENCY REPORT NUMBER

NASA TM-106544

11. SUPPLEMENTARY NOTES

This report was submitted as a thesis in partial fulfillment of the requirements for the degree Master of Science to the University of Akron, Akron, Ohio, December 1993. Responsible person, Julianne M. Conley, organization code 2660, (216) 433-2188.

12a. DISTRIBUTION/AVAILABILITY STATEMENT 12b. DISTRIBUTION CODE

Unclassified - Unlimited

Subject Category 34

\section{ABSTRACT (Maximum 200 words)}

Computational fluid dynamics is being used increasingly to predict flows for aerospace propulsion applications, yet there is still a need for an easy to use, computationally inexpensive turbulence model capable of accurately predicting a wide range of turbulent flows. The Baldwin-Lomax model is the most widely used algebraic model, even though it has known difficulties calculating flows with strong adverse pressure gradients and large regions of separation. The modified mixing length model (MML) was developed specifically to handle the separation which occurs on airfoils and has given significantly better results than the Baldwin-Lomax model. The success of these calculations warrants further evaluation and development of MML. The objective of this work was to evaluate the performance of MML for zero and adverse pressure gradient flows, and modify it as needed. The Proteus Navier-Stokes code was used for this study and all results were compared with experimental data and with calculations made using the Baldwin-Lomax algebraic model, which is currently available in Proteus. The MML model was first evaluated for zero pressure gradient flow over a flat plate, then modified to produce the proper boundary layer growth. Additional modifications, based on experimental data for three adverse pressure gradient flows, were also implemented. The adapted model, called MMLPG (modified mixing length model for pressure gradient flows), was then evaluated for a typical propulsion flow problem, flow through a transonic diffuser. Three cases were examined: flow with no shock, a weak shock and a strong shock. The results of these calculations indicate that the objectives of this study have been met. Overall, MMLPG is capable of accurately predicting the adverse pressure gradient flows examined in this study, giving generally better agreement with experimental data than the Baldwin-Lomax model.

14. SUBJECT TERMS

Navier-Stokes; Turbulent boundary layer; Two-dimensional flow; Mixing length flow theory; Pressure gradients; Flat plates; Computational fluid dynamics

\begin{tabular}{|c|c|}
\hline 17. SECURITY CLASSIFICATION & 18. SECURITY CLASSIFICATION \\
OF REPORT & OF THIS PAGE \\
Unclassified & Unclassified \\
\hline
\end{tabular}

19. SECURITY CLASSIFICATION
OF ABSTRACT
Unclassified

\begin{tabular}{|}
$\begin{array}{c}\text { 15. NUMBER OF PAGES } \\
96\end{array}$ \\
$\begin{array}{c}\text { 16. PRICE CODE } \\
\text { A05 }\end{array}$ \\
20. LIMITATION OF ABSTRACT \\
\end{tabular}

